\title{
Cochrane
}

Library

Cochrane Database of Systematic Reviews

\section{Antiviral treatment for Bell's palsy (idiopathic facial paralysis)} (Review)

Gagyor I, Madhok VB, Daly F, Sullivan F

Gagyor I, Madhok VB, Daly F, Sullivan F.

Antiviral treatment for Bell's palsy (idiopathic facial paralysis).

Cochrane Database of Systematic Reviews 2019, Issue 9. Art. No.: CD001869.

DOI: 10.1002/14651858.CD001869.pub9.

www.cochranelibrary.com

Antiviral treatment for Bell's palsy (idiopathic facial paralysis) (Review) 
TABLE OF CONTENTS

HEADER

ABSTRACT

PLAIN LANGUAGE SUMMARY

SUMMARY OF FINDINGS

BACKGROUND

OBJECTIVES

METHODS

RESULTS

Figure 1.

Figure 2.

Figure 3.

Figure 4.

Figure 5.

Figure 6.

DISCUSSION

AUTHORS' CONCLUSIONS

ACKNOWLEDGEMENTS

REFERENCES

CHARACTERISTICS OF STUDIES

DATA AND ANALYSES

Analysis 1.1. Comparison 1 Antivirals plus corticosteroids versus corticosteroids plus placebo or no treatment (AS versus OS): trials at lower risk of bias, Outcome 1 Incomplete recovery at end of study (trials at lower risk of bias).

Analysis 1.2. Comparison 1 Antivirals plus corticosteroids versus corticosteroids plus placebo or no treatment (AS versus OS): trials at lower risk of bias, Outcome 2 Incomplete recovery at end of study (full data set).

Analysis 1.3. Comparison 1 Antivirals plus corticosteroids versus corticosteroids plus placebo or no treatment (AS versus OS): trials at lower risk of bias, Outcome 3 Incomplete recovery at end of study in severe cases: data set limited to trials at lower risk of bias.

Analysis 1.4. Comparison 1 Antivirals plus corticosteroids versus corticosteroids plus placebo or no treatment (AS versus OS): trials at lower risk of bias, Outcome 4 Incomplete recovery at end of study in severe cases: full data set.

Analysis 1.5. Comparison 1 Antivirals plus corticosteroids versus corticosteroids plus placebo or no treatment (AS versus OS): trials at lower risk of bias, Outcome 5 Motor synkinesis or crocodile tears.

Analysis 1.6. Comparison 1 Antivirals plus corticosteroids versus corticosteroids plus placebo or no treatment (AS versus OS): trials at lower risk of bias, Outcome 6 Adverse events (trials at lower risk of bias).

Analysis 1.7. Comparison 1 Antivirals plus corticosteroids versus corticosteroids plus placebo or no treatment (AS versus OS): trials at lower risk of bias, Outcome 7 Adverse events (full data set).

Analysis 2.1. Comparison 2 Antivirals versus corticosteroids (AO versus OS): trials at lower risk of bias, Outcome 1 Incomplete recovery at end of study: trials at lower risk of bias.

Analysis 2.2. Comparison 2 Antivirals versus corticosteroids (AO versus OS): trials at lower risk of bias, Outcome 2 Incomplete recovery at end of study: full data set.

Analysis 2.3. Comparison 2 Antivirals versus corticosteroids (AO versus OS): trials at lower risk of bias, Outcome 3 Motor synkinesis and crocodile tears: trials at lower risk of bias.

Analysis 2.4. Comparison 2 Antivirals versus corticosteroids (AO versus OS): trials at lower risk of bias, Outcome 4 Motor synkinesis and crocodile tears: full data set.

Analysis 2.5. Comparison 2 Antivirals versus corticosteroids (AO versus OS): trials at lower risk of bias, Outcome 5 Adverse events.

Analysis 3.1. Comparison 3 Antivirals plus corticosteroids versus placebo (AS versus 00), Outcome 1 Incomplete recovery at end of study.

Analysis 3.2. Comparison 3 Antivirals plus corticosteroids versus placebo (AS versus 00), Outcome 2 Motor synkinesis or crocodile tears.

Analysis 3.3. Comparison 3 Antivirals plus corticosteroids versus placebo (AS versus OO), Outcome 3 Adverse events. ............ Analysis 4.1. Comparison 4 Antivirals versus placebo (AO versus OO), Outcome 1 Incomplete recovery at end of study. ........... Analysis 4.2. Comparison 4 Antivirals versus placebo (AO versus OO), Outcome 2 Motor synkinesis or crocodile tears. .............. Analysis 4.3. Comparison 4 Antivirals versus placebo (AO versus OO), Outcome 3 Adverse events. 
[Intervention Review]

\section{Antiviral treatment for Bell's palsy (idiopathic facial paralysis)}

Ildiko Gagyor ${ }^{1}$, Vishnu B Madhok², Fergus Daly ${ }^{3}$, Frank Sullivan ${ }^{4}$

1Department of General Practice, Universitätsklinikum Würzburg, Würzburg, Germany. ${ }^{2}$ Park House Surgery, Bagshot, UK. ${ }^{3}$ Frontier Science (Scotland) Ltd, Kingussie, UK. ${ }^{4}$ Division of Population \& Behavioural Science, University of St Andrews, St Andrews, UK

Contact address: Ildiko Gagyor, Department of General Practice, Universitätsklinikum Würzburg, Josef-Schneider-Straße 2, Würzburg, Bavaria, 97080, Germany. Gagyor_l@ukw.de.

Editorial group: Cochrane Neuromuscular Group

Publication status and date: New search for studies and content updated (conclusions changed), published in Issue 9, 2019.

Citation: Gagyor I, Madhok VB, Daly F, Sullivan F. Antiviral treatment for Bell's palsy (idiopathic facial paralysis). Cochrane Database of Systematic Reviews 2019, Issue 9. Art. No.: CD001869. DOI: 10.1002/14651858.CD001869.pub9.

Copyright (c) 2019 The Cochrane Collaboration. Published by John Wiley \& Sons, Ltd.

\section{A B S T R A C T}

\section{Background}

Corticosteroids are widely used in the treatment of idiopathic facial paralysis (Bell's palsy), but the effectiveness of additional treatment with an antiviral agent is uncertain. This review was first published in 2001 and most recently updated in 2015. Since a significant benefit of corticosteroids for the early management of Bell's palsy has been demonstrated, the main focus of this update, as in the previous version, was to determine the effect of adding antivirals to corticosteroid treatment. We undertook this update to integrate additional evidence and to better assess the robustness of findings, taking risk of bias fully into account.

\section{Objectives}

To assess the effects of antiviral treatments alone or in combination with any other therapy for Bell's palsy.

\section{Search methods}

We searched the Cochrane Neuromuscular Specialised Register, CENTRAL, MEDLINE, Embase, and LILACS in July 2019. We reviewed the bibliographies of the identified trials and contacted trial authors to identify additional published or unpublished data. We searched clinical trials registries for ongoing studies.

\section{Selection criteria}

We considered randomised controlled trials (RCTs) or quasi-RCTs of antivirals with and without corticosteroids versus control therapies for the treatment of Bell's palsy. We excluded trials that followed-up participants for less than three months.

\section{Data collection and analysis}

We independently assessed trials for relevance, eligibility, and risk of bias, using standard Cochrane procedures. We performed sensitivity analyses excluding trials at high or unclear risk of bias in at least five domains, and reported these data as the primary analyses.

\section{Main results}

Fourteen trials, including 2488 participants, met the inclusion criteria. Most were small, and most were at high or unclear risk of bias in multiple domains. We included four new studies at this update.

\section{Incomplete recovery}

A combination of antivirals and corticosteroids may have little or no effect on rates of incomplete recovery in people with Bell's palsy compared to corticosteroids alone (risk ratio (RR) 0.81 , 95\% confidence interval (Cl) 0.38 to 1.74; 3 trials, $\mathrm{N}=766$; random-effects; lowcertainty evidence). We excluded 10 trials that were at high or unclear risk of bias in several domains from this analysis and limited all 
analyses to studies at lower risk of bias. Recovery rates were better in participants receiving corticosteroids alone than antivirals alone (RR 2.69, 95\% Cl 0.73 to $10.01 ; 2$ trials, $\mathrm{N}=667$; random-effects), but the result was imprecise and allowed for the possibility of no effect. The rate of incomplete recovery was lower with antivirals plus corticosteroids than with placebo or no treatment (RR $0.56,95 \% \mathrm{Cl} 0.42$ to 0.76; 2 trials, $\mathrm{N}=658$; random-effects). Antivirals alone had no clear effect on incomplete recovery rates compared with placebo, but the result was imprecise (RR 1.10, 95\% $\mathrm{Cl} 0.87$ to $1.40 ; 2$ trials, $\mathrm{N}=658$; fixed-effect). For people with severe Bell's palsy (House-Brackmann score of 5 and 6 , or equivalent on other scales), we found that the combination of antivirals and corticosteroids had no clear effect on incomplete recovery at month six compared to corticosteroids alone, although the result was again imprecise ( $\mathrm{RR} 0.82,95 \% \mathrm{Cl} 0.57$ to $1.17 ; 2$ trials, $\mathrm{N}=98$; random-effects).

\section{Motor synkinesis or crocodile tears}

Antivirals plus corticosteroids reduced the proportion of participants who experienced these long-term sequelae from Bell's palsy compared to placebo plus corticosteroids (RR $0.56,95 \% \mathrm{Cl} 0.36$ to $0.87 ; 2$ trials, $\mathrm{N}=469$; fixed-effect; moderate-certainty evidence). Antivirals plus corticosteroids reduced long-term sequelae compared to placebo but there was no clear difference in this outcome with antivirals alone compared to placebo.

\section{Adverse events}

Adverse event data were available in four studies providing data on 1592 participants. None of the four comparisons showed clear differences in adverse events between treatment and comparison arms (very low-certainty evidence); for the comparison of antivirals plus corticosteroids and corticosteroids alone in studies at lower risk of bias, the RR was $1.17(95 \% \mathrm{Cl} 0.81$ to $1.69 ; 2$ trials, $\mathrm{N}=656$; fixed-effect; very low-certainty evidence).

\section{Authors' conclusions}

The combination of antivirals and corticosteroids may have little or no effect on rates of incomplete recovery in comparison to corticosteroids alone in Bell's palsy of various degrees of severity, or in people with severe Bell's palsy, but the results were very imprecise. Corticosteroids alone were probably more effective than antivirals alone and antivirals plus corticosteroids were more effective than placebo or no treatment. There was no clear benefit from antivirals alone over placebo.

The combination of antivirals and corticosteroids probably reduced the late sequelae of Bell's palsy compared with corticosteroids alone. Studies also showed fewer episodes of long-term sequelae in corticosteroid-treated participants than antiviral-treated participants.

We found no clear difference in adverse events from the use of antivirals compared with either placebo or corticosteroids, but the evidence is too uncertain for us to draw conclusions.

An adequately powered RCT in people with Bell's palsy that compares different antiviral agents may be indicated.

\section{PLAIN LANGUAGE SUMMARY}

\section{Antiviral treatment for Bell's palsy}

\section{Review question}

We reviewed the evidence about the effect of antiviral therapy (drugs used specifically to treat viral infections), alone or in combination with any other therapy, on Bell's palsy. Our focus in this updated review was combined therapy with antiviral drugs and corticosteroids (which are drugs used to reduce inflammation) as there is already good evidence that corticosteroids can reduce rates of incomplete recovery from Bell's palsy.

\section{Background}

Bell's palsy is a disease of the facial nerve that causes one side of the face to be paralysed. Some studies have suggested that it is caused by the same viral infections that cause cold sores or shingles and investigated the effect of antiviral therapy. Earlier versions of this review have found that antivirals alone are not helpful compared to a dummy pill, and are less effective than corticosteroids alone. However, studies of antiviral treatment in combination with corticosteroids have conflicting results.

\section{Study characteristics}

We identified 14 trials, which included 2488 participants with mild, moderate, or severe one-sided Bell's palsy of unknown cause. Participants were aged from 14 to 84 years. The trials compared:

- antivirals plus corticosteroids to corticosteroids alone or in combination with placebo;

- antivirals alone or in combination with placebo to placebo or no treatment;

- antivirals alone or in combination with placebo to corticosteroid treatment alone or in combination with placebo; or

- antivirals plus corticosteroids to placebo or no treatment. 
For the majority of the studies, no information on funding was given. The remaining were mostly partly public funded, and one trial was funded by a pharmaceutical company.

Eleven studies had high or uncertain risk of bias from various factors that can systematically affect trial results. We chose to base our conclusions only on data from three studies at a lower risk of bias.

\section{Key results and certainty of the evidence}

The review showed that there may be no clear difference in rates of incomplete recovery from Bell's palsy after treatment with the combination of antivirals and corticosteroids, compared to corticosteroids alone. This finding was of low certainty and was based on data from three trials involving 766 people with Bell's palsy of various degrees of severity. We excluded data from 10 trials with multiple potential sources of bias. However, we can be moderately confident that the combined therapy reduced the number of people left with long-term effects of Bell's palsy (excessive tearing of the eyes or an abnormal facial movement) compared to corticosteroid treatment alone.

Data from two studies (98 participants) showed that in people with severe Bell's palsy (complete or almost complete facial paralysis), combined antivirals and corticosteroids had no clear effect on recovery compared with corticosteroid treatment alone.

Corticosteroids alone were more effective than antivirals alone on rates of incomplete recovery (667 participants, 2 trials); antivirals and corticosteroids combined were more effective than placebo or no treatment ( 658 participants, 2 trials); and there was no clear benefit from antivirals alone over placebo (658 participants, 2 trials).

Although, based on data from two trials ( 656 participants), we found no clear difference in the occurrence of side effects between people receiving both antivirals and corticosteroids, compared to those receiving corticosteroids alone, this evidence is too uncertain for us to draw conclusions.

Large studies in people with Bell's palsy comparing additional antiviral agents may be indicated in the future. 
S U M MARY OF FINDINGS

Summary of findings for the main comparison. Antivirals plus corticosteroids compared to corticosteroids plus placebo or no treatment (AS versus OS) for Bell's palsy (idiopathic facial paralysis)

Antivirals plus corticosteroids compared to corticosteroids plus placebo or no treatment (AS versus OS) for Bell's palsy (idiopathic facial paralysis)

Patient or population: Bell's palsy (idiopathic facial paralysis)

Setting: primary, secondary and tertiary care

Intervention: antivirals plus corticosteroids (AS)

Comparison: corticosteroids plus placebo or no treatment (OS)

\begin{tabular}{|c|c|c|c|c|c|c|}
\hline \multirow[t]{2}{*}{ Outcomes } & \multirow{2}{*}{$\begin{array}{l}\text { Relative ef- } \\
\text { fect } \\
(95 \% \mathrm{CI})\end{array}$} & \multicolumn{3}{|c|}{ Anticipated absolute effects ${ }^{\star}(95 \% \mathrm{Cl})$} & \multirow{2}{*}{$\begin{array}{l}\text { Certainty of } \\
\text { the evidence } \\
\text { (GRADE) }\end{array}$} & \multirow[t]{2}{*}{ What happens } \\
\hline & & $\begin{array}{l}\text { Corticos- } \\
\text { teroids plus } \\
\text { placebo or } \\
\text { no treatment } \\
\text { (OS) }\end{array}$ & $\begin{array}{l}\text { Antivirals plus } \\
\text { corticosteroids } \\
\text { (AS) }\end{array}$ & Difference with AS & & \\
\hline \multirow{2}{*}{$\begin{array}{l}\text { Incomplete recovery at end of } \\
\text { study } \\
\text { № of participants: } 766 \\
\text { (3 RCTs) } \\
\text { Follow-up: } 3 \text { to } 12 \text { months }\end{array}$} & \multirow{2}{*}{$\begin{array}{l}\text { RR } 0.81 \\
(0.38 \text { to } 1.74)\end{array}$} & \multicolumn{3}{|c|}{ Study population } & \multirow{2}{*}{$\begin{array}{l}\oplus \oplus \oplus \ominus \\
L^{\prime} w^{a}, b\end{array}$} & \multirow{2}{*}{$\begin{array}{l}\text { There may be little or no difference be- } \\
\text { tween AS and OS in the proportion of } \\
\text { participants with incomplete recovery } \\
\text { at the end of the studies. }\end{array}$} \\
\hline & & 172 per 1000 & $\begin{array}{l}140 \text { per } 1000 \\
(65 \text { to } 300)\end{array}$ & $\begin{array}{l}33 \text { fewer per } 1000 \\
\text { (107 fewer to } 128 \\
\text { more) }\end{array}$ & & \\
\hline \multirow{2}{*}{$\begin{array}{l}\text { Motor synkinesis or crocodile } \\
\text { tears } \\
\text { № of participants: } 469 \\
\text { ( } 2 \text { RCTs) } \\
\text { Follow-up: } 3 \text { to } 12 \text { months }\end{array}$} & \multirow{2}{*}{$\begin{array}{l}\text { RR } 0.56 \\
\text { (0.36 to } 0.87 \text { ) }\end{array}$} & \multicolumn{3}{|c|}{ Study population } & \multirow{2}{*}{$\begin{array}{l}\oplus \oplus \oplus \ominus \\
\text { Moderatec }\end{array}$} & \multirow{2}{*}{$\begin{array}{l}\text { AS probably reduces the proportion of } \\
\text { participants with motor synkinesis or } \\
\text { crocodile tears at } 3 \text { to } 12 \text { months com- } \\
\text { pared to OS. }\end{array}$} \\
\hline & & 194 per 1000 & $\begin{array}{l}109 \text { per } 1000 \\
\text { (70 to } 169)\end{array}$ & $\begin{array}{l}85 \text { fewer per } 1000 \\
\text { (124 fewer to } 25 \text { few- } \\
\text { er per } 1000)\end{array}$ & & \\
\hline \multirow{2}{*}{$\begin{array}{l}\text { Adverse events } \\
\text { № of participants: } 656 \\
\text { (2 RCTs) }\end{array}$} & \multirow{2}{*}{$\begin{array}{l}\text { RR } \\
1.17(0.81 \text { to } \\
1.68)\end{array}$} & \multicolumn{3}{|c|}{ Study population } & \multirow{2}{*}{$\begin{array}{l}\oplus \ominus \odot \odot \\
\text { Very lowd,e }\end{array}$} & \multirow{2}{*}{$\begin{array}{l}\text { It is uncertain whether the number of } \\
\text { people who experience adverse events } \\
\text { is different with AS than OS. }\end{array}$} \\
\hline & & 136 per 1000 & $\begin{array}{l}160 \text { per } 1000 \\
(110 \text { to } 229)\end{array}$ & $\begin{array}{l}24 \text { more per } 1000 \text { ( } 26 \\
\text { fewer to } 93 \text { more) }\end{array}$ & & \\
\hline
\end{tabular}

${ }^{*}$ The risk in the intervention group (and its $95 \% \mathrm{Cl}$ ) is based on the assumed risk in the comparison group and the relative effect of the intervention (and its $95 \% \mathrm{Cl}$ ).

AS: antivirals plus corticosteroids; Cl: confidence interval; OS: corticosteroids plus placebo or no treatment; RR: risk ratio 
High certainty: we are very confident that the true effect lies close to that of the estimate of the effect.

Moderate certainty: we are moderately confident in the effect estimate; the true effect is likely to be close to the estimate of the effect, but there is a possibility that it is substantially different.

Low certainty: our confidence in the effect estimate is limited; the true effect may be substantially different from the estimate of the effect.

Very low certainty: we have very little confidence in the effect estimate; the true effect is likely to be substantially different from the estimate of effect.

aWe downgraded the certainty of evidence once due to differing results of the included studies (inconsistency). As our primary analysis we reported the results of a sensitivity analysis excluding 10 of 13 trials which were at high or unclear risk of bias in several domains. The effect estimate from the full data set was RR $0.54,95 \% \mathrm{Cl} 0.38$ to $0.77 ; 13$ trials, $\mathrm{N}=1729$, but there were very serious study limitations in the full data set, in addition to heterogeneity.

bWe downgraded the certainty of the body of evidence once because the RR had wide Cls that included the possibility of a very little effect and a large effect (imprecision).

cWe downgraded the certainty of evidence for this outcome for publication bias, as only two studies in this comparison reported this outcome.

dWe downgraded the certainty of the body of evidence for this outcome once for publication bias as only 4 of the 13 studies reported adverse events.

eWe downgraded the certainty of the body of evidence twice for imprecision as the Cls were wide and encompassed the possibility of an effect in either direction. 


\section{B A C K G R O U N D}

\section{Description of the condition}

Bell's palsy is an acute, generally unilateral paralysis or weakness of facial musculature consistent with peripheral facial nerve dysfunction, of no detectable cause (Niparko 1993). Additional symptoms frequently include pain around or behind the ear on the affected side, sometimes extending into the occipital or cervical regions. Impaired tolerance to ordinary levels of noise and disturbed sense of taste on the affected side may also be present (Burgess 1984).

Epidemiological studies have reported an annual incidence of 23 to 25 per 100,000 per year, but a recent study using a general practice database suggests it may be even higher, at 37 per 100,000 per year (Victor 1994; Martyn 1997; Morales 2013). The condition affects men and women more or less equally, and was once thought to be most common in the 30- to 45-year age group (Peitersen 1982; Katusic 1986; Yanagihara 1988; Bateman 1992; Brandenberg 1993; Peitersen 2002). However, a recent primary care database study suggests a second peak in the over-70s (Morales 2013). Bell's palsy presents disproportionately amongst pregnant women and people who have diabetes, influenza, a cold, or some other upper respiratory ailment. On average, a British general practitioner will see one person who has developed the condition every 12 to 18 months. Both sides of the face are affected equally often (Prescott 1988).

The aetiology of Bell's palsy is still debated. A viral infection, vascular ischaemia, autoimmune inflammatory disorders, and heredity have been proposed as underlying causes (Adour 1982; Burgess 1984; Lorber 1996; Lackner 2010). A viral aetiology has gained popularity since the isolation of herpes simplex virus type 1 genome from the saliva and facial nerve endoneurial fluid of people with this condition (Murakami 1996; Lackner 2010). On the whole, the prognosis is favourable, though a significant proportion of people who are left untreated have residual symptoms. One of the largest series of people with Bell's palsy, which included people receiving no treatment, showed that $85 \%$ of people began to recover within three weeks after onset (Peitersen 1982). Partial recovery usually occurred within three to six months for the remaining $15 \%$. The same series showed that normal facial expression reappeared in $71 \%$ of cases, $13 \%$ had insignificant sequelae (long-term after effects), and the final $16 \%$ had permanently diminished function with aberrant innervation (expressed as motor synkinesis or autonomic dysfunction), and postparalytic spasms.

\section{Description of the intervention}

The treatment of Bell's palsy was highly controversial until 2008, at which time corticosteroids alone were shown to be effective in treating the condition (Madhok 2016). Previous Cochrane Reviews on the treatment of Bell's palsy examined the effectiveness of oral prednisolone and aciclovir or valaciclovir (Allen 2004; Lockhart 2009; Gagyor 2015c). Several studies excluded from the analysis in these reviews either failed to randomise participants or, when correctly randomised, results were erroneously interpreted in a favourable light (May 1976; Wolf 1978). High-dose corticosteroid therapy has several potential side effects, including peptic ulceration, hypertension, and confusional states. Antiviral therapy was considered expensive, and treatment was reserved for circumstances in which a clear benefit appeared likely. Previous recommendations suggested that antivirals needed to be started within 48 hours, although a study of viral replication in participants with
Bell's palsy suggests that the window might be extended (Abiko 2002).

\section{How the intervention might work}

Bell's palsy is associated with an inflammation of the facial nerve. Since herpes simplex virus has been detected in cerebrospinal fluid of affected patients, antiviral treatment was tested in trials aiming to eradicate the virus (Murakami 1996).

\section{Why it is important to do this review}

Corticosteroids are widely used in the treatment of idiopathic facial paralysis (Bell's palsy), but the effectiveness of additional treatment with an antiviral agent is uncertain. The 2009 update of this Cochrane Review included large-scale randomised controlled trials (RCTs) of antivirals and corticosteroids that had been published in the years before the review. The authors stated that, compared to placebo, antivirals did not contribute to a significant improvement in the rate or extent of recovery of trial participants (Lockhart 2009), but that when added to corticosteroids, the rate of recovery was slightly better than corticosteroids alone or corticosteroids with placebo. This result was confirmed in the last update which included three additional trials (Gagyor 2015c). The review authors requested withdrawal of an update of the review published earlier that year (Gagyor 2015b), as it also included a fourth trial (Abdelghany 2013), which has since been withdrawn. We requested withdrawal of that version of the review and republished our analyses.

Since a significant benefit of corticosteroids for the early management of Bell's palsy has been previously demonstrated (Lockhart 2009; Madhok 2016), the main focus of this update, as in the previous version, was to determine the effect of the combination of antivirals and corticosteroids versus corticosteroids alone or in combination with placebo. The current review updates these findings with additional studies and involves a reanalysis of the results using sensitivity analyses, excluding studies at high or unclear risk of bias in at least five categories.

\section{O B J E C T IVES}

To assess the effects of antiviral treatments alone or in combination with any other therapy for Bell's palsy.

\section{METHODS}

\section{Criteria for considering studies for this review}

\section{Types of studies}

We searched for all randomised controlled trials (RCTs) or quasi-RCTs (which are trials that employ alternate or other systematic allocation) involving an antiviral (aciclovir, valaciclovir, or famciclovir) alone or in combination with any other therapy in the treatment of Bell's palsy, reported in any language. The duration of studies included in this review ranges from three to 12 months; the minimum study duration was three months. Unlike the previous version of the review we did not exclude studies at high risk of bias, but conducted sensitivity analyses to determine their effect on the outcome. Studies were eligible for the review regardless of publication status. 


\section{Types of participants}

We considered all trials where participants had a diagnosis of unilateral facial paralysis of unknown cause and satisfied the trial authors' requirements for eligibility and inclusion.

\section{Types of interventions}

We considered all trials of treatment with any oral antiviral licensed for the treatment of herpes simplex infection in immunocompetent participants. Antivirals include aciclovir; valaciclovir, which is a prodrug of aciclovir; and famciclovir, which is a prodrug of penciclovir. We considered trials where participants received antiviral therapy alone or in combination with any other treatment versus placebo or any other treatment.

\section{Types of outcome measures}

We have described changes to outcome measures in this and previous versions of the review in Differences between protocol and review.

\section{Primary outcomes}

- Incomplete recovery of facial function at the end of study, measured using a validated rating scale

\section{Secondary outcomes}

- Motor synkinesis or crocodile tears at the end of the study

- Adverse events

- Incomplete recovery at month six in severe cases

Some trials have reported other symptoms (pain, discomfort, and embarrassment) as outcomes, but we did not consider them in this review.

\section{Search methods for identification of studies}

\section{Electronic searches}

The Cochrane Neuromuscular Information Specialist searched the following databases.

- The Cochrane Neuromuscular Specialised Register via the Cochrane Register of Studies (CRS-Web) (31 July 2019; Appendix 1).

- The Cochrane Central Register of Controlled Trials (CENTRAL) via the Cochrane Register of Studies (CRS-Web) (31 July 2019; Appendix 2).

- MEDLINE (1946 to 30 July 2019; Appendix 3).

- Embase (1974 to 29 July 2019; Appendix 4).

- LILACS (1982 to 30 July 2019).

We searched for registered trials on:

- ClinicalTrials.gov (June 2019; www.clinicaltrials.gov; Appendix 6);

- Australian New Zealand Clinical Trials Registry (June 2019; www.anzctr.org.au);

- World Health Organization International Clinical Trials Registry Platform (June 2019; www.who.int/ictrp/en; Appendix 7).

\section{Searching other resources}

We also reviewed the bibliographies of the identified trials and contacted trial authors and known experts in the field and relevant drug companies to identify additional published or unpublished data.

\section{Data collection and analysis}

We conducted the following four comparisons.

- Antiviral treatment in combination with corticosteroids versus corticosteroid treatment alone or in combination with placebo

- Antiviral treatment alone or in combination with placebo versus placebo or no treatment

- Antiviral treatment alone or in combination with placebo versus corticosteroid treatment alone or in combination with placebo

- Antiviral treatment in combination with corticosteroids versus placebo or no treatment

\section{Selection of studies}

Two review authors working in pairs (IG and VM) scrutinised titles and abstracts for potentially eligible studies. Both review authors independently assessed each full-text paper for eligibility and selected studies for inclusion. We had no disagreements about inclusion. FS supervised all steps of the study selection.

\section{Data extraction and management}

Two review authors (IG and VM) extracted data onto a data extraction form and double-checked data extraction in pairs. They agreed data input into the Cochrane authoring and statistical software, Review Manager 5 (RevMan 2014). They discussed any disagreements with a third review author (FD) to reach a resolution. We arranged translation of papers where necessary.

\section{Assessment of risk of bias in included studies}

Two review authors (IG and VM) independently assessed the risk of bias in included studies using the 'Risk of bias' methodology described in the Cochrane Handbook for Systematic Reviews of Interventions (Higgins 2011). FD reviewed the 'Risk of bias' assessments to achieve agreement where there were differences. The review authors considered methods of randomisation and allocation concealment, blinding (of treatment administrator and participants, and outcome assessors), selective outcome reporting (for example, failure to report adverse events), and incomplete outcome data (i.e. dropouts). We assessed each trial as at high, low, or unclear risk of bias for each of these criteria.

\section{Measures of treatment effect}

All our outcomes were dichotomous. We analysed the data as risk ratios (RRs) with corresponding 95\% confidence intervals (Cls).

When comparing studies that used different symptom scales to assess the primary outcome, incomplete recovery, we used the House-Brackmann scale when available (House 1985), as this was used most widely and could be compared with other scales. The main outcome in all trials was complete recovery. For this review, the review authors calculated the number of participants with incomplete recovery by subtracting the number of participants with complete recovery from the number of participants in the reference group. 
When assessing adverse events, we used the number of participants affected as opposed to the number of events, to facilitate data comparison.

\section{'Summary of findings' table}

We created a 'Summary of findings' table for the comparison 'antivirals plus corticosteroids versus corticosteroids plus placebo or no treatment'. We presented this single comparison because corticosteroids are known to be effective, and the main focus of this update, as for the previous version, was to determine whether adding antivirals to corticosteroid treatment provides additional benefit. We presented the following outcomes.

- Incomplete recovery at the end of the study (House-Brackmann scale; House 1985)

- Motor synkinesis or crocodile tears at the end of the study (House-Brackmann scale)

- Adverse events

We used the five GRADE considerations (risk of bias, inconsistency of effect, imprecision, indirectness, and publication bias) to assess the certainty of a body of evidence (studies that contribute data for the prespecified outcomes) using the GRADEpro GDT $2015 \mathrm{com}$ puter programme. We started with a judgement for RCTs at high certainty and downgraded the evidence one level to moderate certainty, two levels to low certainty, and three levels to very low certainty according to the GRADE criteria. For any single consideration, we downgraded the evidence once, if present, to a serious degree and twice, if very serious. We employed methods and recommendations described in Section 8.5 and Chapter 12 of the Cochrane Handbook for Systematic Reviews of Interventions (Higgins 2011), using GRADEpro software (GRADEpro GDT 2015). We justified all decisions to downgrade or upgrade the certainty of evidence using footnotes.

\section{Unit of analysis issues}

Each of the included studies carried out randomisation at the participant level. Twelve trials used a simple parallel-group design (Adour 1996; Li 1997; De Diego 1998; Hato 2007; Kawaguchi 2007; Minnerop 2008; Vázquez 2008; Yeo 2008; Shahidullah 2011; Lee 2013; Khajeh 2015; Khedr 2016). Two trials used a factorial design (Sullivan 2007; Engström 2008).

For studies with a factorial design, we aggregated groups according to whether or not antivirals were administered. We have described details in the Results.

\section{Dealing with missing data}

We contacted authors of three studies for additional data that were required for analysis but which were not provided in their papers (Minnerop 2008; Khajeh 2015; Khedr 2016), but only one responded with unpublished data (Minnerop 2008). We used the Kawaguchi 2007 data provided in previous versions of this review.

\section{Assessment of heterogeneity}

We used the $\mathrm{I}^{2}$ statistic to assess heterogeneity among the included studies in each analysis. If we found substantial unexplained heterogeneity, we reported it and explored possible causes according to the subgroup analyses.

\section{Assessment of reporting biases}

We produced a funnel plot to assess the likelihood of publication and small-study bias as there were sufficient studies in our antivirals plus corticosteroids versus corticosteroids plus placebo or no treatment incomplete recovery analysis (Egger 1997).

\section{Data synthesis}

We calculated a treatment effect using the Mantel-Haenszel method (Egger 2007). We used the random-effects model where we found marked heterogeneity $\left(\mathrm{I}^{2}=40 \%\right.$ or greater) between studies. If we had found little or no heterogeneity, we would have used a fixed-effect analysis.

\section{Subgroup analysis and investigation of heterogeneity}

We expected heterogeneity in the effect estimates for incomplete recovery due to the following factors and conducted a subgroup analysis when the published studies or study authors provided sufficient data.

- The investigated corticosteroid was prednisolone; however, different antivirals were used. Most trials combined prednisolone with aciclovir, but some trials used valaciclovir or famciclovir. We performed subgroup analysis for each antiviral to assess potential differences in participant response to the three different antiviral medications.

- We planned to investigate whether time to treatment had an influence on incomplete recovery, when data were available.

Some studies included participants with a broad range of symptom severity, while others included severe cases only. We performed an additional antivirals plus corticosteroids versus corticosteroids plus placebo or no treatment analysis for incomplete recovery of people with severe Bell's palsy at baseline, using data from four trials. Severe Bell's palsy was defined as severe-to-complete facial paralysis, graded as equal to or greater than $\mathrm{V}$ in the House-Brackmann grading system (House 1985; Table 1), equal to or less than 20 in the Sunnybrook score (Ross 1996; Table 2), and equal to or less than 20 in the Yanagihara score (Yanagihara 2003; Table 3). We did not perform an analysis of non-severe cases.

\section{Sensitivity analysis}

We performed sensitivity analyses to investigate:

- the effects of bias by excluding trials that had a high or unclear risk of bias in at least five categories;

- whether our conclusions were altered when we excluded studies with a follow-up of less than six months; and

- the robustness of the results by changing between a fixed-effect model and a random-effects model.

\section{RES U L T S}

\section{Description of studies}

\section{Results of the search}

The previous version of the review included 10 studies and we added four studies that we had previously excluded. We found 222 records through database searching for this update and none through other sources. After removal of duplicates, we screened 183 records and excluded 149 records based on their titles and ab- 
stracts. After checking the full texts, we excluded 20 full-text articles. We included 14 studies (which were reported in 14 separate publications) in the review, and included all 14 in quantitative syn- thesis (meta-analysis). (Figure 1). We did not find any ongoing studies in the World Health Organization International Clinical Trials Registry Platform (www.who.int/ictrp/en). 
Figure 1. Study flow diagram.

10 studies were included in the previous review

\section{2 records were identified by updating the database searches}

0 additional records identified through other sources

e.g. bibliographies \& registries

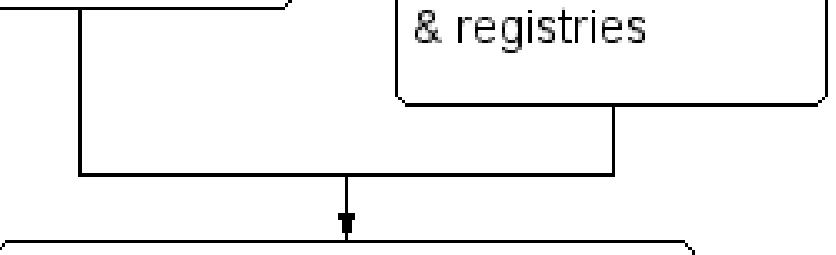

183 records after duplicates removed
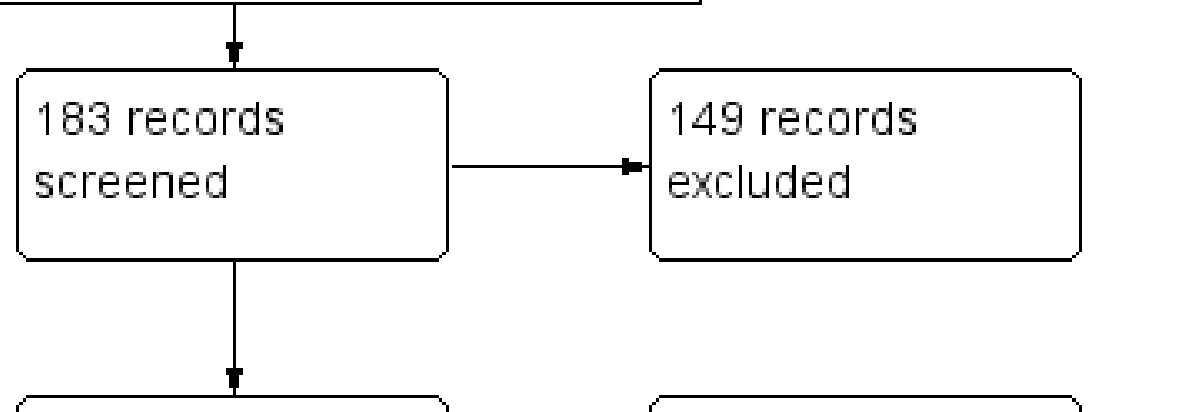

34 full-text articles
assessed for
eligibility $\longrightarrow \begin{aligned} & 20 \text { full-text articles } \\ & \text { excluded, with } \\ & \text { reasons }\end{aligned}$
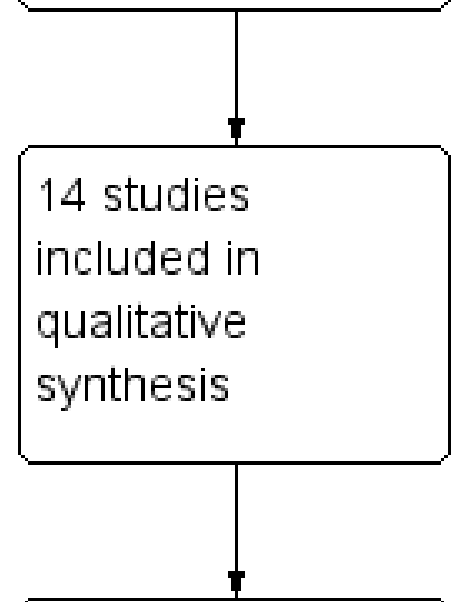

14 studies

included in 


\section{Included studies}

We added four RCTs with 208 participants to the previous version of this review, which had 10 trials and 2280 participants. The newly added trials were Minnerop 2008, Shahidullah 2011, Khajeh 2015 and Khedr 2016. Two trials have been published since previous searches in the 2015 review (Khajeh 2015; Khedr 2016). Although we excluded Minnerop 2008 and Shahidullah 2011 from the previous update (Gagyor 2015c), due to their high or unclear risk of bias, we included both studies in the current analysis, and assessed the 'Risk of bias' and the certainty of evidence, as recommended by the Cochrane Handbook for Systematic Reviews of Interventions (Higgins 2011).

\section{Diagnostic criteria}

Thirteen studies gave adequate information (Li 1997; De Diego 1998; Hato 2007; Kawaguchi 2007; Sullivan 2007; Engström 2008; Minnerop 2008; Vázquez 2008; Yeo 2008; Shahidullah 2011; Lee 2013; Khajeh 2015; Khedr 2016). All studies explicitly mentioned a diagnosis of Bell's palsy and stated that they had considered and excluded other causes of facial palsy. Three trials, Hato 2007, Kawaguchi 2007 and Shahidullah 2011, retrospectively excluded participants on the basis of positive serology for herpes simplex or varicella zoster virus, or due to other exclusion criteria. Lee 2013 excluded participants who did not fulfil inclusion criteria, without specifying the reasons. Two studies mentioned referral to specialists for diagnostic confirmation (Sullivan 2007; Engström 2008). Khedr 2016 excluded people with mild to moderate Bell's palsy. The remaining study, Adour 1996, stated that participants were diagnosed with Bell's palsy, but did not give any further information.

\section{Outcome criteria}

All studies used referenced facial function scoring systems to grade recovery from facial paralysis. Adour 1996 and De Diego 1998 used the Facial Paralysis Recovery Profile (Adour 1971), and Adour 1996 also used the Facial Paralysis Recovery Index (Adour 1974). Hato 2007 and Kawaguchi 2007 used the Yanagihara scoring system (Yanagihara 2003), which has a validated system for conversion to the House-Brackmann scale (House 1985). Li 1997, Sullivan 2007, Engström 2008, Yeo 2008, Minnerop 2008, Shahidullah 2011, Lee 2013, Khajeh 2015, and Khedr 2016 presented results using the House-Brackmann scale. Engström 2008 and Khedr 2016 supplemented this with use of the Sunnybrook scale to minimise the effects of inter-rater variability (Ross 1996). Vázquez 2008 used a facial grading scale related to the Sunnybrook scale (Ross 1996).

The 14 studies in the current review included 2488 participants (see Characteristics of included studies).

Adour 1996 was a single-centre study that recruited 119 participants, of whom 99 were included in the published analysis. The study was double-blind and placebo-controlled. Participants were recruited within three days or less of onset of paralysis and received either aciclovir and prednisolone or placebo and prednisolone. The study duration was four months; participants were reviewed at two weeks, two months, and four months. The Facial Paralysis Recovery Index was used to measure facial function; the primary trial outcome was incomplete recovery defined by a Facial Paralysis Recovery Index of 7 or less.
De Diego 1998 recruited 113 participants and included 101 participants in the final analysis. Participants were randomly assigned to treatment. Baseline assessment was carried out within 48 hours of the onset of symptoms. Participants received either aciclovir for 10 days or prednisolone for 16 days (reducing dose). Reviews were scheduled for one, three, six, and 12 weeks after initial contact, with further contact if persistent incomplete recovery was noted. The primary study outcome was recovery, as defined by a House-Brackmann scale of 2 or less (House 1985), or a Facial Paralysis Recovery Profile (Adour 1974) of 8 or more. The report did not give the final length of follow-up, but stated that it continued "until complete recovery or stabilization of the paralysis".

Li 1997 recruited 51 participants within four days of onset of Bell's palsy. Participants were randomly assigned into two groups, who received either aciclovir plus prednisolone or prednisolone. Good recovery was defined as a House-Brackmann scale of 1 or 2 at month six (House 1985). Li 1997 reported outcomes for 46 participants; five were lost to follow-up.

Hato 2007 randomised 296 participants within seven days after onset, using sealed envelopes into two treatment groups: valaciclovir with prednisolone or placebo with prednisolone. The final analysis included 221 participants. Administrators and those assessing recovery status were not blinded to the treatment allocation, but participants were blinded to the treatment received. Disease severity was assessed using the Yanagihara 40-point scoring system (Yanagihara 2003); participants were considered to have completely recovered if they attained a score greater than 36 . Participants were assessed at onset and monthly thereafter for either six months or until completely recovered, if recovery occurred before six months.

Kawaguchi 2007 recruited 150 participants who were treated within seven days of onset and randomised using sealed envelopes into two treatment groups: valaciclovir plus prednisolone or prednisolone alone. There was inadequate clinician blinding. Kawaguchi and colleagues provided unpublished data on incomplete recovery for a previous update. Participants were assessed at one, two, three, four, five, and six months after inclusion using the Yanagihara scale (Yanagihara 2003). We could not contact the authors to obtain data for subsequent updates, but we included the data published in the earlier version of the review.

Sullivan 2007 recruited 551 participants, who were treated within 72 hours of onset. Participants were randomised by a dedicated remote telephone computerised mechanism, in a two-stage process, into four treatment groups: aciclovir with prednisolone, aciclovir with placebo, placebo with prednisolone, or double placebo, in a factorial design. The trial was blinded for administrator, participant, and assessment of recovery status until the end of follow-up. Participants were assessed at onset, after three months and, if still unwell at three months, and after nine months. Recovery status was measured using the House-Brackmann scale (House 1985), with complete recovery defined as House-Brackmann Grade 1. Data analysis included an assessment of treatment interaction. Sullivan 2007 reported final outcomes on 496 completed participants at three months and nine months, in treatment groups that were aggregated, as for Engström 2008.

Engström 2008 recruited 829 participants, who were treated within 72 hours of onset and randomised in a two-stage process by a computerised mechanism into four treatment groups: valaciclovir 
with prednisolone, valaciclovir with placebo, placebo with prednisolone, or double placebo, in a factorial design. The trial was double-blind (administrator and participant) for assessment of recovery status until the end of follow-up. Participants were assessed at onset, after two weeks (11 to 17 days), and after one, two, three, six, and 12 months. The disease status was measured using the House-Brackmann grading system (House 1985), and the Sunnybrook scale (Ross 1996). Complete recovery status was defined by a Sunnybrook score of 100 and House-Brackmann Grade 1. Time to recovery was estimated. Data analysis included an assessment of treatment interaction. For this review, we analysed the recovery rates 12 months after the onset of facial palsy, and defined complete recovery as a House-Brackmann Grade 1.

Minnerop 2008 included 167 participants with facial paralysis, aged 18 years and older, who were treated within five days after onset. Participants were randomised in two parallel groups: those admitted on even dates were assigned to prednisone (10 days), participants admitted on odd dates were randomised to prednisone and famciclovir (7 days). Treatment was administered unblinded. Of the 167 participants randomised, 50 were lost to follow-up, and only 117 participants were analysed. Although the main outcome was defined as complete recovery at three months, only 47 were assessed as planned. The rest of the study participants returned before month three or after month 12. Data from these 47 participants were sent by the trial author. The assessors in the trial used the House-Brackman scale or a similar score and complete recovery was not defined.

Vázquez 2008 included 42 participants and reported outcomes at six and 12 months using the Sunnybrook Facial Grading System (Ross 1996). Scores greater than 90 were defined as a satisfactory recovery. Participants in the intervention group were treated with prednisone and valaciclovir and in the control group with prednisone and placebo. The main study outcome was the proportion of participants with total recovery at six months' follow-up in each group, and average time to recovery in each group.

Yeo 2008 recruited 91 participants who were randomised to receive either aciclovir and prednisolone or prednisolone alone. Participants also received physical therapy and plasma volume expanders as adjuncts. The trial was double-blind and investigators followed up participants for six months, or until complete recovery. Recovery was assessed using the House-Brackmann scale and was defined as a House-Brackmann scale of 2 or less (House 1985).

Shahidullah 2011 carried out a randomised, controlled, open-label study with clinic patients aged 15 years and older who had unilateral facial paralysis of unknown cause. Participants were quasi-randomised, based on odd and even numbers, and were treated either with famiciclovir ( 5 days) plus prednisolone ( 7 days), or with prednisolone alone ( 7 days). Of the 107 participants recruited, 30 had exclusion criteria and nine were lost to follow-up, so data from 68 patients were analysed. Participants were assessed at baseline using the House-Brackman scale and were followed up one week, one month and three months after inclusion. Complete recovery was defined as House-Brackman scale Grade 1.

Lee 2013 was a RCT in participants with severe-to-complete Bell's palsy, which used the House-Brackmann scale for assessment (House 1985). The trial included 201 participants with a score of 5 or more. After randomisation into two groups, participants received either famciclovir plus prednisolone together, or pred- nisolone alone. Recovery was designated as a score of 1 or 2 on the House-Brackmann scale at month six.

Khajeh 2015 randomised 43 children, aged from 2 to 18 years, with unilateral Bell's palsy in two parallel groups. Participants were treated within three days after onset of Bell's palsy with either prednisolone and aciclovir or prednisolone only for seven days. The randomisation method was not stated. This open-label trial did not use a placebo. The trial assessed the severity of Bell's palsy by the House-Brackman scale. Complete recovery was defined as Grade 1. Participants were assessed at onset, four weeks, and three months after onset.

Khedr 2016 recruited 65 people with Bell's palsy, between 18 and 60 years old, and excluded 15 people with mild and moderate Bell's palsy. The 50 included participants were randomised in two groups using serially-numbered, opaque, closed envelopes. Participants began treatment with prednisolone and aciclovir or prednisolone alone within three days after onset and treatment lasted seven days for prednisolone, and five days for aciclovir. The trial authors stated that the study was blinded, but did not use a placebo. Outcome data were assessed at baseline, two weeks, two months, and three months after inclusion, using the House-Brackman scale. Complete recovery was defined as Grades 1 and 2 .

\section{Excluded studies}

The authors of the previous version of this review excluded Antunes 2000 because of incomplete data in 44 participants. Despite our attempts to contact the authors, there was still insufficient information for the data to be usefully included in analyses.

The authors of a previous version of this review reassessed the inclusion of the two studies that were awaiting assessment (de Aquino 2001; Roy 2005). Dr D Allen, the author of a previous version of this review, attempted to contact the lead author of de Aquino 2001 for clarification of the data, but this was not forthcoming. We therefore excluded this trial because of a lack of adequate information. The latter study recruited 82 participants, of whom 18 dropped out, and compared aciclovir plus methylprednisolone to methylprednisolone alone, reporting no benefit from the addition of aciclovir. The authors did not provide outcome data in the abstract, which appeared in a journal supplement, and according to the search strategies employed, the trial has not been published to date as a full paper. We excluded this trial due to a lack of adequate information.

A further study was classified as awaiting assessment in the previous version of this review (Inanli 2001). This paper was included in another systematic review and a meta-analysis (de Almeida 2009; Goudakos 2009). We excluded it from the current review because we could not find it in print or electronic form. See Characteristics of excluded studies.

Overall, we excluded six studies for not being RCTs (Ibarrondo 1999; Axelsson 2003; Hato 2003; Hultcrantz 2005; Ahangar 2006; Kang 2015); three for having a very short follow-up (Zhou 1999; Chen 2005; Ferreira 2016); three because reports provided insufficient information to assess the methods or outcomes (Antunes 2000; de Aquino 2001; Roy 2005); three due to scarcity of data and the wrong study population (only an abstract was available and 15 of 45 participants had Ramsay Hunt syndrome, and were given intravenous therapy) (Ramos Macias 1992), another trial had a lack of outcome 
data, as described above (Roy 2005), one paper was not available (Inanli 2001); and we excluded one paper from the previous update, as the paper was found to be plagiarised and has since been retracted (Abdelghany 2013).

\section{Ongoing studies}

We identified two trial reports in children with Bell's palsy in a search of ClinicalTrials.gov and the Australian New Zealand Clinical Trials Registry just prior to completion of the review (www.clinicaltrials.gov; www.who.int/ictrp/en). Both studies are still recruiting. See Ongoing studies.

\section{Studies awaiting classification}

We found one trial in children and adults with Bell's palsy in a search of the World Health Organization International Clinical Trials Registry Platform (www.who.int/ictrp/en), which was characterised as completed. We contacted the authors for more information about the current status of the trial but did not receive a reply. See Studies awaiting classification.

\section{Risk of bias in included studies}

We have summarised 'Risk of bias' assessments in Figure 2. 
Figure 2. A summary of review authors' 'Risk of bias' assessments for included studies. Red = high risk of bias; yellow $=$ unclear risk of bias; green $=$ low risk of bias.

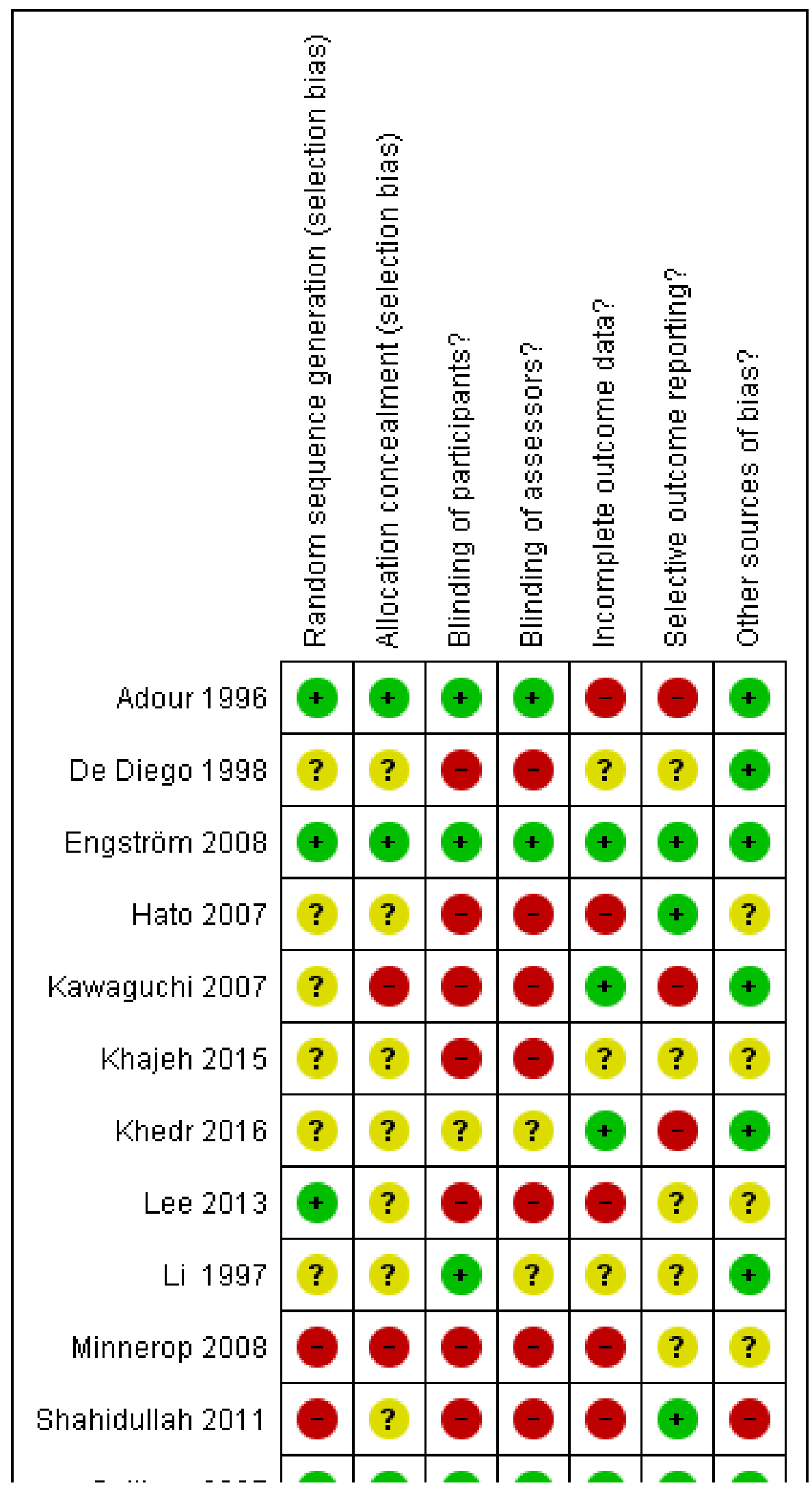


Figure 2. (Continued)

\begin{tabular}{|r|c|c|c|c|c|c|c|}
\cline { 2 - 7 } Shahidullah 2011 & - & $?$ & - & - & - & + & - \\
\cline { 2 - 7 } Sullivan 2007 & + & + & + & + & + & + & + \\
\cline { 2 - 7 } Vázquez 2008 & $?$ & $?$ & $?$ & $?$ & + & $?$ & + \\
\cline { 2 - 7 } Yeo 2008 & $?$ & $?$ & $?$ & $?$ & $?$ & $?$ & + \\
\cline { 2 - 8 }
\end{tabular}




\section{Allocation}

Three studies were at low risk of selection bias, being adequately randomised, with allocation concealment (Adour 1996; Sullivan 2007; Engström 2008).

Two other studies were at low risk of bias from the method of randomisation, but at high or unclear risk of bias from inadequate allocation concealment (Kawaguchi 2007; Lee 2013). Lee 2013 reported a later onset of the treatment in the combination treatment group, without significance. The trial used a simple randomisation generated by Microsoft Excel to intervention and control but the authors did not provide information on allocation concealment (Lee 2013). Kawaguchi 2007 did not conceal allocation, the allocation envelope contained the name of the treatment group, Although this trial reported a significant difference between mean ages of the treatment groups, further analysis of the age distribution using the $\mathrm{Chi}^{2}$ test revealed no significant difference.

In seven studies, the risk of bias from the method of randomisation and allocation concealment were unclear (Li 1997; De Diego 1998; Hato 2007; Vázquez 2008; Yeo 2008; Khajeh 2015; Khedr 2016). De Diego 1998, Vázquez 2008, Yeo 2008 and Khajeh 2015 did not describe the randomisation method or measures to conceal allocation. Li 1997 used codes, but provided little information on randomisation. Khedr 2016 and Hato 2007 reported the use of envelopes, and in Khedr 2016 these were serially-numbered, opaque and closed, but the reports provided insufficient detail for a clear judgement.

Minnerop 2008 and Shahidullah 2011 were at high risk of bias for randomisation as they used even and odd days or numbers to randomise the participants. In Minnerop 2008, there were 25\% more participants in the prednisolone group than in the combination treatment group. Shahidullah 2011 included more participants with severe Bell's palsy in the combination treatment group than in the prednisolone alone group. Minnerop 2008 was not blinded and unlikely to have concealed allocation. Allocation concealment in Shahidullah 2011 was unclear.

\section{Blinding}

Adour 1996, Li 1997, Sullivan 2007 and Engström 2008 were described as double-blind and placebo-controlled trials and we assessed them at low risk of performance bias. All used placebo and described methods for adequate blinding of the trial drug. De Diego 1998, Hato 2007, Kawaguchi 2007, Minnerop 2008, Shahidullah 2011, Lee 2013, and Khajeh 2015 were open-label and we assessed them at high risk of bias. Vázquez 2008, Yeo 2008 and Khedr 2016 stated that the study was double-blind; however, the text does not describe this and the trials were not placebo-controlled, so we assessed their risk of bias for blinding (performance bias) as unclear.

For blinding of the outcome assessor, we assessed two trials at low risk of bias (Sullivan 2007; Engström 2008). The remaining studies were at high or unclear risk of bias.

\section{Incomplete outcome data}

All studies except Yeo 2008 and Khajeh 2015 reported frequencies, and often reasons, for failure to complete follow-up. We assessed five trials at low risk for incomplete outcome data (Kawaguchi 2007;
Sullivan 2007; Vázquez 2008; Engström 2008; Khedr 2016). These trials reported a dropout rate of less than $10 \%$.

We assessed De Diego 1998 at unclear risk of bias due to a dropout rate of $10 \%$. Two trials also reported a dropout rate of less than $10 \%$ but reasons for drop out were not given in the paper (Yeo 2008; Li 1997). We assessed these studies at unclear risk of bias for this reason, as for Khajeh 2015. The remaining five studies were at high risk of bias in this category: Lee 2013 reported a dropout rate of $13.1 \%$, Adour 1996 17\%, Hato 2007 25\%, and Shahidullah 2011 27\%. Minnerop 2008 reported a loss to follow-up rate of $30 \%$, but for the current review, data from only $30 \%$ of the study population (participants assessed between 3 and 12 months) fulfilled the inclusion criteria of this review. None of the studies assessed as high and unclear risk of bias used the intention-to-treat approach to control this.

\section{Selective reporting}

All studies except Adour 1996 and Kawaguchi 2007 reported all intended primary outcomes. Adour 1996 failed to report on audiometry and stapedial reflex testing. Engström 2008 reported all primary outcomes; secondary outcomes were reported in later published papers (Axelsson 2012; Berg 2012). Minnerop 2008 reported the main outcome for all participants independently from the time of the assessment, and published data were insufficient to differentiate between those who were eligible to be included in this review (participants who were assessed within the defined time period of 3 to 12 months) and those who were not. Khajeh 2015 did not report baseline data.

Seven studies did not report adverse events (Li 1997; De Diego 1998; Kawaguchi 2007; Yeo 2008; Lee 2013; Khajeh 2015; Khedr 2016).

\section{Other potential sources of bias}

\section{Statistical analysis}

Twelve of the 14 studies analysed gave adequate detail; they clearly stated and then used appropriate statistical tests. We only scored Hato 2007 'unclear' in this category, as the authors did not adequately describe the tests used. We scored Shahidullah 2011 'high' for this and in addition due to baseline differences between groups at inclusion.

\section{Baseline differences between groups}

Eight of the 14 trials were adequate in this category. De Diego 1998 found a significant difference in rates of hypertension between the two groups, but further analysis revealed that there was no significant difference in trial outcomes as a result. Kawaguchi 2007 reported a significant difference between mean ages of the treatment groups, but further analysis of the age distribution using the $\mathrm{Chi}^{2}$ test revealed no significant difference. Lee 2013 reported a later onset of treatment in the combination treatment group, without significance but it was of unclear risk for excluding of two participants with adverse events in the steroid group (not clearly specified) from the analysis.

We assessed two trials at unclear risk in this category: Khajeh 2015 reported only age and sex at baseline and there was a difference between the groups, and in Minnerop 2008 there were 25\% more participants in the prednisolone group than in the combination treatment group. We scored Shahidullah 2011 as high risk of bias; it in- 
cluded more participants with severe Bell's palsy in the combination group than in the prednisolone alone group.

\section{Effects of interventions}

See: Summary of findings for the main comparison Antivirals plus corticosteroids compared to corticosteroids plus placebo or no treatment (AS versus OS) for Bell's palsy (idiopathic facial paralysis)

As the included trials reported different intervals and lengths of follow-up, we performed the analyses on data reported at three months (De Diego 1998; Khajeh 2015; Khedr 2016; Shahidullah 2011), six months (Li 1997; Hato 2007; Kawaguchi 2007; Vázquez 2008; Yeo 2008; Lee 2013), nine months (Sullivan 2007), or 12 months (Engström 2008), after the start of treatment.

For the subgroup analysis of incomplete recovery in participants with severe Bell's palsy at onset, we either extracted data at month six, in Hato 2007 and Lee 2013, or imputed data to month six, in Sullivan 2007 and Engström 2008.

Throughout this section of the review, we utilised the following notation.

- AO: antiviral treatment alone or in combination with placebo
- AS: antiviral treatment in combination with corticosteroids

- OO: placebo or no treatment

- OS: corticosteroid treatment alone or in combination with placebo

\section{Antivirals plus corticosteroids versus corticosteroids plus placebo or no treatment (AS versus OS)}

This comparison included 13 studies with 1729 participants (Adour 1996; Li 1997; Hato 2007; Kawaguchi 2007; Sullivan 2007; Engström 2008; Minnerop 2008; Vázquez 2008; Yeo 2008; Shahidullah 2011; Lee 2013; Khajeh 2015; Khedr 2016). We restricted our main analyses to studies at low or unclear risk of bias in fewer than five domains. See Summary of findings for the main comparison.

\section{Incomplete recovery}

Three studies comparing AS and OS were at high or unclear risk of bias in fewer than five categories (Adour 1996; Sullivan 2007; Engström 2008). Pooled data from these three studies found no clear difference between AS and OS (risk ratio (RR) 0.81, 95\% confidence interval $(\mathrm{Cl}) 0.38$ to $1.74 ; 3$ trials, $\mathrm{N}=766$; random-effects; low-certainty evidence). The result showed substantial heterogeneity $\left(\mathrm{Chi}^{2}\right.$ $\left.=5.30, \mathrm{df}=2(\mathrm{P}=0.07) ; \mathrm{I}^{2}=62 \%\right)$ and was imprecise, with a $\mathrm{Cl}$ that encompassed effects in either direction (Analysis 1.1; Figure 3).

Figure 3. Forest plot of comparison: 1 Antivirals plus corticosteroids versus corticosteroids plus placebo or no treatment (AS versus OS): sensitivity analysis based on risk of bias (excluding studies at high or unclear risk of bias in fewer than five domains), outcome: 1.1 Incomplete recovery at end of study.

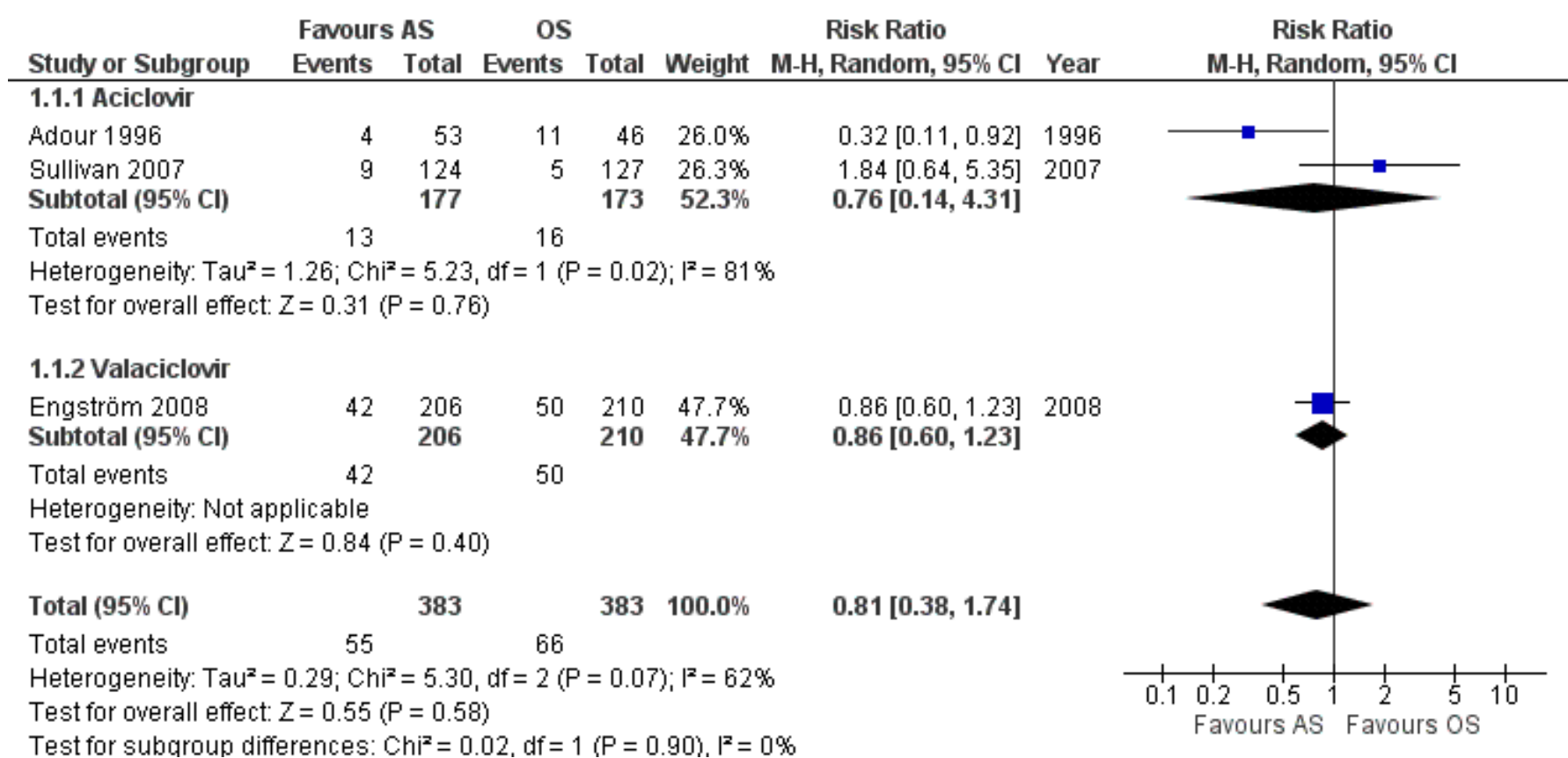

When the analysis used all the available evidence, the rate of incomplete recovery was lower after AS than OS (RR 0.59, 95\% Cl 0.47 to $0.70 ; 13$ trials, $\mathrm{N}=1729$; fixed-effect; very low-certainty evidence).
Heterogeneity was substantial $\left(C^{2} i^{2}=20.03, \mathrm{df}=12(P=0.07), \mathrm{I}^{2}=\right.$ $40 \%$ ); we used the random-effects model to adjust for this (RR 0.54 , $95 \% \mathrm{Cl} 0.38$ to 0.77 ; Analysis 1.2; Figure 4). 
Figure 4. Forest plot of comparison: 1 Antivirals plus corticosteroids versus corticosteroids plus placebo or no treatment (AS versus OS): trials at lower risk of bias, outcome: 1.2 Incomplete recovery at end of study (full data set).

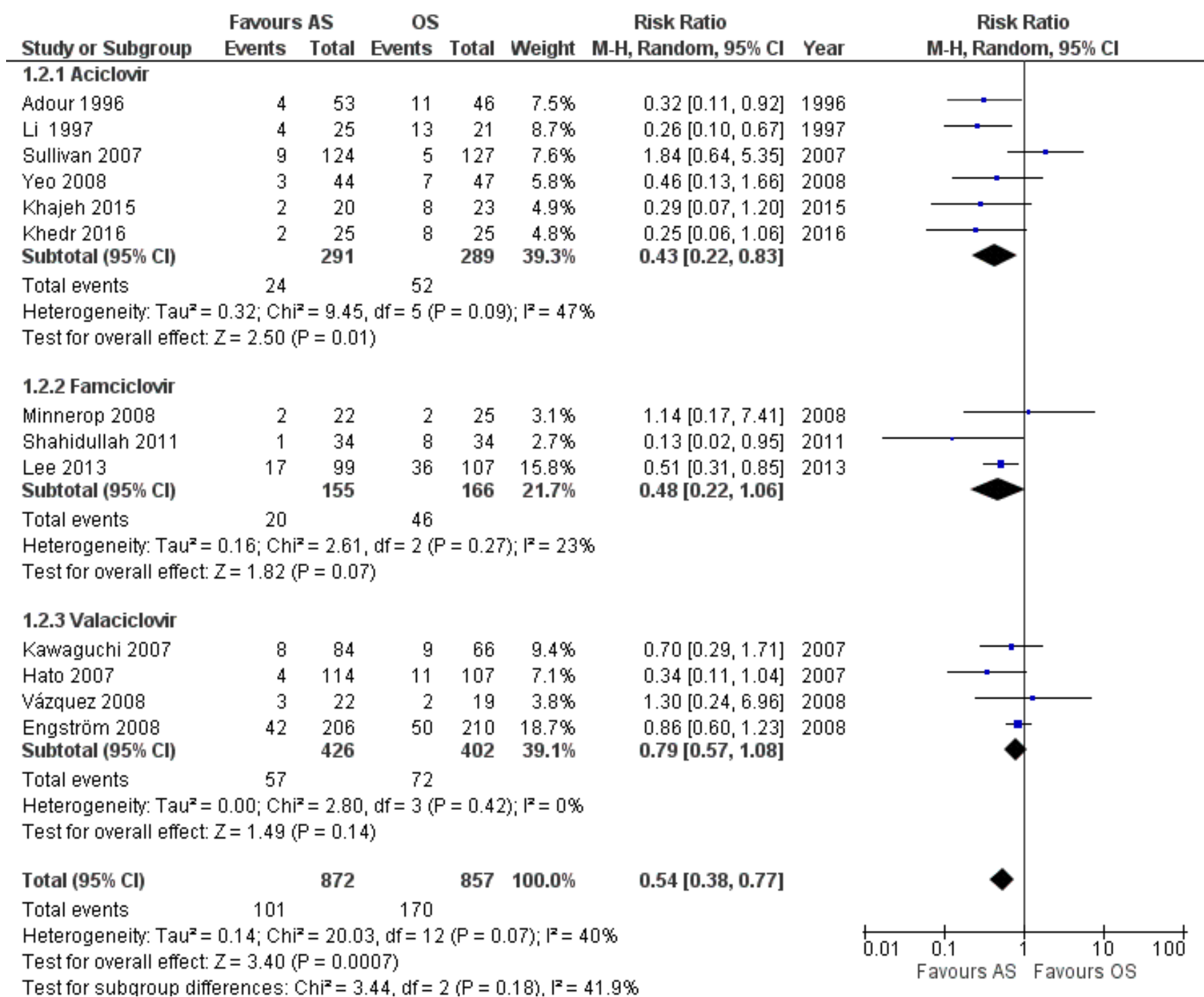

We also investigated the effect of AS versus OS by performing a sensitivity analysis (on the whole data set) to investigate the effect of removing studies with a follow-up of less than six months (i.e. Adour 1996; Shahidullah 2011; Khajeh 2015; Khedr 2016). We found that this did not substantially alter the findings (RR $0.65,95 \% \mathrm{Cl} 0.45$ to $0.94 ; \mathrm{Chi}^{2}=12.75, \mathrm{df}=8(\mathrm{P}=0.12) ; \mathrm{I}^{2}=37 \%$; 9 trials, $\mathrm{N}=1469$; random-effects).

\section{Subgroup analysis: effect of different antiviral agents}

In our analysis of trials at lower risk of bias, we presented data for this outcome subgrouped by antiviral agent: aciclovir (Adour 1996; Sullivan 2007), or valaciclovir (Engström 2008). There were too few trials for reliable subgroup analysis (Analysis 1.1)

We performed this subgroup analysis on the full data set: aciclovir (Adour 1996; Li 1997; Sullivan 2007; Yeo 2008; Khajeh 2015; Khedr 2016); famciclovir (Minnerop 2008; Shahidullah 2011; Lee 2013); and valaciclovir (Hato 2007; Engström 2008; Vázquez 2008;
Kawaguchi 2007). Trials that studied the effects of aciclovir (RR $0.43,95 \% \mathrm{Cl} 0.22$ to $0.83 ; 6$ trials, $\mathrm{N}=580$ ) and famiciclovir (RR 0.48 , $95 \% \mathrm{Cl} 0.22$ to $1.06 ; 3$ trials, $\mathrm{N}=321$ ) showed large effects in favour of AS over OS. Yet, the valaciclovir subgroup showed a smaller effect in favour of AS over OS and more imprecision (RR $0.79,95 \% \mathrm{Cl}$ 0.57 to 1.08 ; 4 trials, $\mathrm{N}=828$; Analysis 1.2). The statistical test for subgroup differences did not support a subgroup effect: $\mathrm{Chi}^{2}=3.44$, $d f=2(P=0.18) ;\left.\right|^{2}=41.9 \%$.

\section{Additional analysis: severe cases}

For this comparison, we extracted data from four studies (Hato 2007; Sullivan 2007; Engström 2008; Lee 2013).

We restricted our main analysis to two studies at lower risk of bias (Sullivan 2007; Engström 2008). The proportion of participants with incomplete recovery showed no clear difference in the AS group versus the OS group among people with severe Bell's palsy (RR 0.82, $95 \% \mathrm{Cl} 0.57$ to $1.17 ; 2$ studies, $\mathrm{N}=98 ; \mathrm{Chi}^{2}=0.72, \mathrm{df}=1(\mathrm{P}=0.40) ; \mathrm{I}^{2}$ 
$=0 \%$; random-effects; Analysis 1.3; Figure 5). The result was impre-

cise but without statistical heterogeneity.

\section{Figure 5. Forest plot of comparison: 3 Antivirals plus corticosteroids versus placebo, outcome: 3.1 Incomplete recovery at end of study.}

\begin{tabular}{|c|c|c|c|c|c|c|c|c|c|c|c|}
\hline Study or Subgroup & $\begin{array}{r}\text { AS } \\
\text { Events } \\
\end{array}$ & Total & $\begin{array}{r}00 \\
\text { Events }\end{array}$ & Total & Weight & $\begin{array}{c}\text { Risk Ratio } \\
\text { M-H, Random, } 95 \% \mathrm{Cl}\end{array}$ & Year & \multicolumn{4}{|c|}{$\begin{array}{c}\text { Risk Ratio } \\
\text { M-H, Random, } 95 \% \mathrm{Cl} \\
\end{array}$} \\
\hline Sullivan 2007 & 9 & 124 & 18 & 122 & $15.6 \%$ & $0.49[0.23,1.05]$ & 2007 & & & & \\
\hline Engström 2008 & 42 & 206 & 73 & 206 & $84.4 \%$ & $0.58[0.41,0.80]$ & 2008 & & & & \\
\hline Total $(95 \% \mathrm{Cl})$ & & 330 & & 328 & $100.0 \%$ & $0.56[0.42,0.76]$ & & & & & \\
\hline Total events & 51 & & 91 & & & & & & & & \\
\hline $\begin{array}{l}\text { Heterogeneity: Tau } \\
\text { Test for overall effeo }\end{array}$ & $\begin{array}{l}0.00 ; \mathrm{Ch} \\
Z=3.77\end{array}$ & $\begin{array}{l}P=0.1 \\
P=0.0\end{array}$ & $\begin{array}{l}4, d f=1 \\
002)\end{array}$ & $=0$. & $;\left.\right|^{2}=09$ & & & 0.2 & $\begin{array}{c}0.5 \\
\text { Favours AS }\end{array}$ & $\frac{2}{2}$ & 5 \\
\hline
\end{tabular}

When the analysis used all the available evidence (i.e. also including Hato 2007 and Lee 2013), the proportion of participants with incomplete recovery was slightly lower in the AS group versus the OS group in people with severe Bell's palsy. The result was also imprecise (RR $0.64,95 \% \mathrm{Cl} 0.41$ to $0.99 ; 4$ trials, $\mathrm{N}=478$; random-effects). Heterogeneity was moderate $\left(\mathrm{Chi}^{2}=5.2, \mathrm{P}=0.16, \mathrm{I}^{2}=42 \%\right)$ (see Analysis 1.4).

\section{Motor synkinesis or crocodile tears}

Adour 1996 and Engström 2008 provided data on motor synkinesis or crocodile tears, assessed at the end of the study. The analysis included 469 participants and showed that fewer participants experienced these long-term sequelae after AS than after OS (RR 0.56, $95 \% \mathrm{Cl} 0.36$ to $0.87 ; 2$ trials, $\mathrm{N}=469 ; \mathrm{Chi}^{2}=0.25, \mathrm{df}=1(\mathrm{P}=0.62)$; $\mathrm{I}^{2}=0 \%$; fixed-effect; moderate certainty-evidence; Analysis 1.5). As both trials were of low risk of bias in most domains, we did not perform a sensitivity analysis.

\section{Adverse events}

Four trials comparing AS versus OS reported on adverse events, reporting data from 945 participants (Hato 2007; Sullivan 2007; Engström 2008; Shahidullah 2011).

The analysis including only the studies at a low risk of bias (i.e. Sullivan 2007 and Engström 2008), showed no clear difference between AS and OS in the number of participants experiencing adverse events (RR 1.17, 95\% Cl 0.81 to $1.69 ; 2$ trials, $\mathrm{N}=656 ; \mathrm{Chi}^{2}=$ $0.26, d f=1(P=0.61) ; I^{2}=0 \%$; fixed-effect; Analysis 1.6).

The result using all the available evidence was similar to evidence from studies at low risk of bias, with no clear difference in the number of participants with adverse events between the AS and the OS group (RR 1.16, 95\% Cl 0.83 to $1.63 ; 4$ trials, $\mathrm{N}=945 ; \mathrm{Chi}^{2}=0.39, \mathrm{df}=$ $3(P=0.94) ; I^{2}=0 \%$; fixed-effect; very low-certainty evidence; Analysis 1.7).

\section{Antivirals versus corticosteroids (AO versus $O S$ )}

This comparison contained three studies (De Diego 1998; Sullivan 2007; Engström 2008).

\section{Incomplete recovery}

All three studies (768 participants) provided data for our primary outcome, incomplete recovery at the end of the study.
Our primary analysis, which excluded De Diego 1998 due to a high or unclear risk of bias in five domains, produced a RR of $2.69,95 \%$ $\mathrm{Cl} 0.73$ to $10.01 ; 2$ studies, $\mathrm{N}=667 ; \mathrm{Chi}^{2}=7.41, \mathrm{df}=1(\mathrm{P}=0.006) ; \mathrm{I}^{2}$ $=87 \%$; random-effects; Analysis 2.1). The result favoured corticosteroids; however heterogeneity was substantial and the $\mathrm{Cl}$ did not exclude the possibility of no difference between the groups.

Analysis of all three trials (i.e. including De Diego 1998), also found a greater proportion of participants treated with $\mathrm{AO}$ had incomplete recovery than those treated with OS. Initial calculations using the fixed-effect model showed a RR of $1.96,95 \% \mathrm{Cl} 1.48$ to $2.59 ; 3$ trials, $\mathrm{N}=768$, but with a high degree of heterogeneity $\left(\mathrm{Chi}^{2}=8.78, \mathrm{df}=2\right.$ $\left.(P=0.01) ; I^{2}=77 \%\right)$. We repeated the analysis using the random-effects model to adjust for this, and the RR was $2.82,95 \% \mathrm{Cl} 1.09$ to 7.32; Analysis 2.2).

\section{Motor synkinesis or crocodile tears}

De Diego 1998 and Engström 2008 provided data for the outcome, motor synkinesis or crocodile tears at the end of the study.

After removing De Diego 1998 (unclear or high risk of bias in 5 domains) the results from Engström 2008 showed that more participants had sequelae with $\mathrm{AO}$ than $\mathrm{OS}$ (RR $1.70,95 \% \mathrm{Cl} 1.15$ to 2.50; 1 trial, $\mathrm{N}=371$; Analysis 2.3).

Analysis of the full data set including 472 participants also found more participants had sequelae after AO than OS (RR 1.52, 95\% Cl 1.08 to $2.12 ; 2$ trials, $N=472 ; C^{2} i^{2}=1.50,(P=0.22) ; I^{2}=33 \%$; fixedeffect; Analysis 2.4).

\section{Adverse events}

Two trials reported this outcome (Sullivan 2007; Engström 2008).

Fewer participants experienced adverse events in the $\mathrm{AO}$ group than the OS group (RR $0.85,95 \% \mathrm{Cl} 0.57$ to 1.28 ; 2 trials, $\mathrm{N}=658$; $\mathrm{Chi}^{2}=0.05, \mathrm{df}=1$ (P = 0.82); $\mathrm{I}^{2}=0 \%$; fixed-effect; very low-certainty evidence; Analysis 2.5), but the Cls included the possibility of the opposite effect (Sullivan 2007; Engström 2008). Due to a low risk of bias in most domains of both trials, we did not perform a sensitivity analysis.

\section{Antivirals plus corticosteroids versus placebo (AS versus 00)}

This comparison contained two studies and outcome data on 658 participants (Sullivan 2007; Engström 2008). 


\section{Incomplete recovery}

There was a large effect on the rates of incomplete recovery at the end of the study that favoured AS compared with OO (RR 0.56, 95\% $\mathrm{Cl} 0.42$ to $0.76 ; 2$ trials, $\mathrm{N}=658 ; \mathrm{Chi}^{2}=0.14, \mathrm{df}=1(\mathrm{P}=0.71) ; \mathrm{I}^{2}=$ $0 \%$; random-effects; Analysis 3.1; Figure 5 ). We did not perform a sensitivity analysis in this data set since the risk of bias was low in both included studies.

\section{Motor synkinesis or crocodile tears}

One trial reported the effect of the intervention on motor synkinesis or crocodile tears (Engström 2008), and showed a reduction in the AS versus the $\mathrm{OO}$ group, with a RR of $0.37,95 \% \mathrm{Cl} 0.23$ to $0.59 ; 1$ trial, $\mathrm{N}=372$; random-effects; Analysis 3.2).

\section{Adverse events}

Using the data from both trials, there was little or no difference between treatment with AS and $\mathrm{OO}$ in the proportion of participants with adverse events (RR $1.14,95 \% \mathrm{Cl} 0.79$ to $1.65 ; 2$ trials, $\mathrm{N}=649$, $\mathrm{Chi}^{2}=0.13, \mathrm{df}=1(\mathrm{P}=0.72) ; \mathrm{I}^{2}=0 \%$; fixed-effect; Analysis 3.3).

\section{Antivirals versus placebo ( $\mathrm{AO}$ versus $\mathrm{OO}$ )}

Two studies investigated this comparison (Sullivan 2007; Engström 2008). We did not perform a sensitivity analysis in this comparison, as both trials were at lower risk of bias.

\section{Incomplete recovery}

Two trials compared antivirals versus placebo without any complicating additional treatment (Sullivan 2007; Engström 2008). AO had no clear effect on the proportion of participants with incomplete recovery (RR $1.10,95 \% \mathrm{Cl} 0.87$ to $1.40 ; 2$ trials, $\mathrm{N}=658$ ). There was imprecision and the heterogeneity was moderate $\left(\mathrm{Chi}^{2}=1.63, \mathrm{P}=\right.$ $0.20, \mathrm{I}^{2}=39 \%$; fixed-effect; Analysis 4.1 ).

\section{Motor synkinesis or crocodile tears}

Only Engström 2008 reported results for this outcome (RR 1.04, 95\% $\mathrm{Cl} 0.75$ to $1.43 ; 1$ trial, $\mathrm{N}=373$; random-effects; Analysis 4.2.

\section{Adverse events}

The proportion of participants who had adverse events was similar in the $\mathrm{AO}$ and $\mathrm{OO}$ groups, but the result was imprecise (RR 0.83, 95\% Cl 0.56 to $1.24 ; 2$ trials, $N=651 ; C^{2}{ }^{2}=0.33, d f=1(P=0.57) ;\left.\right|^{2}=0 \%$; fixed-effect; Analysis 4.3).

\section{Funnel plot}

We included a funnel plot, which shows some asymmetry of the distribution of the studies. This suggests small-study effects and may reflect differences in methodological quality or publication bias (Figure 6).

Figure 6. Funnel plot of comparison: 1 Antivirals plus corticosteroids versus corticosteroids plus placebo or no treatment (AS versus OS): trials at lower risk of bias, outcome: 1.2 Incomplete recovery at end of study (full data set).

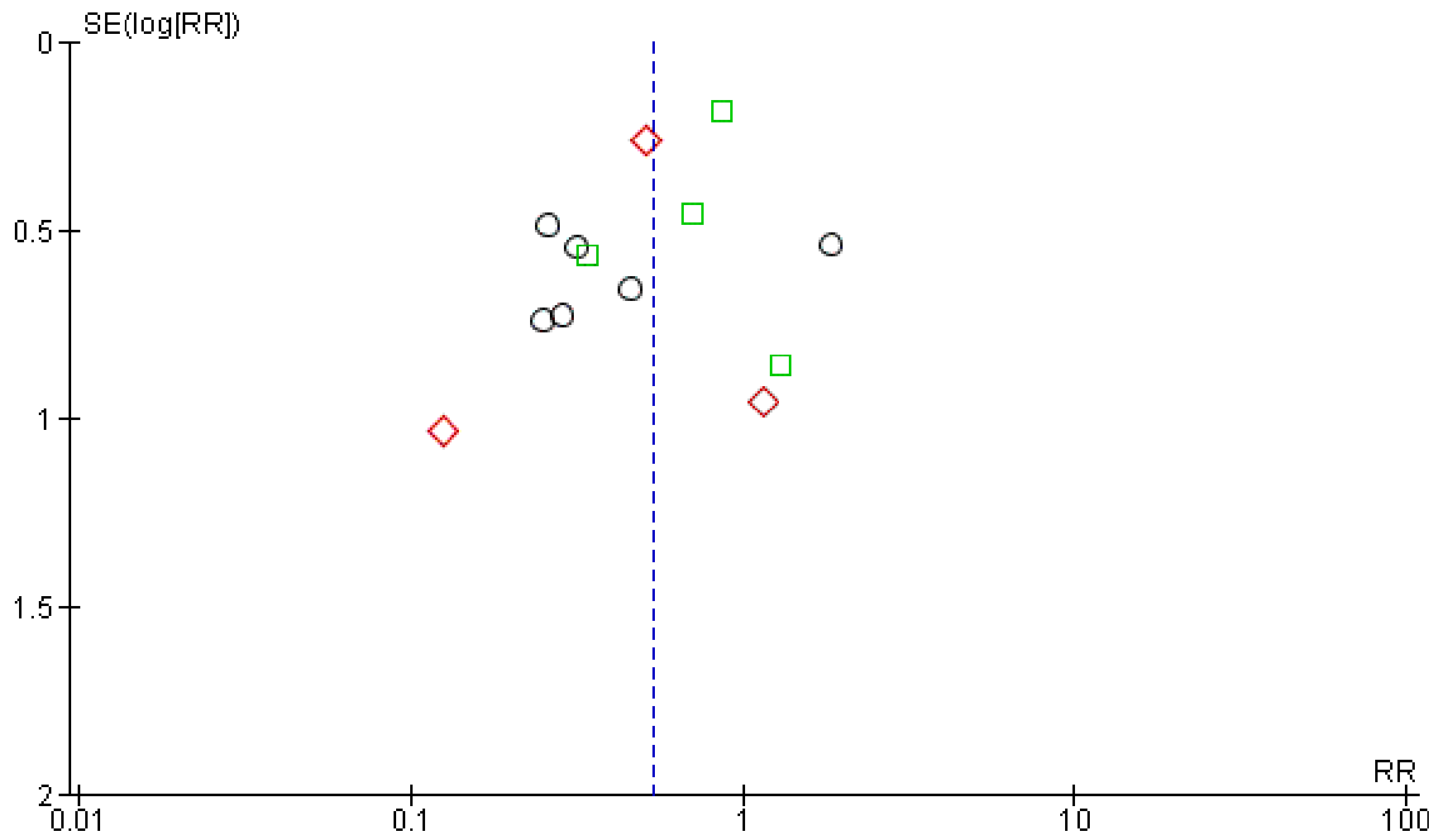

Subgroups Aciclovir 


\section{DISCUSSION}

\section{Summary of main results}

We identified 14 studies of antivirals in Bell's palsy that provided data for analyses. They included 2488 participants. We were unable to draw any conclusions from analysis of the 14 studies, as the certainty of evidence was very low, primarily due to study limitations and inconsistency. When we limited our analysis to data from three studies at lower risk of bias, results indicated that the combination of antivirals and corticosteroids may have little or no effect on rates of incomplete recovery compared to corticosteroids alone (see Summary of findings for the main comparison). There was no clear difference in rates of incomplete recovery among participants with severe Bell's palsy in the group treated with the combination of antiviral treatment and corticosteroids versus those who received corticosteroid treatment alone or in combination with placebo, in contrast with results based on the full data set from people with severe disease, which found a slightly lower rate of incomplete recovery with antiviral treatment in combination with corticosteroids compared to corticosteroid treatment alone or in combination with placebo.

The rate of incomplete recovery was higher in participants receiving antivirals alone or in combination with placebo than in those who received corticosteroids alone or in combination with placebo. The rate of incomplete recovery was lower with the combination of antivirals and corticosteroids than with placebo or no treatment, but antivirals alone or in combination with placebo had no clear effect compared with placebo or no treatment. For these outcomes, we analysed data from two or three trials only. Apart from the comparison of antivirals in combination with corticosteroids versus placebo or no treatment, the trials showed a moderate to high degree of heterogeneity and wide confidence intervals (Cls).

Three studies evaluated sequelae (long-term effects) of Bell's palsy, crocodile tears and motor synkinesis, at the end of the study. They found that there were probably fewer instances of long-term sequelae in people who received the combination of antivirals and corticosteroids compared with the group who received corticosteroids alone or in combination with placebo (Engström 2008). These sequelae were also less frequent in those who were treated with antivirals alone or in combination with placebo compared with corticosteroids alone or in combination with placebo (Adour 1996; Engström 2008), and in those treated with the combination of antivirals and corticosteroids compared with placebo or no treatment (Engström 2008).

Data did not show clear differences in the adverse events in any of the comparisons.

\section{Overall completeness and applicability of evidence}

Although the number of included studies and participants have increased since the last update of this review, the additional studies did not contribute to the certainty of the evidence. The external validity of most evidence was low, which limited interpretation of the results. The heterogeneity found in analyses may be due to clinical variation, for example in participant characteristics, age, disease severity at baseline, delay in receiving treatment, or different type of antiviral agent used, and also different time points of measurements of the outcome. Heterogeneity was exacerbated in many studies by keeping the inclusion criteria fairly broad; this maximised data inclusion, and therefore power, but results must be interpreted with this in mind. Furthermore, the different definitions of severe Bell's palsy in the trials, depending on the symptom scores should also be considered a potential source of heterogeneity. Other limitations are the high or unclear risk of bias in several domains and the small size of the majority of included trials. Given the likely overall small or absent effect of antivirals, it is unlikely that different antiviral compounds will have a significant effect on incomplete recovery at the end of the study, despite the difference in bioavailability (Sullivan 2007).

We found differences in severity at recruitment: Li 1997, Hato 2007, Vázquez 2008, Yeo 2008, Lee 2013 and Khedr 2016 included a more severe spectrum of palsy. Hato 2007 and Engström 2008 stratified participants by severity of disease status at onset. Hato 2007 found that in cases of complete or severe palsy, the recovery rate for the combination treatment was greater than for participants treated only with OS. Lee 2013 included only severe cases and found a higher rate of recovery in the group receiving a combination treatment using famciclovir. Khedr 2016 excluded patients with mild to moderate palsy and showed benefit from a combination treatment. In contrast, Engström 2008 could not confirm these findings in treatment of participants with severe Bell's palsy, whereas in Sullivan 2007, combined treatment with antivirals and corticosteroids showed increased rates of incomplete recovery over corticosteroids alone. The analysis of participants with severe Bell's palsy showed no clear effect of the combination treatment.

We found variation in the clinical endpoints chosen as defining recovery: Sullivan 2007, Engström 2008, Shahidullah 2011 and Khajeh 2015 used House-Brackmann scale Grade 1 (House 1985), while Li 1997, Yeo 2008, Lee 2013 and Khedr 2016 used House-Brackmann scale Grade 1 and 2. Minnerop 2008 did not define recovery. The other studies used a variety of different scales that show more or less equivalence to these. We have provided details of the symptoms scales and comparisons, where available (Table 1, Table 2, Table 3).

Equally, heterogeneity could be due to methodological or design differences in the studies, such as the method of randomisation, use of blinding, choice of outcome measures and recovery cut-off points, or trial duration. In particular, Li 1997, De Diego 1998, Hato 2007, Kawaguchi 2007, Minnerop 2008, Shahidullah 2011, Khajeh 2015 and Khedr 2016 had methodological weaknesses, either in baseline group assessment or in completeness of follow-up, and adequacy of blinding. Any of these factors could result in bias and introduce inaccuracy. Sensitivity analysis of trials not meeting current best standards (that is, high or unclear risk of bias) changed the findings from a large effect into little or no effect, especially in the primary outcome of our main analysis. We concluded that it was the studies at higher risk of bias that suggested benefit from the combination treatment. Our sensitivity analysis of trials with a sixmonth endpoint corresponded with this finding and also showed a change in the result compared to the whole group analysis.

Subgroup analyses on the whole data set revealed some differences between the different antivirals used. We showed a benefit for the combination treatment with aciclovir and famciclovir but not for valaciclovir. This appears to be a subgroup effect but this can also be explained by the heterogeneity of the trials. The statistical test for subgroup differences did not identify a significant differ- 
ence. An additional analysis among participants with severe Bell's palsy, showed little or no effect of the combination treatment. Taking both into account, subgroup analyses and the analysis in people with severe Bell's palsy were helpful in explaining the heterogeneity of the overall analysis.

From the data available for analysis of motor synkinesis or crocodile tears at the end of the study, the results favoured antiviral treatment in combination with corticosteroids compared to corticosteroid treatment alone or in combination with placebo, and also corticosteroid treatment alone or in combination with placebo compared to antiviral treatment alone or in combination with placebo (Analysis 1.5; Analysis 2.3). In the analysis of the whole data set (3 studies with a total of 941 participants), the degree of clinical heterogeneity (different clinical assessment scales used) and methodological heterogeneity (different treatment regimens and follow-up plans) limited interpretation of the data. There was no clear difference between groups based on data from trials at a lower risk of bias, but the data were imprecise.

Adverse event data were available in four studies, giving comparison data for 1592 participants, but the certainty of evidence was very low; the $\mathrm{Cls}$ in the analyses were wide and encompassed the possibility of an effect in either direction (Sullivan 2007; Hato 2007; Engström 2008; Shahidullah 2011).

It was unclear whether time to treatment influenced recovery. Neither Kawaguchi 2007 nor Yeo 2008 found an association between time to treatment and final recovery status, but most of the trials did not provide data on this outcome.

The review included studies conducted in Asia, North and Middle America, and Europe. It is possible that genetic differences in drug metabolism or response or even different aetiological processes may account for some of the observed variation in response.

The primary outcome result raises another important consideration, namely health economic issues: a 10-day course of aciclovir $400 \mathrm{mg}$ five times per day costs GBP 2.04 (USD 2.69, EUR 2.29). The cost of valaciclovir is similar: $1000 \mathrm{mg}$ three times per day for seven days costs GBP 10.12 (USD 12.97, EUR 11.38); $2 \mathrm{~g}$ once daily for seven days costs GBP 6.75 (USD 8.90, EUR 7.59), or 1000 mg once daily for 5 days costs GBP 2.41 (USD 3.18, EUR 2.71). Famciclovir 250 $\mathrm{mg}$ three times per day for seven days and $250 \mathrm{mg}$ three times per day for five days is significantly more expensive and likely to cost the same at GBP 155.32 (USD 204.90, EUR 174.69). A 10-day course of prednisolone (2 $25 \mathrm{mg}$ tablets daily) costs GBP 26.79 (USD 35.34 EUR 30.13), much less than for the antivirals. These cost data are specific to the UK market (NHS Surrey Downs 2018), and costs vary significantly in other countries (Hernández 2008).

\section{Certainty of the evidence}

The certainty of evidence in the current review does not allow robust conclusions regarding incomplete recovery for the comparison of antiviral treatment in combination with corticosteroids versus corticosteroid treatment alone or in combination with placebo (Summary of findings for the main comparison). We downgraded the certainty of evidence for the main comparison to low since the risk ratio (RR) had a wide $\mathrm{Cl}$ that included the possibility of very little effect (imprecision) and for inconsistency of the results. This analysis was performed after removal of studies at high or unclear risk of bias and did not confirm the previously demonstrated effect Sum- mary of findings for the main comparison. Some studies showed a benefit and others a detrimental effect of AS in participants with Bell's palsy. The funnel plot shows asymmetry of the distribution of the studies, indicating the possibility of publication bias and smallstudy effects (Figure 6).

The body of evidence identified for motor synkinesis and crocodile tears was small because only two trials provided data and one of them had a small sample size.

Very low-certainty evidence showed no differences in the occurrence of adverse events. We downgraded the body of evidence due to publication bias, for imprecision, as the Cls were wide and encompassed the possibility of an effect in either direction, and because the proportion of participants lost to follow-up was large in some of the included trials.

\section{Potential biases in the review process}

To help ensure that decisions about which studies to include in this review were reproducible, two review authors repeated the review process. Regarding application of the eligibility criteria and assessing the relevance of studies, review authors were aware of the names of the study authors, institutions, journal of publication, and results. FS and FD were authors of the Sullivan 2007 study.

According to previous practice in this review, we excluded several studies and a published abstract for different reasons (Excluded studies). As a result, there could be some risk of publication and selective reporting bias due to data from some studies being unavailable.

At this update our main analyses excluded studies at high or unclear risk of bias in at least five domains. We listed this sensitivity analysis in the methods in a previous version of this review, but did not previously present it as the primary analysis. Even this restricted set of data included a trial at high risk of bias in two domains with a large effect size, which if excluded from the analysis would move the results of the efficacy analyses for antiviral treatment in combination with corticosteroids versus corticosteroid treatment alone or in combination with placebo closer towards the null (Adour 1996). The results are highly sensitive to study inclusion and risk of bias decisions, and true effects may be substantially different from the estimates in the review. We used the Cochrane 'Risk of bias' tool as currently implemented to assess bias in studies (Higgins 2011), and checked and corrected previous judgements as appropriate. It is probable that implementation of the new 'Risk of bias' tool will again change estimates of effect (Higgins 2019). Future updates will restrict the main analyses to studies at a low overall risk of bias based on judgements in the new tool.

On the advice of the Cochrane Neuromuscular Statistical Editor, we did not also perform a prespecified sensitivity analysis, excluding studies with fewer than 200 participants, which had also been described in the methods of a previous version of the review, as this was considered too arbitrary a restriction.

\section{Agreements and disagreements with other studies or reviews}

We found two systematic reviews, three meta-analyses and a network meta-analysis comparing corticosteroids and antivirals for the treatment of Bell's palsy (de Almeida 2009; Goudakos 2009; Quant 2009; Numthavaj 2011; Dong 2015; Fu 2018). De Almeida and 
colleagues compared any corticosteroid treatment with antivirals and included 18 trials in the meta-analysis. Some of the trials did not meet the inclusion criteria for this review (i.e. for follow-up duration of at least 3 months). De Almeida reported a benefit from corticosteroids for people with Bell's palsy and the probability of additional benefit when corticosteroids were combined with antivirals. A systematic review and meta-analysis by Goudakos and colleagues compared corticosteroids with corticosteroids plus antivirals for the treatment of Bell's palsy. This review included only four trials and omitted other important studies, for example Engström 2008 , which is the largest trial conducted on this topic. Goudakos did not find an additional benefit from combining corticosteroids with antivirals. The meta-analyses by Numthavaj and colleagues and Quant and colleagues included six trials for analysis, with a great overlap (Quant 2009; Numthavaj 2011). In both papers the authors reported higher rates of recovery when corticosteroids were combined with antivirals compared to corticosteroids alone, but the difference was small. Also Dong and colleagues recommended the combination treatment of corticosteroids and antivirals, based on the results of a meta-analysis with eight trials (Dong 2015). Fu and colleagues conducted a network meta-analysis and included data of 4623 participants from 23 studies. The analysis comprised a large number of studies and included also data of a withdrawn trial Abdelghany 2013. The authors concluded that the effect of the combined treatment of antivirals and corticosteroids was significantly better than antiviral or corticosteroid therapy alone with regard to overall recovery in people with Bell's palsy (Fu 2018). However, none of the meta-analyses reported data from studies with a low risk of bias separately, as the current meta-analysis does.

\section{AUTHORS' CONCLUSIONS}

\section{Implications for practice}

Among participants with Bell's palsy of various degrees of severity, combination therapy with antivirals and corticosteroids may have little or no effect on rates of incomplete recovery in comparison to corticosteroids alone, and there may be no clear difference with the combination therapy compared to corticosteroids alone among people with severe Bell's palsy.

Corticosteroids alone were probably more effective than antivirals alone with regard to recovery rates, and antivirals plus corticosteroids were more effective than placebo or no treatment. There was no clear benefit from antivirals alone over placebo.

The combination of antivirals and corticosteroids probably reduce the late sequelae of Bell's palsy compared with corticosteroids alone. The studies also showed fewer episodes of long-term sequelae in corticosteroid-treated participants compared with antiviral-treated participants.

We found no clear difference in adverse events from the use of antivirals compared with either placebo or corticosteroids, but the evidence was too uncertain for us to draw conclusions.

\section{Implications for research}

When we excluded small trials at high risk of bias from our analyses, we did not find convincing evidence of an improvement in rates of incomplete recovery in people with severe Bell's palsy following combined treatment with antivirals and corticosteroids, compared to corticosteroids alone. Although this evidence came from less than one-third of the trials, they were those at low risk of bias, and the evidence, while still of low certainty, may be more reliable than the complete data set. A further large independent, well-conducted study might help replicate and confirm these findings. Additional work in this area could address the question of the best treatment for mild to moderate and severe Bell's palsy raised by the possible causes of heterogeneity in most of the comparisons in this review. Depending upon the results of this analysis, an adequately powered randomised controlled trial (RCT) in people with Bell's palsy comparing additional antiviral agents or immune modulators may be indicated.

More work is needed to assess the likelihood of long-term cosmetic sequelae, which should be reported in all future trials. There is no further need to conduct trials with a placebo group on this topic, as a clear benefit from corticosteroid therapy is evident. Moreover, in future studies, antivirals should be tested in combination with corticosteroids and not alone if an antiviral effect is expected. Future studies should be done to assess the impact of the variables, such as time from diagnosis until treatment, severity of palsy at baseline, and age of participants at presentation on outcomes. Work assessing a wider range of endpoints, such as quality of life and perceived disability, should be undertaken with the goal of developing a better understanding of Bell's palsy for the affected person.

\section{ACK N O WLEDGEMENTS}

Dr J Sipe, Mrs L Dunn, Dr D Allen, Dr P Lockhart, Ms N Comerford, and Ms M Pitkethly authored previous editions of this review; we are very grateful for their hard work and enthusiasm. We also extend our thanks to Ruth Brassington for her valuable assistance with the writing process; to Angela Gunn, who provided search results; and to the Cochrane Neuromuscular Group for their extensive technical assistance and support. We thank C Schuchardt for his support in the Description of the studies section and Lena Nanavati from the Surrey Health CCG for providing information on drug costs.

This project was supported by the National Institute for Health Research (NIHR) via Cochrane Infrastructure funding to Cochrane Neuromuscular. The views and opinions expressed therein are those of the review authors and do not necessarily reflect those of the Systematic Reviews Programme, NIHR, National Health Service (NHS), or the Department of Health. Cochrane Neuromuscular is also supported by the Queen Square Centre for Neuromuscular Diseases.

The Cochrane Neuromuscular Managing Editor populated the Characteristics of ongoing studies tables. 


\section{R E F E R E N C E S}

\section{References to studies included in this review}

\section{Adour 1996 \{published data only\}}

Adour KK, Ruboyianes JM, Von Doersten PG, Byl FM, Trent CS, Quesenberry CP Jr, et al. Bell's palsy treatment with acyclovir and prednisone compared with prednisone alone: a doubleblind, randomized, controlled trial. Annals of Otology, Rhinology and Laryngology 1996;105(5):371-8. [PUBMED: 8651631]

\section{De Diego 1998 \{published data only\}}

De Diego JI, Prim MP, De Sarria MJ, Madero R, Gavilan J. Idiopathic facial paralysis: a randomized, prospective, and controlled study using single-dose prednisone versus acyclovir three times daily. Laryngoscope 1998;108(4 Pt 1):573-5. [PUBMED: 9546272]

\section{Engström 2008 \{published data only\}}

Engström M, Berg T, Stjernquist-Desatnik A, Axelsson S, Pitkäranta A, Hultkrantz M, et al. Prednisolone and valaciclovir in Bell's palsy: a randomised, double blind, placebo controlled, multicentre trial. Lancet Neurology 2008;7(11):993-1000. [DOI: 10.1016/51474-4422(08)70221-7; PUBMED: 18849193]

\section{Hato 2007 \{published data only\}}

Hato N, Yamada H, Kohno H, Matsumoto S, Honda N, Gyo K, et al. Valacyclovir and prednisolone treatment for Bell's palsy: a multicenter, randomized, placebo-controlled study. Otology and Neurotology 2007;28(3):408-13. [PUBMED: 17414047]

\section{Kawaguchi 2007 \{published data only\}}

Kawaguchi K, Inamura H, Abe Y, Koshu H, Takashita E, Muraki Y, et al. Reactivation of herpes simplex virus type 1 and varicellazoster virus and therapeutic effects of combination therapy with prednisolone and valacyclovir in patients with Bell's palsy. Laryngoscope 2007;117(1):147-56. [PUBMED: 17202945]

\section{Khajeh 2015 \{published data only\}}

Khajeh A, Fayyazi A, Soleimani G, Miri-Aliabad G, Shaykh Veisi S, Khajeh B. Comparison of the efficacy of combination therapy of prednisolone - acyclovir with prednisolone alone in Bell's palsy. Iranian Journal of Child Neurology 2015;9(2):17-20. [PUBMED: 26221158]

\section{Khedr 2016 \{published data only\}}

Khedr EM, Badry R, Ali AM, Abo El-Fetoh N, El-Hammady DH, Ghandour AM, et al. Steroid/antiviral treatment of Bell's palsy: double blind randomized clinical trial. Restorative Neurology and Neuroscience 2016;34(6):897-905. [PUBMED: 27689547]

\section{Lee 2013 \{published data only\}}

Lee HY, Byun JY, Park MS, Yeo SG. Steroid-antiviral treatment improves the recovery rate in patients with severe Bell's palsy. American Journal of Medicine 2013;126(4):336-41. [PUBMED: 23394867]

\section{Li 1997 \{published data only\}}

Li Y, Gao P, Mao X, Cao P. Randomized clinical trial of acyclovir plus prednisone versus prednisone alone in Bell's palsy. Ceylon Journal of Medical Science 1997;40(2):37-41.
Minnerop 2008 \{published and unpublished data\}

Minnerop M, Herbst M, Fimmers R, Kaabar P, Matz B, Klockgether T, et al. Bell's palsy: combined treatment of famciclovir and prednisone is superior to prednisone alone. Journal of Neurology 2008;255(11):1726-30. [PUBMED: 18769863]

\section{Shahidullah 2011 \{published data only\}}

Shahidullah M, Haque A, Islam MR, Rizvi AN, Sultana N, Mia BA, et al. Comparative study between combination of famciclovir and prednisolone with prednisolone alone in acute Bell's palsy. Mymensingh Medical Journal: MMJ 2011;20(4):605-13. [CRS: 8300125000010514; EMBASE: 22081178; CN-00857180; PUBMED: 22081178]

\section{Sullivan 2007 \{published and unpublished data\}}

Sullivan FM, Swan IR, Donnan PT, Morrison JM, Smith BH, McKinstry $B$, et al. Early treatment with prednisolone or acyclovir in Bell's palsy. New England Journal of Medicine 2007;357(16):1598-607. [PUBMED: 17942873]

\section{Vázquez 2008 \{published data only\}}

Vázquez MC, Sánchez N, Calvo J, Perna A. Efficacy of antiviral in Bell's palsy [Eficacia de los antivirales en la parálisis de Bell]. Revista Medica del Uruguay 2008;24(3):167-74. [LILACS 501670]

\section{Yeo 2008 \{published data only\}}

Yeo SG, Lee YC, Park DC, Cha Cl. Acyclovir plus steroid versus steroid alone in the treatment of Bell's palsy. American Journal of Otolaryngologyy 2008;29(3):163-6. [PUBMED: 18439948]

\section{References to studies excluded from this review}

\section{Abdelghany 2013 \{published data only\}}

Abdelghany AM, Kamel SB. Retracted: the effect of prednisolone and/or acyclovir in relation to severity of Bell's palsy at presentation. Egyptian Journal of Ear, Nose, Throat and Allied Sciences 2013;14(3):155-9. [DOI: https://doi.org/10.1016/ j.ejenta.2013.04.003]

* Abdelghany AM, Kamel SB. Retraction notice to "The effect of prednisolone and/or acyclovir in relation to severity of Bell's palsy at presentation" [Egypt. J. Ear NoseThroat Allied Sci 14(3) (2013) 155-9]. Egyptian Journal of Ear, Nose and Throat 2017;18(3):329. [DOI: org/10.1016/j.ejenta.2013.04.003]

\section{Ahangar 2006 \{published data only\}}

Ahangar AA, Hosseini S, Saghebi R. Comparison of the efficacy of prednisolone versus prednisolone and acyclovir in the treatment of Bell's palsy. Neurosciences (Riyadh, Saudi Arabia) 2006;11(4):256-9. [PUBMED: 22266433]

\section{Antunes 2000 \{published data only (unpublished sought but not} used)\}

Antunes ML, Fukuda Y, Testa JRG. Clinical treatment of Bell's palsy: comparative study among valaciclovir plus deflazacort, deflazacort and placebo [Tratamento clinico da paralisia de Bell: estudo comparativo com o uso de valaciclovir mais 
deflazacort versus deflazacort versus placebo]. Acta Associação William House de Otologia 2000;19(2):68-75.

\section{Axelsson 2003 \{published data only\}}

Axelsson S, Lindberg S, Stjernquist-Desatnik A. Outcome of treatment with valacyclovir and prednisone in patients with Bell's palsy. Annals of Otology, Rhinology and Laryngology 2003;112(3):197-201.

\section{Chen 2005 \{published data only\}}

Chen WL, Yang ZH, Huang ZQ. Outcome of treatment of 46 patients with Bell's palsy with aciclovir and prednisone. Shanghai Kou Qiang Yi Xue [Shanghai Journal of Stomatology] 2005;14(6):590-2.

\section{de Aquino 2001 \{published data only (unpublished sought but not used)\}}

de Aquino JE, Cruz Filho NA. Comparative study of three types of treatment of idiopathic facial palsy (Bell) [Estudo comparativo com tres tipos de tratamento clinico na paralisa facial idiopatica (Bell)]. Acta Associação William House de Otologia 2001;20(4):195-200. [lil-299927]

\section{Ferreira 2016 \{published data only\}}

Ferreira M, Firmino MJ, Marques EA, Santos PC, Duarte JA. Are corticosteroids useful in all degrees of severity and rapid recovery of Bell's palsy?. Acta Oto-Laryngologica 2016;136(7):736-41. [PUBMED: 27003272]

\section{Hato 2003 \{published data only\}}

Hato N, Matsumoto S, Kisaki H, Takahashi H, Wakisaka H, Honda N, et al. Efficacy of early treatment of Bell's palsy with oral acyclovir and prednisolone. Otology \& Neurotology 2003;24(6):948-51. [PUBMED: 14600480 ]

\section{Hultcrantz 2005 \{published data only\}}

Hultcrantz M. Treatment of facial paresis - evidencebased recommendations [Behandling avfacialispares evidensbaserade rekommendationer]. Lakartidningen 2005;102(10):744-75. [PUBMED: 15839165]

\section{Ibarrondo 1999 \{published data only\}}

Ibarrondo J, Navarrete ML, Encarnación LF, Quesada P, Crespo F, García M, et al. Treatment of idiopathic facial paralysis: corticoids versus acyclovir versus empirical treatment [Tratamiento de la paralisis facial idiopatica: corticoides versus aciclovir versus empirico]. Acta Otorrinolaringologica Espanola 1999;50(2):118-20. [PUBMED: 10217684]

Inanli 2001 \{published data only\}

Inanli S, Tutkun A, Ozturk O, Batman C, Uneri C, Sehitoglu MA. Idiopathic facial nerve paralysis treatment with acyclovir and prednisolone compared with prednisolone alone [Idiopatik fasiyal sinir paralizisinde prednizolon ve asiklovir Kkmbine tedavisinin prednizolon tedavisi ile karsilastirlmasi]. Turkish Archives of Otolaryngology 2001;39(1):19-24.

\section{Kang 2015 \{published data only\}}

Kang HM, Jung SY, Byun JY, Park MS, Yeo SG. Steroid plus antiviral treatment for Bell's palsy. Journal of Internal Medicine 2015;277(5):532-9. [PUBMED: 25041467]
Ramos Macias 1992 \{published data only\}

Ramos Macías A, De Miguel Martínez I, Martín Sánchez AM, Gómez González JL, Martín Galán A. Incorporation of acyclovir in the treatment of peripheral paralysis. A study of 45 cases [Incorporación del aciclovir en el tratamiento de la parálisis periférica. Un estudio en 45 casos]. Acta Otorrinolaringológica Espanola 1992;43(2):117-20. [PUBMED: 1605959]

Roy 2005 \{published data only\}

Roy A, Jose J, Kamath V, Matthew T. Efficacy of aciclovir and methylprednisolone versus methylprednisolone alone in the treatment of Bell's palsy. Journal of the Neurological Sciences 2005;238(Suppl 1):S207-8.

Zhou 1999 \{published data only\}

Zhou P. Aciclovir in treating Bell's palsy. Chinese Journal of New Drugs and Clinical Remedies 1999;18(1):13-4.

\section{References to studies awaiting assessment}

IRCT201109187575N1 \{published and unpublished data\}

\section{References to ongoing studies \\ ACTRN12615000563561 \{published data only\}}

ACTRN12615000563561. Bell's Palsy in Children (BellPIC): protocol for a multicentre, placebo-controlled randomized trial. www.anzctr.org.au/Trial/Registration/TrialReview.aspx? id=368505 (first received 7 May 2015).

\section{NCT03781700 \{published data only\}}

NCT03781700. Evaluation of cortisone treatment in children with acute facial nerve palsy (FACE). clinicaltrials.gov/ct2/show/ NCT03781700 (date received 20 December 2018).

\section{Additional references}

\section{Abiko 2002}

Abiko Y, Ikeda M, Hondo R. Secretion and dynamics of herpes simplex virus in tears and saliva of patients with Bell's Palsy. Otology \& Neurotology 2002;23(5):779-83. [PUBMED: 12218634]

\section{Adour 1971}

Adour KK, Swanson PJ Jr. Facial paralysis in 403 consecutive patients: emphasis on treatment response in patients with Bell's palsy. Transactions - American Academy of Ophthalmology and Otolaryngology 1971;75(6):1284-301.

\section{Adour 1974}

Adour KK, Wingerd J. Idiopathic facial paralysis (Bell's palsy): factors affecting severity and outcome in 446 patients. Neurology 1974;24(12):1112-6.

\section{Adour 1982}

Adour KK. Current concepts in neurology: diagnosis and management of facial paralysis. New England Journal of Medicine 1982;307(6):348-51. [PUBMED: 7088100] 


\section{Axelsson 2012}

Axelsson S, Berg T, Jonsson L, Engström M, Kanerva M, Stjernquist-Desatnik A. Bell's palsy - the effect of prednisolone and/or valaciclovir versus placebo in relation to baseline severity in a randomised controlled trial. Clinical Otolaryngology 2012;37(4):283-90. [PUBMED: 22776019]

\section{Bateman 1992}

Bateman DE. Facial palsy. British Journal of Hospital Medicine 1992;47(6):430-1. [PUBMED: 1568084]

\section{Berg 2012}

Berg T, Bylund N, Marsk E, Jonsson L, Kanerva M, Hultcrantz M, et al. The effect of prednisolone on sequelae in Bell's palsy. Archives of Otolaryngology - Head \& Neck Surgery 2012;138(5):445-9. [PUBMED: 22652942]

\section{Brandenberg 1993}

Brandenberg NA, Annegers JF. Incidence and risk factors for Bell's Palsy in Laredo, Texas: 1974-1982. Neuroepidemiology 1993;12(6):313-25. [PUBMED: 8309506]

\section{Burgess 1984}

Burgess LP, Yim DW, Lepore ML. Bell's palsy: the steroid controversy revisited. Laryngoscope 1984;94(11 Pt 1):1472-6. [PUBMED: 6387352 ]

\section{de Almeida 2009}

de Almeida JR, Al Khabori M, Guyatt GH, Witterick IJ, Lin VY, Nedzelski JM, et al. Combined corticosteroid and antiviral treatment for Bell palsy: a systematic review and meta-analysis. JAMA 2009;302(9):985-93. [PUBMED: 19724046]

\section{Dong 2015}

Dong Y, Zhu Y, Ma C, Zhao H. Steroid-antivirals treatment versus steroids alone for the treatment of Bell's palsy: a meta-analysis. International Journal of Clinical and Experimental Medicine 2015;8(1):413-21. [PUBMED: 25785012]

\section{Egger 1997}

Egger M, Davey Smith G, Schneider M, Minder C. Bias in meta-analysis detected by a simple, graphical test. BMJ 1997;315(7109):629-34. [PUBMED: 9310563]

\section{Egger 2007}

Egger M, Davey Smith G, Altman DG. Systematic Reviews in Health Care: Meta-Analysis in Context. 6th Edition. London: BMJ Books, 2007. [ISBN: 978-0-7279-1488-0]

\section{Fu 2018}

Fu X, Tang L, Wang C, Li M, Wu H, Li J, et al. A network metaanalysis to compare the efficacy of steroid and antiviral medications for facial paralysis from Bell's palsy. Pain Physician 2018;21(6):559-69. [PUBMED: 30508985]

\section{Goudakos 2009}

Goudakos JK, Markou KD. Corticosteroids versus corticosteroids plus antiviral agents in the treatment of Bell Palsy: a systematic review and meta-analysis. Archives of Otolaryngology - Head \& Neck Surgery 2009;135(6):558-64. [PUBMED: 19528403]

\section{GRADEpro GDT 2015 [Computer program]}

McMaster University (developed by Evidence Prime). GRADEpro GDT. Version (accessed prior to 30 July 2018). Hamilton (ON): McMaster University (developed by Evidence Prime), 2015.

\section{Harris 2001}

Harris DL, Carr AT. The Derriford Appearance Scale (DAS59): a new psychometric scale for the evaluation of patients with disfigurements and aesthetic problems of appearance. British Journal of Plastic Surgery 2001;54(3):216-22. [PUBMED: 11254413]

\section{Hernández 2008}

Hernández RA, Sullivan F, Donnan P, Swan I, Vale L, BELLS Trial Group. Economic evaluation of early administration of prednisolone and/or aciclovir for the treatment of Bell's palsy. Family Practice 2009;26(2):137-44. [PUBMED: 19244470]

\section{Higgins 2011}

Higgins JP, Green S, editor(s). Cochrane Handbook for Systematic Reviews of Interventions Version 5.1.0 (updated March 2011). The Cochrane Collaboration, 2011. Available from handbook.cochrane.org.

\section{Higgins 2019}

Higgins JP, Savović J, Page MJ, Sterne JA, on behalf of the ROB2 Development Group. Revised Cochrane risk of bias tool for randomized trials (RoB 2). Available from sites.google.com/site/ riskofbiastool/welcome/rob-2-0-tool/current-version-of-rob-2 9 July 2019.

\section{House 1983}

House JW. Facial nerve grading systems. Laryngoscope 1983;93:1056-69.

\section{House 1985}

House JW, Brackmann DE. Facial nerve grading system. Otolarnygology - Head \& Neck Surgery 1985;93(2):146-7. [PUBMED: 3921901]

\section{Katusic 1986}

Katusic SK, Beard CM, Wiederholt WC, Bergstralh EJ, Kurland LT. Incidence, clinical features and prognosis in Bell's Palsy, Rochester, Minnesota, 1968-1982. Annals of Neurology 1986;20(5):622-7. [PUBMED: 3789675]

\section{Lackner 2010}

Lackner A, Kessler HH, Walch C, Quasthoff S, Raggam RB. Early and reliable detection of herpes simplex virus type 1 and varicella zoster virus DNAs in oral fluid of patients with idiopathic peripheral facial nerve palsy: Decision support regarding antiviral treatment?. Journal of Medical Virology 2010;82(9):1582-5. [PUBMED: 20648613]

\section{Lorber 1996}

Lorber B. Are all diseases infectious?. Annals of Internal Medicine 1996;125(10):844-51. [PUBMED: 8928993]

\section{Madhok 2016}

Madhok VB, Gagyor I, Daly F, Somasundara D, Sullivan M, Gammie F, et al. Corticosteroids for Bell's palsy (idiopathic facial 
paralysis). Cochrane Database of Systematic Reviews 2016, Issue 7. [DOI: 10.1002/14651858.CD001942.pub5]

\section{Martyn 1997}

Martyn CN, Hughes RA. Epidemiology of peripheral neuropathy. Journal of Neurology, Neurosurgery \& Psychiatry 1997;62(4):310-8. [PUBMED: 9120441]

\section{May 1976}

May M, Wette R, Hardin WB Jr, Sullivan J. The use of steroids in Bell's palsy: a prospective controlled study. Laryngoscope 1976;86(8):1111-22. [PUBMED: 781439]

\section{Morales 2013}

Morales DR, Donnan PT, Daly F, Staa TV, Sullivan FM. Impact of clinical trial findings on Bell's palsy management in general practice in the UK 2001-2012: interrupted time series regression analysis. BMJ Open 2013;3(7):e003121. [PUBMED: 23864211]

\section{Murakami 1996}

Murakami S, Mizobuchi M, Nakashiro Y, Doi T, Hato N, Yanagihara N. Bell palsy and herpes simplex virus: identification of viral DNA in endoneurial fluid and muscle. Annals of Internal Medicine 1996;124(1 Pt 1):27-30. [PUBMED: 7503474]

\section{NHS Surrey Downs 2018}

National Health Service. The Surrey Downs Clinical Commisioning Group. www.surreydownsccg.nhs.uk 2018.

\section{Niparko 1993}

Niparko JK, Mattox DE. Bell's palsy and herpes zoster oticus. In: Johnson RT, Griffin JW editor(s). Current Therapy in Neurologic Disease. 4th Edition. St Louis, Missouri: BC Decker, 1993:355-61. [ISBN: 0801677300]

\section{Numthavaj 2011}

Numthavaj P, Thakkinstian A, Dejthevaporn C, Attia J. Corticosteroid and antiviral therapy for Bell's palsy: a network meta-analysis. BMC Neurology 2011;11(1):1-10. [DOI: 10.1186/1471-2377-11-1; PUBMED: 21208452]

\section{Peitersen 1982}

Peitersen E. The natural history of Bell's Palsy. American Journal of Otology 1982;4(2):107-11. [PUBMED: 7148998 ]

\section{Peitersen 2002}

Peitersen E. Bell's palsy: the spontaneous course of 2,500 peripheral facial nerve palsies of different etiologies. Acta OtoLaryngologica 2002;122(Suppl 549):4-30. [PUBMED: 12482166 ]

\section{Prescott 1988}

Prescott CA. Idiopathic facial nerve palsy (the effect of treatment with steroids). Journal of Laryngology and Otology 1988;102(5):403-7. [PUBMED: 3397632 ]

\section{Quant 2009}

Quant EC, Jeste SS, Muni RH, Cape AV, Bhussar MK, Peleg AY. The benefits of steroids versus steroids plus antivirals for treatment of Bell's palsy: a meta-analysis. BMJ 2009;339:b3354. [PUBMED: 19736282]

\section{RevMan 2014 [Computer program]}

Nordic Cochrane Centre, The Cochrane Collaboration. Review Manager 5 (RevMan 5). Version 5.3. Copenhagen: Nordic Cochrane Centre, The Cochrane Collaboration, 2014.

\section{Ross 1996}

Ross BG, Fradet G, Nedzelski JM. Development of a sensitive clinical facial grading system. Otolargynology - Head and Neck Surgery 1996;114(3):380-6. [PUBMED: 8649870]

\section{Victor 1994}

Victor M, Martin J. Disorders of the cranial nerves. In: Isselbacher KJ editor(s). Harrison's Principles of Internal Medicine. 13th Edition. New York: McGraw-Hill, 1994:2347-52. [ISBN: 0070323704]

\section{Wolf 1978}

Wolf SM, Wagner JH, Davidson S, Forsythe A. Treatment of Bell's palsy with prednisone: a prospective randomized study. Neurology 1978;28(2):158-61. [PUBMED: 340980]

\section{Yanagihara 1977}

Yanagihara N. Grading of facial palsy. Third international symposium on facial nerve surgery; 1976 Aug 9-12; Zurich. Birmingham (AL): Aesculapius, 1977:533-5.

\section{Yanagihara 1988}

Yanagihara N, Yumoto E, Shibahara T. Familial Bell's palsy: analysis of 25 families. Annals of Otology, Rhinology and Laryngology Supplement 1988;137:8-10. [PUBMED: 3144233]

\section{Yanagihara 2003}

Yanagihara N, Hato N. Assessment of facial nerve function following acoustic neuroma surgery: facial nerve grading system. In: Kanzaki J, Tos M, Sanna M, Moffat DA, Kunihiro T, Inoue Y editor(s). Acoustic Neuroma. Consensus on Systems for Reporting Results. 1st Edition. Vol. 10, Tokyo: Springer Japan, 2003:91-8. [DOI: 10.1007/978-4-431-53942-116]

\section{References to other published versions of this review}

\section{Allen 2004}

Allen D, Dunn L. Aciclovir or valaciclovir for Bell's palsy (idiopathic facial paralysis). Cochrane Database of Systematic Reviews 2004, Issue 3. [DOI: 10.1002/14651858.CD001869.pub2; PUBMED: 15266457 ]

\section{Gagyor 2015a}

Gagyor I, Madhok VB, Daly F, Somasundara D, Sullivan M, Gammie F, et al. Antiviral treatment for Bell's palsy (idiopathic facial paralysis). Cochrane Database of Systematic Reviews 2015, Issue 5. [DOI: 10.1002/14651858.CD001869.pub5; PUBMED: 25938618 ]

\section{Gagyor 2015b}

Gagyor I, Madhok VB, Daly F, Somasundara D, Sullivan M, Gammie F, et al. Antiviral treatment for Bell's palsy (idiopathic facial paralysis). Cochrane Database of Systematic Reviews 2015, Issue 7. [DOI: 10.1002/14651858.CD001869.pub6; PUBMED: 26130372] 


\section{Gagyor 2015c}

Gagyor I, Madhok VB, Daly F, Somasundara D, Sullivan M, Gammie F, et al. Antiviral treatment for Bell's palsy (idiopathic facial paralysis). Cochrane Database of Systematic Reviews 2015, Issue 11. [DOI: 10.1002/14651858.CD001869.pub8; PUBMED: 26559436 ]

\section{Lockhart 2009}

Lockhart P, Daly F, Pitkethly M, Comerford N, Sullivan F. Antiviral treatment for Bell's palsy (idiopathic facial paralysis). Cochrane Database of Systematic Reviews 2009, Issue 4. [DOI: 10.1002/14651858.CD001869.pub4; PUBMED: 19821283]

\section{Sipe 2001a}

Sipe J, Dunn L. Aciclovir for Bell's palsy (idiopathic facial paralysis). Cochrane Database of Systematic Reviews 2001, Issue 2. [DOI: 10.1002/14651858.CD001869; PUBMED: 11406014]

\section{Sipe 2001b}

Sipe J, Dunn L. Aciclovir for Bell's palsy (idiopathic facial paralysis). Cochrane Database of Systematic Reviews 2001, Issue 4. [DOI: 10.1002/14651858.CD001869.pub2; PUBMED: 11687127]

* Indicates the major publication for the study

\section{CHARACTERISTICS OF STUDIES}

\section{Characteristics of included studies [ordered by year of study]}

Adour 1996

Methods Randomised, placebo-controlled double-blind trial, two parallel groups

Participants

The trial was conducted in primary care clinics and emergency departments in North America in 119 participants with confirmed facial paralysis. Data of 99 participants were published. Age range: > 18 years

The mean age was 41.9 (SD 14.1) years in the aciclovir plus prednisolone group ( $N=53$ ) and 44.6 (SD 15.1 ) years in the prednisolone plus placebo group $(N=46)$. In the combination treatment group $45 \%$ were women, whereas the prednisolone group had $57 \%$ women.

\section{Inclusion criteria}

- Paralysis commenced $\leq 3$ days before treatment

- All participants over 18 years of age

- Good physical health determined by history and physical exam

- No contraindication for corticosteroid or aciclovir treatment

- All women of childbearing age had a negative pregnancy test result

lack of clear definition of diagnostic criteria (possibly affects generalisability/validity)

\section{Exclusion criteria}

- Any other medication for idiopathic facial paralysis

- Urea nitrogen or creatinine $>2 x$ upper limit of normal

- Liver transaminase $>3 x$ upper limit of normal

- Haemoglobin level $<100 \mathrm{~g} / \mathrm{L}$

- Platelet count $<75,000 / \mathrm{mm}^{3}$ or neutrophil count $<1 \times 10$ to the $6 / \mathrm{L}$

Loss to follow-up: 20 patients (group allocation unknown)

Interventions Aciclovir (2000 mg per day for 10 days) and prednisone $(1 \mathrm{mg} / \mathrm{kg}$ for 5 days tapered to $10 \mathrm{mg} /$ day for remaining 5 days) or placebo and prednisone $(1 \mathrm{mg} / \mathrm{kg}$ for 5 days tapered to $10 \mathrm{mg} /$ day for remaining 5 days)

Outcomes

\section{Primary outcome}

- Recovery on facial paralysis recovery index, where incomplete recovery is a Facial Paralysis Recovery Profile $\leq 7$ (Adour 1974), at 4 months

Maximal stimulation test with or without electroneurography at follow-up at 2 weeks, 2, 3, and 4 months (if incomplete recovery) after paralysis onset 
Adour 1996 (Continued)

Final outcomes reported at 3 months or when recovered or palsy stabilised (not more clearly defined)

\section{Seconday outcomes}

- Motor synkinesis

- Adverse events

Funding Grants from Burroughs Welcome Company and the Community Service Program of Kaiser Foundation
Hospitals Inc. Elmore C. Wallace contributed additional funding

\begin{tabular}{ll}
\hline Conflicts of interest & Information not given \\
\hline Date conducted & Information not given, presumably 1995 \\
\hline Notes & Single-centre \\
& $\begin{array}{l}\text { The authors stated a dropout rate of } 16.8 \% . \text { The reason for dropout was documented for each partici- } \\
\text { pant, such as inability to keep appointments, low adherence to the treatment regimen, adverse events, } \\
\text { and moving from the area. }\end{array}$
\end{tabular}

\section{Risk of bias}

\begin{tabular}{lll}
\hline Bias & Authors' judgement & Support for judgement \\
\hline $\begin{array}{l}\text { Random sequence genera- } \\
\text { tion (selection bias) }\end{array}$ & Low risk & $\begin{array}{l}\text { Quote: "the bottles [of aciclovir and placebo], provided by Burroughs Well- } \\
\text { come, were randomised in groups of 10" }\end{array}$ \\
\hline $\begin{array}{l}\text { Allocation concealment } \\
\text { (selection bias) }\end{array}$ & Low risk & $\begin{array}{l}\text { Quote: "Each bottle...had a sealed identification label which was removed in- } \\
\text { tact and kept with the patient's record" }\end{array}$ \\
\hline Blinding of participants? & Low risk & $\begin{array}{l}\text { Quote: "eligible patients were given identical, unlabeled bottles of 100 cap- } \\
\text { sules that contained either placebo or aciclovir (Zovirax), 200 mg" }\end{array}$ \\
& Comment: participants in each group received identical follow-up
\end{tabular}

Blinding of assessors? Low risk The study was reported as double-blind; the method reported was consistent
with being able to achieve this

\begin{tabular}{lll}
$\begin{array}{l}\text { Incomplete outcome da- } \\
\text { ta? }\end{array}$ & High risk & $\begin{array}{l}\text { The numbers of participants unable to complete the study was given. High } \\
\text { dropout rate reported: } 16.8 \% \text {. Not an intention-to-treat analysis }\end{array}$ \\
$\begin{array}{l}\text { Selective outcome report- } \\
\text { ing? }\end{array}$ & High risk & $\begin{array}{l}\text { Primary outcomes of facial paralysis recovery profile and bilateral facial nerve } \\
\text { electrical testing reported, but no data given on audiometry with stapedial re- } \\
\text { flex testing; adverse events were not specified }\end{array}$ \\
\hline
\end{tabular}

Other sources of bias? Low risk No other risks of bias reported

Li 1997

\begin{tabular}{ll}
\hline Methods & Randomised, placebo-controlled, double-blind trial, two parallel groups \\
\hline Participants & This trial in the Second Teaching Hospital of the Ya'an Medical College, Shaanxi, China included 51 par- \\
ticipants, 5 of whom were lost to follow-up. Participants with other causes of facial palsy were exclud- \\
ed. The age range was 15 to 73 years. The mean age was 39.2 in the aciclovir plus prednisolone group \\
and 40.3 in the prednisolone group.
\end{tabular}

\section{Inclusion criteria}


Li 1997 (Continued)

- Acute Bell's palsy, 4 days before enrolment to study

- No association with acute or chronic middle ear disease, cranial or otologic trauma, known central or peripheral neurological disease, autoimmune disease and herpes zoster oticus

\section{Exclusion criteria}

- Contraindication to corticosteroid therapy

- Peptic ulcer disease

- Active tuberculosis

- Pregnancy

- Hypertension

- Diabetes mellitus

$\begin{array}{ll}\text { Interventions } & \text { Randomised to receive either aciclovir and prednisone or placebo and prednisone. Prednisone was ad- } \\ \text { ministered to both groups in a dose of } 60 \mathrm{mg} \text { for } 5 \text { days then tapered in steps of } 10 \mathrm{mg} \text { for a further } 5 \\ \text { days. In the intervention group } 800 \mathrm{mg} \text { aciclovir was given } 5 \text { times daily for } 7 \text { days. All participants re- } \\ \text { ceived artificial tears and ophthalmic ointments }\end{array}$

\section{Outcomes Primary outcome}

- Recovery of facial motor function up to 6 months

House-Brackmann scale was used for assessment; recovery was taken as Grade 1 to 2

Follow-up weekly for the first month, then monthly until recovery

Final outcomes reported at 6 months, adverse events were not reported

\begin{tabular}{ll}
\hline Funding & No information given \\
\hline Conflicts of interest & No information given \\
\hline Date conducted & January 1995 to June 1996 \\
\hline Notes & Single-centre
\end{tabular}

\section{Risk of bias}

\begin{tabular}{|c|c|c|}
\hline Bias & Authors' judgement & Support for judgement \\
\hline $\begin{array}{l}\text { Random sequence genera- } \\
\text { tion (selection bias) }\end{array}$ & Unclear risk & $\begin{array}{l}\text { Simple randomisation by coding of treatment drugs; little information provid- } \\
\text { ed }\end{array}$ \\
\hline $\begin{array}{l}\text { Allocation concealment } \\
\text { (selection bias) }\end{array}$ & Unclear risk & Allocation concealment not clearly described \\
\hline Blinding of participants? & Low risk & $\begin{array}{l}\text { Blinding procedure described as coded tablets containing either aciclovir or } \\
\text { placebo }\end{array}$ \\
\hline Blinding of assessors? & Unclear risk & Blinding procedure not clearly described \\
\hline $\begin{array}{l}\text { Incomplete outcome da- } \\
\text { ta? }\end{array}$ & Unclear risk & $\begin{array}{l}\text { Per protocol analysis, } 5 \text { participants were lost to follow-up. Unclear whether } \\
\text { intention-to-treat analysis was used }\end{array}$ \\
\hline $\begin{array}{l}\text { Selective outcome report- } \\
\text { ing? }\end{array}$ & Unclear risk & Primary outcomes were reported, adverse events were not reported \\
\hline Other sources of bias? & Low risk & Not identified \\
\hline
\end{tabular}


De Diego 1998

\begin{tabular}{|c|c|}
\hline Methods & Randomised, controlled trial, two parallel groups \\
\hline Participants & $\begin{array}{l}\text { The trials was carried out in Spain at the Department c } \\
\text { tonomous University, Madrid, Spain. } 113 \text { participants } \\
\text { cluded in published analysis. The mean age was } 43 \text { yea } \\
\text { men ( } 55.4 \%) \text { and } 45 \text { were women ( } 44.6 \%) \text {. } \\
\text { Inclusion criteria } \\
\text { - Diagnosis of idiopathic facial nerve paralysis and ba } \\
\text { Exclusion criteria } \\
\text { - Acute or chronic middle ear disease } \\
\text { - Cranial or otologic trauma } \\
\text { - Known central or peripheral neurologic disorders } \\
\text { - Autoimmune diseases } \\
\text { - Tumors } \\
\text { - Herpes zoster oticus (Ramsay Hunt syndrome) }\end{array}$ \\
\hline
\end{tabular}

Patients must have no contraindications to corticosteroid or aciclovir therapy. These included peptic ulcer, tuberculosis, moderate or severe diabetes, moderate or severe hypertension, glaucoma, manifest cardiac disease, psychosis, renal or hepatic dysfunction, and pregnancy. To be considered as having mild hypertension, patients must not have had blood pressure levels higher than $140 / 90 \mathrm{~mm} \mathrm{Hg}$ with diet or medical therapy.
Aciclovir $(2400 \mathrm{mg} /$ day for 10 days) $(\mathrm{N}$ (analysed) $=54)$ or prednisone $(1 \mathrm{mg} / \mathrm{kg}$ for 10 days then tapered to zero over the next 6 days) ( $\mathrm{N}$ (analysed) $=47$ )

\section{Primary outcome}

- Complete recovery using the House-Brackmann scale $(\leq 2)$ and the Facial Paralysis Recovery Profile $(\geq 8)$

\section{Secondary outcomes}

- Sequelae and synkinesis reported separately

Final outcomes reported at 4 months

Follow-up at 1, 3, 6, 12 weeks after first visit. Participants with incomplete recovery at 12 weeks were followed up until recovery or stabilisation of paralysis

\begin{tabular}{ll}
\hline Funding & Information not given \\
\hline Conflicts of interest & Information not given \\
\hline Date conducted & Between May 1994 and August 1995 \\
\hline Notes & Single-centre \\
\hline
\end{tabular}

\section{Risk of bias}

\begin{tabular}{lll}
\hline Bias & Authors' judgement & Support for judgement \\
\hline $\begin{array}{l}\text { Random sequence genera- } \\
\text { tion (selection bias) }\end{array}$ & Unclear risk & $\begin{array}{l}\text { Quote: "patients were randomly assigned". Randomisation method not de- } \\
\text { scribed }\end{array}$ \\
\hline
\end{tabular}


De Diego 1998 (Continued)

\begin{tabular}{lll}
$\begin{array}{l}\text { Allocation concealment } \\
\text { (selection bias) }\end{array}$ & Unclear risk & No clear information on concealment \\
\hline Blinding of participants? & High risk & $\begin{array}{l}\text { Presence of blinding not clearly described, although groups received different } \\
\text { treatment regimens } \\
\text { No placebo }\end{array}$ \\
\hline Blinding of assessors? & High risk & Not done \\
\hline $\begin{array}{l}\text { Incomplete outcome da- } \\
\text { ta? }\end{array}$ & Unclear risk & $\begin{array}{l}\text { Number of dropouts was reported: } 10 \% \text { were lost to follow-up, not an inten- } \\
\text { tion-to-treat analysis }\end{array}$ \\
\hline $\begin{array}{l}\text { Selective outcome report- } \\
\text { ing? }\end{array}$ & Unclear risk & Adverse events were not reported \\
\hline Other sources of bias? & Low risk & No other potential risk of bias \\
\hline
\end{tabular}

Kawaguchi 2007

\begin{tabular}{|c|c|}
\hline Methods & $\begin{array}{l}\text { Randomised, controlled, open-label trial parallel-group design } \\
\text { Intention-to-treat analysis: yes }\end{array}$ \\
\hline Participants & $\begin{array}{l}\text { The trial was conducted in } 12 \text { university hospitals in Japan. } 150 \text { participants randomly assigned to } \\
\text { prednisolone group (66) or prednisolone and valaciclovir group (84). All participants received treat- } \\
\text { ment within } 7 \text { days of onset of Bell's palsy. }\end{array}$ \\
\hline & $\begin{array}{l}\text { Age range: > } 15 \text { years. The mean age in the valaciclovir plus prednisolone group was } 54.5 \text { (SD 17.3) and } \\
58 \% \text { of these participants were women. In the prednisolone group the mean age was } 47.0 \text { (SD 18.6) and } \\
62 \% \text { were women. }\end{array}$ \\
\hline
\end{tabular}

\section{Inclusion criteria}

- Patients with Bell's palsy treated within 7 days of onset, no other initial treatment

\section{Exclusion criteria}

- Ramsay-Hunt-Syndrom

- Contraindications for treatment with prednisolone or valaciclovir

- Severe diabetes mellitus

- Psychologic disease

- Pregnancy

- Peptic ulcer

- Connective tissue disease

- Renal dysfunction 2 days, then $10 \mathrm{mg}$ daily for 2 days plus valaciclovir $500 \mathrm{mg}$ twice daily for 5 days or prednisolone (the same regimen) alone

Outcomes

- Virological examination for anti-herpes simplex virus and anti-varicella zoster virus antibodies

- Detection of herpes simplex virus and herpes zoster virus reactivation

Facial movement and recovery measured using the Yanagihara rating scale (Yanagihara 1977), defined as a score of $\geq 36$ 
Kawaguchi 2007 (Continued)

Follow-up for 6 months at 1 and 2 weeks after treatment and then at 1, 2, 3, 4, 5, and 6 months after treatment

Frequency of incomplete recovery at end of the study and adverse events. Final outcomes reported at 6 months

\begin{tabular}{ll}
\hline Funding & $\begin{array}{l}\text { Partly funded by a Grant-in-Aid for Scientific Research, Ministry of Education, Science and Culture, } \\
\text { Japan }\end{array}$ \\
\hline Conflicts of interest & No information given \\
\hline Date conducted & October 2002 to January 2005 \\
\hline Notes & Multicentre: 12 university hospitals \\
\hline
\end{tabular}

\section{Risk of bias}

Bias Authors' judgement Support for judgement

Random sequence genera- Unclear risk tion (selection bias)
Quote: "The patients were randomly assigned to one of the treatment groups by simple randomisation."

Comment: the method of generating the random sequence is not described

\begin{tabular}{lll}
\hline $\begin{array}{l}\text { Allocation concealment } \\
\text { (selection bias) }\end{array}$ & High risk & $\begin{array}{l}\text { Not used; when participants were entered into the trial, the allocation enve- } \\
\text { lope contained the name of the treatment group }\end{array}$ \\
\hline Blinding of participants? & High risk & Not done \\
\hline Blinding of assessors? & High risk & Not done \\
\hline $\begin{array}{l}\text { Incomplete outcome da- } \\
\text { ta? }\end{array}$ & Low risk & $\begin{array}{l}\text { Numbers of participants who did not complete clearly documented: 10\% were } \\
\text { lost to follow-up }\end{array}$ \\
\hline $\begin{array}{l}\text { Selective outcome report- } \\
\text { ing? }\end{array}$ & High risk & $\begin{array}{l}\text { Frequency of incomplete recovery at end of the study and adverse events not } \\
\text { reported in the paper }\end{array}$ \\
\hline \begin{tabular}{l} 
Other sources of bias? \\
\hline
\end{tabular} & Low risk & No other potential sources of bias identified \\
\hline
\end{tabular}

Sullivan 2007

Methods Double-blind, placebo-controlled, randomised, 2 × 2 factorial trial

Participants

551 participants randomised; 496 included in final outcome assessment. Referred for assessment and treatment within 72 hours of paralysis onset. All participants aged 16 or older and no contraindications to corticosteroids or antivirals. The mean age was $44.0 \pm 16.4$.

Patients were recruited in primary and secondary care setting and treated in 17 hospitals in Scotland, UK. Patients were recruited through their family doctors, emergency departments, the national 24hour medical telephone consultancy service, and dentists' offices.

\section{Inclusion criteria}

- Unilateral facial nerve weakness of no identifiable cause who presented to primary care or the emergency department and could be referred to a collaborating otorhinolaryngologist within 72 hours after the onset of symptoms

\section{Exclusion criteria}


Sullivan 2007 (Continued)

- Pregnancy

- Breastfeeding

- Uncontrolled diabetes (glycated haemoglobin level, > 8\%)

- Peptic ulcer disease

- Suppurative otitis media

- Herpes zoster

- Multiple sclerosis

- Systemic infection

- Sarcoidosis and other rare conditions

- An inability to provide informed consent

Interventions

Participants allocated to 1 of 4 treatment groups: either aciclovir, prednisolone, both agents, or placebo. Participants received prednisolone $25 \mathrm{mg}$ twice daily for 10 days or aciclovir $400 \mathrm{mg} 5$ times daily for 10 days, both treatments, or neither treatment, depending upon allocation

Primary outcome
- Recovery, rated on House-Brackmann scale (House 1983; House 1985), wher
Secondary outcomes
- Health-related quality of life
- Health Utilities Index Mark 3
- Facial appearance (Derriford Appearance Scale; Harris 2001)
- Pain
- Adverse outcomes
Frequency of incomplete recovery at end of study was recorded.
Follow-up at 3 months and 9 months. Final outcomes reported at 9 months

Funding

Supported by a grant (02/09/04) from the Health Technology Assessment Programme of the National Institute for Health Research (Department of Health, England). The Scottish School of Primary Care was funded by the Scottish Executive (Chief Scientist Office and National Health Service Education for Scotland) during the study. Practices were reimbursed for their contributions through national Support for Science mechanisms

Conflicts of interest

Drs. Sullivan and Donnan report receiving grant support from GlaxoSmithKline for projects unrelated to this trial. No other potential conflict of interest relevant to this article was reported.

\begin{tabular}{ll}
\hline Date conducted & June 2004 to June 2006 \\
\hline Notes & Multicentre: 17 hospitals
\end{tabular}

\section{Risk of bias}

\begin{tabular}{lll}
\hline Bias & Authors' judgement & Support for judgement \\
\hline $\begin{array}{l}\text { Random sequence genera- } \\
\text { tion (selection bias) }\end{array}$ & Low risk & $\begin{array}{l}\text { Quote: "...patient was randomly assigned to a study group by an independent, } \\
\text { secure, automated telephone randomisation service." }\end{array}$ \\
\hline $\begin{array}{l}\text { Allocation concealment } \\
\text { (selection bias) }\end{array}$ & Low risk & All parties blinded to allocation \\
\hline Blinding of participants? & Low risk & $\begin{array}{l}\text { Participants not receiving active drug received placebo. All administered med- } \\
\text { ication identical and in identical containers }\end{array}$ \\
\hline
\end{tabular}


Sullivan 2007 (Continued)

\begin{tabular}{lll} 
Blinding of assessors? & Low risk & Assessors blinded to treatment group \\
\hline $\begin{array}{ll}\text { Incomplete outcome da- } & \text { Low risk }\end{array}$ & $\begin{array}{l}\text { All participants who were unable to complete were documented - both fre- } \\
\text { quency and reason. Intention-to-treat analysis performed }\end{array}$
\end{tabular}

Selective outcome report- Low risk All planned outcome measures reported
ing?

Other sources of bias? Low risk No other potential sources of bias identified

Hato 2007

\begin{tabular}{ll}
\hline Methods & Randomised, placebo-controlled, single-blind study, two parallel groups \\
\hline Participants & $\begin{array}{l}296 \text { participants were recruited in six university hospitals in Japan, } 221 \text { randomised: } 114 \text { to valaciclovir } \\
\text { and prednisolone, } 107 \text { to placebo and prednisolone. All participants commenced treatment within } 7 \\
\text { days of onset of palsy. }\end{array}$ \\
& $\begin{array}{l}\text { Age range: }>15 \text { years. The mean age was } 48.4 \text { (range 15-80) in the valaciclovir plus prednisolone group } \\
\text { and } 52.3(15-84) \text { in the prednisolone plus placebo group. Of the AS group } 48 \% \text { and of the OS group } 47 \% \\
\text { were women. }\end{array}$
\end{tabular}

\section{Inclusion criteria}

- Patients with Bell's palsy who were treated within 7 days of the onset

- No contraindications to antivirals or corticosteroids

\section{Exclusion criteria}

- Facial palsy attributable to central nervous system disorders, neoplasms, otitis media, trauma, Ramsay Hunt syndrome, or zoster sine herpete, which is a form of Ramsay Hunt syndrome without manifestation of herpetic vesicles at the auricle or ear canal

$\begin{array}{ll}\text { Interventions } & \text { Randomised to receive prednisolone } 60 \mathrm{mg} \text { for } 5 \text { days, } 30 \mathrm{mg} \text { for } 3 \text { days, and } 10 \mathrm{mg} \text { for } 2 \text { days } \pm \text { valaci- } \\ \text { clovir } 1000 \mathrm{mg} / \text { day for } 5 \text { days. Following corticosteroids, all participants received methylcobalamin } \\ 1500 \mu \mathrm{g} \text { per day for } 6 \text { months or until complete recovery }\end{array}$

Outcomes Primary outcome

- Full recovery based on a score of $\geq 36$ on the Yanagihara scale (Yanagihara 1977) (conversion scale to House-Brackmann scale included in paper; House 1983; House 1985)

Follow-up at 1, 3, and 6 months after commencing treatment. Final outcomes reported at 6 months

\begin{tabular}{ll}
\hline Funding & Granted by the Ministry of Education, Culture, Sports, Science and Technology of Japan \\
\hline Conflicts of interest & No information given \\
\hline Date conducted & February 2002 to March 2004 \\
\hline Notes & $\begin{array}{l}\text { Multicentre: } 6 \text { academic tertiary referral centres. } 23 \text { participants were excluded after randomisation be- } \\
\text { cause of herpes zoster; } 52 \text { were lost to follow-up (25.3\%). Frequency and reasons for dropout of partici- } \\
\text { pants who did not complete the study were documented }\end{array}$ \\
\hline
\end{tabular}

\section{Risk of bias}

Bias Authors' judgement Support for judgement


Hato 2007 (Continued)

\begin{tabular}{|c|c|c|}
\hline $\begin{array}{l}\text { Random sequence genera- } \\
\text { tion (selection bias) }\end{array}$ & Unclear risk & $\begin{array}{l}\text { Quote: "the patients were randomly divided into two groups using the enve- } \\
\text { lope method". Randomisation was carried out without stratification. No cen- } \\
\text { tral randomisation }\end{array}$ \\
\hline
\end{tabular}

\begin{tabular}{lll}
\hline $\begin{array}{l}\text { Allocation concealment } \\
\text { (selection bias) }\end{array}$ & Unclear risk & $\begin{array}{l}\text { Participants were assigned to one of the groups by moderators, but the alloca- } \\
\text { tion concealment was not clearly described }\end{array}$ \\
\hline Blinding of participants? & High risk & $\begin{array}{l}\text { Inadequate. Participants blinded to treatment, but different treatments with } \\
\text { different frequencies meant that true blinding was not achieved }\end{array}$ \\
\hline Blinding of assessors? & High risk & Not done. Assessors were not blinded to treatment \\
\hline $\begin{array}{l}\text { Incomplete outcome da- } \\
\text { ta? }\end{array}$ & High risk & $\begin{array}{l}\text { Frequency and reasons for dropouts documented. High dropout rate reported; } \\
25.3 \% \text {. Intention-to-treat analysis performed }\end{array}$ \\
\hline $\begin{array}{l}\text { Selective outcome report- } \\
\text { ing? }\end{array}$ & Low risk & Main outcome measures, adverse events all reported \\
\hline \begin{tabular}{l} 
Other sources of bias? \\
\hline
\end{tabular} & Unclear risk & Statistical tests employed not clearly stated \\
\hline
\end{tabular}

Engström 2008

\begin{tabular}{ll}
\hline Methods & Randomised, placebo-controlled double-blind trial with $2 \times 2$ factorial design \\
\hline Participants & This trial in 829 participants was carried out in 16 otorhinolaryngological centres in Sweden and one in \\
& Finland. Participants were randomised within 72 hours of facial palsy onset.
\end{tabular}

Age range: 18 to 75 years

The mean age was 42 in the prednisolone plus valaciclovir group and 38 in the prednisolone plus placebo group (range 31-54). In the AS group 39\% and in the OS group $42 \%$ were women.

\section{Inclusion criteria}

- Participants were randomised within 72 hours of facial palsy onset

- No contraindications to corticosteroid or antivirals

\section{Exclusion criteria}

- Systemic anti-herpetic medication within the past 2 weeks

- Ongoing systemic corticosteroid medication

- Allergy to aciclovir, valaciclovir, famciclovir, or ganciclovir

- Pregnancy

- Breastfeeding

- Being a woman of child-bearing age who was unwilling to use contraceptives during the medication period

- Other neurological diseases

- Diabetes

- Badly controlled hypertension

- Current or a history of serious heart disease

- History of renal or hepatic disease

- Gastric or duodenal ulcer

- History of glaucoma, acute otitis or history of ipsilateral chronic otitis

- History of tuberculosis

- History of immunodeficiency syndromes 
Engström 2008 (Continued)

- Recent head injury, psychiatric disease, or any other condition that was at risk of being influenced by the study medication or that might have affected completion of the study
Participants allocated into 1 of 4 treatment groups: valaciclovir with prednisolone, valaciclovir with placebo, placebo with prednisolone, or double placebo

Dosages: valaciclovir $1000 \mathrm{mg} 3$ times daily for 7 days; prednisolone $60 \mathrm{mg}$ daily for 5 days

\section{Outcomes}

\section{Primary outcome}

- Recovery of facial function, as assessed at all visits with the Sunnybrook scale (Ross 1996) and the House-Brackmann scale (House 1983; House 1985). Complete recovery was taken as Sunnybrook scale 100 and House-Brackmann scale Grade 1

\section{Other outcomes}

- Degree of pain, as recorded during the first 2 months

- Adverse events recorded for the first month

- Frequency of severe pain, synkinesis, facial spasm, and residual facial symptoms at 12 months

Follow-up at 2 weeks, 1, 2, 3, 6, and 12 months after randomisation, according to recovery. Final outcomes reported at 12 months

\begin{tabular}{ll}
\hline Funding & GlaxoSmithKline and Pfizer (Sweden) \\
\hline Conflicts of interest & Information not given \\
\hline Date conducted & May 2001 to September 2006 \\
\hline Notes & Multicentre \\
& Some secondary outcomes were reported in papers published separately (Axelsson 2012; Berg 2012)
\end{tabular}

\section{Risk of bias}

\begin{tabular}{lll}
\hline Bias & Authors' judgement & Support for judgement \\
\hline $\begin{array}{l}\text { Random sequence genera- } \\
\text { tion (selection bias) }\end{array}$ & Low risk & $\begin{array}{l}\text { Quote: "...randomization code was developed by Glaxo Wellcome GmBH, with } \\
\text { a computer number generator to select random permuted blocks of eight" }\end{array}$ \\
\hline $\begin{array}{l}\text { Allocation concealment } \\
\text { (selection bias) }\end{array}$ & Low risk & $\begin{array}{l}\text { Randomisation code double-blind and held by a third party. Medication dis- } \\
\text { pensed in identical containers to conceal allocation }\end{array}$ \\
\hline Blinding of participants? & Low risk & $\begin{array}{l}\text { Study drugs issued in identical containers. All participants blinded to treat- } \\
\text { ment group until study completion }\end{array}$ \\
\hline $\begin{array}{l}\text { Blinding of assessors? } \\
\text { Incomplete outcome da- }\end{array}$ & Low risk & $\begin{array}{l}\text { All study personnel and data analysts blinded to treatment group until study } \\
\text { completion }\end{array}$ \\
\hline $\begin{array}{l}\text { Selective outcome report- } \\
\text { ing? }\end{array}$ & Low risk & $\begin{array}{l}\text { Numbers lost to follow-up and reasons given. Modified intention-to-treat } \\
\text { analysis (829 of the 839 participants included) }\end{array}$ \\
\hline \begin{tabular}{l} 
Other sources of bias? \\
\hline
\end{tabular} & Low risk & $\begin{array}{l}\text { All primary outcomes reported. Other outcomes were reported in another pa- } \\
\text { per due to space constrictions }\end{array}$ \\
\hline
\end{tabular}


Minnerop 2008

Randomised controlled, open-label trial with two parallel groups
Although the main outcome was defined as complete recovery at three months, only 47 were assessed
as planned. The rest of them returned before month three or after month 12. Data of these 47 patients
were sent by the author

Participants

167 patients with facial paralysis of 18 years and older in the trial within 5 days after onset; 50 patients were lost to follow-up and only 127 were analysed. The mean age was $40.6 \pm 20.5$ in the prednisolone group and $42.6 \pm 30.9$ in the combined treatment group. The study was carried out in the Department of Neurology, University Hospital of Bonn, Germany

\section{Inclusion criteria}

- Patients with acute untreated facial paralysis palsy

\section{Exclusion criteria}

- Contraindications to corticosteroid or famciclovir therapy were peptic ulcer, insulin-dependent diabetes mellitus, renal or hepatic dysfunction, immune suppression, and pregnancy, Lyme disease, zoster oticus, or other symptomatic causes

Interventions

Patients admitted on even dates were assigned to prednisone, patients admitted on odd dates to prednisone and famciclovir. Of the prednisolone $1 \mathrm{mg} / \mathrm{kg}$ body weight was given for 4 days, and was subsequently tapered over the following 8 days; famciclovir was administered orally three times per day (250 $\mathrm{mg}$ ) for 7 days. All patients received $\mathrm{H} 2$-receptor blockers, artificial tears and ophthalmic ointment for eye care. Follow-up visit: 3 months after onset of Bell's palsy

\begin{tabular}{ll}
\hline Outcomes & $\begin{array}{l}\text { Complete recovery at three months. The assessors in the trial used the House-Brackman scale (House } \\
\text { 1983; House 1985), or a similar score and complete recovery was not defined }\end{array}$ \\
\hline Funding & No information given \\
\hline Conflicts of interest & The authors declare no conflict of interest \\
\hline Date conducted & January 2001 to June 2005 \\
\hline Notes & Single-centre
\end{tabular}

\section{Risk of bias}

\begin{tabular}{lll}
\hline Bias & Authors' judgement & Support for judgement \\
\hline $\begin{array}{l}\text { Random sequence genera- } \\
\text { tion (selection bias) }\end{array}$ & High risk & Even days and odd days \\
\hline $\begin{array}{l}\text { Allocation concealment } \\
\text { (selection bias) }\end{array}$ & High risk & The trial was not blinded \\
\hline $\begin{array}{l}\text { Blinding of participants? } \\
\text { Blinding of assessors? }\end{array}$ & High risk & High risk \\
\hline $\begin{array}{l}\text { Incomplete outcome da- } \\
\text { ta? }\end{array}$ & High risk & No blinding \\
\hline $\begin{array}{l}\text { Selective outcome report- } \\
\text { ing? }\end{array}$ & Unclear risk & $\begin{array}{l}\text { Of the 167 participants, 50 were lost to follow-up, most of them in the com- } \\
\text { bined treatment group. Only 47 participants were assessed within the defined } \\
\text { time period. No intention-to-treat analysis }\end{array}$ \\
\hline
\end{tabular}


Minnerop 2008 (Continued)

Other sources of bias?
Unclear risk
It looks as if the dates for reassessment were not clearly communicated to the patients.

Unclear why more patients in the combination treatment group were lost to follow-up

\section{Vázquez 2008}

\begin{tabular}{|c|c|}
\hline Methods & Double-blind, placebo-controlled, randomised trial. Two parallel groups \\
\hline Participants & $\begin{array}{l}\text { Included } 42 \text { participants assigned to } 2 \text { treatment groups. Participants with other causes of facial palsy } \\
\text { were excluded } \\
\text { Age range was } 14-82 \text { years and the mean age was } 42.5 \pm 20.8 \text { in the combined treatment group } 40.1 \pm \\
18.5 \text { in the prednisolone group. Patients were recruited in Neurología del Hospital de Clínicas de Mon- } \\
\text { tevideo in Uruguay. } \\
\text { Inclusion criteria } \\
\text { - Acute onset of facial paralysis in patients }>14 \text { years, not associated with neurological or systemic } \\
\text { diseases, otologic or parotid diseases, traumatic brain injury, tumours of the region or herpes zoster } \\
\text { oticus } \\
\text { Exclusion criteria } \\
\text { - Chronic kidney disease } \\
\text { - HIV infection } \\
\text { - Tuberculosis } \\
\text { - Pregnant or breastfeeding women } \\
\text { - Hypertonus }>160 / 100 \mathrm{mmHg} \\
\text { - Peptic ulcer } \\
\text { - Glaucoma } \\
\text { - Decompensated heart failure } \\
\text { - Ramsay-Hunt Syndrom }\end{array}$ \\
\hline Interventions & $\begin{array}{l}\text { Randomised to receive either valaciclovir plus prednisone or prednisone plus placebo. Both groups re- } \\
\text { ceived } 1 \mathrm{mg} / \mathrm{kg} \text { weight prednisone for } 7 \text { days, then reduced doses for } 14 \text { days } \\
\text { Participants in the treatment group received } 2 \mathrm{~g} \text { valaciclovir for } 7 \text { days } \\
\text { All participants undertook eye protection and received rehabilitation }\end{array}$ \\
\hline
\end{tabular}

\section{Outcomes}

\section{Primary outcome}

- Recovery on facial grading system (Sunnybrook scale; Ross 1996), where recovery was taken as > 90

Follow-up at 1, 2, 4, 8, and 12 months. Final outcomes reported at 6 months

Adverse events were not reported

\begin{tabular}{ll}
\hline Funding & Information not given \\
\hline Conflicts of interest & Information not given \\
\hline
\end{tabular}

Date conducted December 2002 to December 2003

Notes Single-centre


Vázquez 2008 (Continued)

Risk of bias

\begin{tabular}{|c|c|c|}
\hline Bias & Authors' judgement & Support for judgement \\
\hline $\begin{array}{l}\text { Random sequence genera- } \\
\text { tion (selection bias) }\end{array}$ & Unclear risk & Simple randomisation, not specified \\
\hline $\begin{array}{l}\text { Allocation concealment } \\
\text { (selection bias) }\end{array}$ & Unclear risk & Not reported \\
\hline Blinding of participants? & Unclear risk & $\begin{array}{l}\text { Different treatment regimens in both groups, blinding and usage of placebo } \\
\text { not described }\end{array}$ \\
\hline Blinding of assessors? & Unclear risk & Blinding method of the assessors not clearly described \\
\hline $\begin{array}{l}\text { Incomplete outcome da- } \\
\text { ta? }\end{array}$ & Low risk & All outcome data were reported \\
\hline $\begin{array}{l}\text { Selective outcome report- } \\
\text { ing? }\end{array}$ & Unclear risk & $\begin{array}{l}\text { All planned outcome measures reported; authors reported synkinesis and ad- } \\
\text { verse effects, but without assigning the cases to the groups }\end{array}$ \\
\hline Other sources of bias? & Low risk & No other potential sources of bias identified \\
\hline
\end{tabular}

Yeo 2008

\begin{tabular}{ll}
\hline Methods & Randomised, double-blind, controlled trial, 2 parallel groups \\
\hline Participants & 91 participants; other causes of facial palsy were excluded. No maximum period after onset stated, but \\
actual time to treatment recorded. All participants were admitted to hospital and received physical \\
therapy and plasma volume expanders as adjuncts. The trial was carried out in the Department of Oto- \\
laryngology, College of Medicine, Kyung Hee University, \\
South Korea. \\
Mean age in the aciclovir and prednisolone group was $42.7 \pm 15.7$ years, prednisolone group: $40.2 \pm 18.4$ \\
years \\
Inclusion criteria \\
- Peripheral facial palsy that developed suddenly (age or age range was not given) \\
Exclusion criteria \\
- Patients with central nervous system abnormalities, neoplasms, acute or chronic middle ear disease \\
- Patients with facial palsy caused by temporal bone fracture \\
- Patients with facial nerve paralysis caused by surgery \\
- Patients with Ramsay Hunt syndrome \\
or duodenal ulcer
\end{tabular}

Interventions

Randomised to receive either aciclovir and prednisolone or prednisolone alone. Aciclovir given at a dose of $2400 \mathrm{mg} /$ day for 5 days. Prednisolone given as $1 \mathrm{mg} / \mathrm{kg} /$ day for 5 days, then tapered on days 6 to 10 . All participants admitted to hospital and received physical therapy (facial massage and treatment with an electrical stimulator, together with facial expression practice) and plasma volume expanders as adjuncts. All patients were administered eye ointment to prevent ocular injury.

\section{Outcomes}

\section{Primary outcome}


Yeo 2008 (Continued)

- Recovery on House-Brackmann scale (House 1983; House 1985), where recovery was Grade $\leq 2$

Subgroup analysis of early versus delayed treatment

Follow-up at 2 and 6 months. Final outcomes reported at 6 months

\begin{tabular}{ll}
\hline Funding & No information given \\
\hline Conflicts of interest & No information given \\
\hline Date conducted & January 2003 to July 2006 \\
\hline Notes & Single-centre. All participants admitted \\
\hline
\end{tabular}

\section{Risk of bias}

\begin{tabular}{lll}
\hline Bias & Authors' judgement & Support for judgement \\
\hline $\begin{array}{l}\text { Random sequence genera- } \\
\text { tion (selection bias) }\end{array}$ & Unclear risk & States 'randomised' in study title, but no description of this in the paper \\
\hline $\begin{array}{l}\text { Allocation concealment } \\
\text { (selection bias) }\end{array}$ & Unclear risk & No clear statement of this in the study \\
\hline Blinding of participants? & Unclear risk & $\begin{array}{l}\text { States 'double-blind' in study title, but no description of methods employed } \\
\text { for this in text }\end{array}$ \\
\hline $\begin{array}{l}\text { Blinding of assessors? } \\
\text { Incomplete outcome da- }\end{array}$ & Unclear risk & $\begin{array}{l}\text { States 'double-blind' in study title, but no description of methods employed } \\
\text { for this in text }\end{array}$ \\
\hline $\begin{array}{l}\text { Selective outcome report- } \\
\text { ing? }\end{array}$ & Unclear risk & $\begin{array}{l}\text { Incomplete follow-up data not mentioned in the study. No intention-to-treat } \\
\text { population described }\end{array}$ \\
\hline \begin{tabular}{l} 
Other sources of bias? \\
\hline
\end{tabular} & Low risk & \begin{tabular}{l} 
Stated primary outcome measure reported, no adverse events reported \\
\hline
\end{tabular}
\end{tabular}

\section{Shahidullah 2011}

\begin{tabular}{|c|c|}
\hline Methods & Randomised-controlled, open-label trial, two parallel groups \\
\hline \multirow[t]{5}{*}{ Participants } & $\begin{array}{l}107 \text { clinic patients of } 15 \text { years and older with unilateral facial paralysis of unknown cause were recruit- } \\
\text { ed and } 68 \text { were analysed. Of these patients, } 33 \text { had exclusion criteria and } 9 \text { were lost to follow-up so } \\
\text { that data of } 68 \text { patients were analysed. The trial was carried out in the Department of Neurology in } \\
\text { Bangabandu Sheikh Mujib Medical University. }\end{array}$ \\
\hline & Inclusion criteria \\
\hline & $\begin{array}{l}\text { - Untreated acute Bell's palsy. The mean age was } 31+/-9.6 \text { years and in the prednisolone plus aciclovir } \\
\text { group and } 35.1+/-11.7 \text { in the prednisolone group }\end{array}$ \\
\hline & Exclusion criteria: \\
\hline & $\begin{array}{l}\text { - Abnormalities of central nervous system, neoplasm, acute ore chronic middle ear disease, temporal } \\
\text { bone fracture, Bell's palsy with vesicle, uncontrolled diabetes, duodenal ulcer }\end{array}$ \\
\hline
\end{tabular}


Shahidullah 2011 (Continued)

Interventions $\quad$ Famiciclovir ( $250 \mathrm{mg}$ three times a day for 5 days) plus prednisolone (60 mg a day 7 days) or prednisolone alone (60 $\mathrm{mg}$ a day for 7 days). All patients received $\mathrm{H} 2$-receptor blocker, artificial tears and ophthalmic ointment for eye care.

Outcomes Complete recovery of facial function at the end of study. Patients were assessed at baseline using the House-Brackman scale (House 1983; House 1985), and were followed up one week, one month and three months after inclusion. Complete recovery was defined as House-Brackman Grade 1

\begin{tabular}{ll}
\hline Funding & Information not given \\
\hline Conflicts of interest & Information not given \\
\hline Date conducted & July 2008 to June 2009 \\
\hline Notes & Single-centre
\end{tabular}

\section{Risk of bias}

\begin{tabular}{lll}
\hline Bias & Authors' judgement & Support for judgement \\
\hline $\begin{array}{l}\text { Random sequence genera- } \\
\text { tion (selection bias) }\end{array}$ & High risk & Patients were randomised based on odd and even numbers \\
\hline $\begin{array}{l}\text { Allocation concealment } \\
\text { (selection bias) }\end{array}$ & Unclear risk & Not clearly described \\
\hline Blinding of participants? & High risk & No blinding \\
\hline Blinding of assessors? & High risk & No blinding \\
\hline $\begin{array}{l}\text { Incomplete outcome da- } \\
\text { ta? }\end{array}$ & High risk & $\begin{array}{l}\text { Per protocol analysis only. 27\% of the participants were either excluded or lost } \\
\text { to follow-up. No intention-to-treat analysis }\end{array}$ \\
\hline $\begin{array}{l}\text { Selective outcome report- } \\
\text { ing? }\end{array}$ & Low risk & \begin{tabular}{l} 
Not identified \\
\hline $\begin{array}{l}\text { Other sources of bias? } \\
\text { High risk }\end{array}$
\end{tabular} \\
\hline
\end{tabular}

Lee 2013

\begin{tabular}{|c|c|}
\hline Methods & Randomised, controlled, double-blind study, parallel-group design \\
\hline \multirow[t]{3}{*}{ Participants } & $\begin{array}{l}269 \text { participants with severe Bell's palsy were recruited; } 206 \text { were included in the final analysis. } 99 \\
\text { participants were assigned to the famciclovir and prednisolone group, } 107 \text { participants to the pred- } \\
\text { nisolone group. The mean age was } 46.7 \text { (SD 16.2) years in the AS group and } 48.6 \text { (SD 15.1) in the OS } \\
\text { group. Half of the AS group ( } 50 \% \text { ) and } 52 \% \text { of the OS group were female. The authors state that there } \\
\text { was no difference between both groups. All participants received treatment within } 7 \text { days of onset of } \\
\text { palsy. Age range: } 16-77 \text { years }\end{array}$ \\
\hline & Inclusion criteria \\
\hline & $\begin{array}{l}\text { - Acute unilateral peripheral facial paralysis without skin lesions or intraoral lesions occurring within } \\
7 \text { days of presentation }\end{array}$ \\
\hline
\end{tabular}


Lee 2013 (Continued)

- Only patients with severe-to-complete Bell's palsy (House-Brackmann scale Grade 5 or more) were enrolled

\section{Exclusion criteria}

- Bell's palsy that occurred more than 7 days before presentation

- Suspected Ramsay-Hunt syndrome

- Meningitis

- Myelitis

- Vasculopathy

- Patients who could not be observed for at least 6 months

- Initial use of several different types of treatments

- Pregnancy or breastfeeding

- Uncontrolled diabetes or hypertension

- Poor general medical conditions in which corticosteroid or antiviral therapy cannot be used

- Suspicion of Borrelia infection

- Tendency for neuropsychiatric disease

- Refusal to participate in the study

Interventions

AS group: prednisolone $64 \mathrm{mg}$ for 4 days, $48 \mathrm{mg}$ for 2 days, $32 \mathrm{mg}$ for 2 days, and $16 \mathrm{mg}$ for 2 days with famciclovir $750 \mathrm{mg} /$ day for 7 days intravenously $(\mathrm{N}=99)$

OS group: famciclovir $750 \mathrm{mg} /$ day for 7 days intravenously $(\mathrm{N}=107)$. Both drugs were given simultaneously

\section{Outcomes Primary outcome}

- Full recovery, based on the House-Brackmann scale (Grades 1 and 2) at 6 months (House 1983; House 1985)

Evaluation of prognostic factors for incomplete recovery. Follow-up at 2 weeks and 6 months after commencing treatment

\begin{tabular}{|c|c|c|}
\hline Funding & \multicolumn{2}{|c|}{ Kyung Hee University Research Fund } \\
\hline Conflicts of interest & \multicolumn{2}{|c|}{ The authors state having no conflict of interest } \\
\hline Date conducted & \multicolumn{2}{|c|}{ September 2008 to August 2011} \\
\hline Notes & \multicolumn{2}{|c|}{ Single-centre, Department of Otopharyngology at the Kyung Hee University in Korea } \\
\hline \multicolumn{3}{|l|}{ Risk of bias } \\
\hline Bias & Authors' judgement & Support for judgement \\
\hline $\begin{array}{l}\text { Random sequence genera- } \\
\text { tion (selection bias) }\end{array}$ & Low risk & Random sequence generation using computer codes \\
\hline $\begin{array}{l}\text { Allocation concealment } \\
\text { (selection bias) }\end{array}$ & Unclear risk & No information on concealment \\
\hline Blinding of participants? & High risk & No placebo. No information on concealment of the intervention \\
\hline Blinding of assessors? & High risk & $\begin{array}{l}\text { Different treatment regimens in both groups. No information on concealment } \\
\text { of the intervention }\end{array}$ \\
\hline
\end{tabular}


Lee 2013 (Continued)

Incomplete outcome da- High risk Per protocol analysis only. Dropout rate reported: 13.1\%. No intention-to-treat ta? analysis

\begin{tabular}{lll}
$\begin{array}{l}\text { Selective outcome report- } \\
\text { ing? }\end{array}$ & Unclear risk & Adverse events were not reported \\
\hline Other sources of bias? & Unclear risk & $\begin{array}{l}\text { Two participants with adverse events in the corticosteroid group (not clearly } \\
\text { specified) were excluded from the analysis }\end{array}$
\end{tabular}

Khajeh 2015

\begin{tabular}{|c|c|}
\hline Methods & Randomised, controlled, not blinded trial, parallel-group design \\
\hline Participants & $\begin{array}{l}\text { This study was conducted in the Department of Pediatrics, Children and Adolescent Health in Zahedan, } \\
\text { Iran. } 43 \text { children between } 2 \text { and } 18 \text { years were randomly assigned in the prednisolone and aciclovir } \\
\text { group ( } N=20 \text { ) or in the prednisolone group ( } N=23) \text {. Participants received treatment within three days } \\
\text { of onset of Bell's palsy. The mean age was } 8.4(S D 4.9) \text { in the AS group and } 8.6 \text { years (SD 5.1) in the OS } \\
\text { group. More female patients were in the AS group than in the OS group ( } 55 \% \text { versus } 39 \%) \text {. } \\
\text { Inclusion criteria } \\
\text { - Acute unilateral peripheral facial palsy } \\
\text { Exclusion criteria } \\
\text { - Patients with paralysis of other cranial nerves } \\
\text { - Passing more than } 3 \text { days of symptoms onset } \\
\text { - Patients less than } 2 \text { years of age and older than } 18 \text { years } \\
\text { - Presence of secondary causes of the } 7 \text { th nerve palsy } \\
\text { - Suspicion of meningitis, vasculopathy, Ramsey Hunt syndrome, peptic ulcer } \\
\text { - Anti-herpetic treatment within the last } 2 \text { weeks } \\
\text { - Sensitivity to aciclovir }\end{array}$ \\
\hline
\end{tabular}

Interventions The participants were treated with either a combination of $2 \mathrm{mg} / \mathrm{kg} / \mathrm{day}$ prednisolone and $10 \mathrm{mg} / \mathrm{kg} /$
day aciclovir every eight hours for seven days or with prednisolone alone following the same scheme.

Primary outcome
- Severity of Bell's palsy on the House-Brackmann scale (House 1983; House 1985)
Secondary outcomes
- Not reported

\begin{tabular}{ll}
\hline Funding & No information given \\
\hline Conflicts of interest & The authors declare no conflict of interest \\
\hline Date conducted & September 2011 to March 2014 \\
\hline Notes & The paper provides little information on trial methods and procedures \\
\hline
\end{tabular}

\section{Risk of bias}

Bias Authors' judgement Support for judgement


Khajeh 2015 (Continued)

Random sequence genera- Unclear risk Sequence generation not stated, randomisation procedure not described tion (selection bias)

\begin{tabular}{lll}
\hline $\begin{array}{l}\text { Allocation concealment } \\
\text { (selection bias) }\end{array}$ & Unclear risk & Not described by the authors \\
\hline Blinding of participants? & High risk & No blinding \\
\hline Blinding of assessors? & High risk & No blinding \\
\hline $\begin{array}{l}\text { Incomplete outcome da- } \\
\text { ta? }\end{array}$ & Unclear risk & $\begin{array}{l}\text { Number of participants lost to follow-up not given. Unclear whether inten- } \\
\text { tion-to-treat analysis was performed }\end{array}$ \\
\hline $\begin{array}{l}\text { Selective outcome report- } \\
\text { ing? }\end{array}$ & Unclear risk & Only one outcome was predefined \\
\hline \begin{tabular}{l} 
Other sources of bias? \\
\hline
\end{tabular} & Unclear risk & Trial procedures poorly reported \\
\hline
\end{tabular}

\section{Khedr 2016}

Methods Randomised, controlled trial, parallel-group design, unclear whether blinded or not

Participants The trial was conducted in the Neuropsychiatry Department of the Assiut University hospital in Egypt. 65 patients between 15 to 60 years with one-sided Bell's palsy were recruited within three days of onset. Fifteen patients were excluded due to exclusion criteria. The mean age of the patients in the aciclovir plus prednisolone group was 36.3 (SD 14.0) and 37.4 (SD 13.4) in the prednisolone group. Data on sex are missing.

\section{Inclusion criteria}

- Patients with acute onset facial palsy (unilateral) and within the first 3 days of onset

\section{Exclusion criteria}

- Patients with brittle diabetes mellitus

- Morbid obesity

- Renal or liver impairment

- Osteopenia

- Pregnancy

- Breastfeeding

- Uncontrolled hypertension

- Prior history of corticosteroid intolerance

Interventions

Prednisolone $60 \mathrm{mg}$ a day and aciclovir $400 \mathrm{mg}$ three times a day were given in the intervention group and prednisolone $60 \mathrm{mg}$ a day alone in the control group within three days after onset. The treatment lasted seven days for prednisolone and five days for aciclovir.

\section{Outcomes Primary outcome}

- Change in House-Brackmann scale three months after palsy onset (House 1983; House 1985)

Outcome data were assessed at baseline, two weeks, two and three months after inclusion. Complete recovery was defined as Grades 1 and 2

Funding No information given


Khedr 2016 (Continued)

Conflicts of interest Authors declare having no conflict of interest

\begin{tabular}{ll}
\hline Date conducted & April 2014 to December 2014 \\
\hline Notes & Single-centre \\
\hline
\end{tabular}

\section{Risk of bias}

\begin{tabular}{lll}
\hline Bias & Authors' judgement & Support for judgement \\
\hline $\begin{array}{l}\text { Random sequence genera- } \\
\text { tion (selection bias) }\end{array}$ & Unclear risk & $\begin{array}{l}\text { Patients were randomised in two groups using serially-numbered opaque } \\
\text { closed envelopes. The method of generating the random sequence is not de- } \\
\text { scribed }\end{array}$
\end{tabular}

\begin{tabular}{lll}
\hline $\begin{array}{l}\text { Allocation concealment } \\
\text { (selection bias) }\end{array}$ & Unclear risk & $\begin{array}{l}\text { Patients were randomised in two groups using serially-numbered opaque } \\
\text { closed envelopes }\end{array}$ \\
\hline Blinding of participants? & Unclear risk & $\begin{array}{l}\text { The study was stated as blinded but the masking procedure was not de- } \\
\text { scribed. The authors describe it as follows: Quote: "...although this was not } \\
\text { placebo-controlled trial, since it was an add-on design to test the effect of ad- } \\
\text { ministering an antiviral drug, participants did not know who was getting the } \\
\text { antiviral and who was not." }\end{array}$ \\
\hline
\end{tabular}

\begin{tabular}{|c|c|c|}
\hline Blinding of assessors? & Unclear risk & $\begin{array}{l}\text { It is not clearly described how assessors were blinded. Especially as it is not } \\
\text { clear whether patients were blinded sufficiently. The authors stated that: } \\
\text { Quote: "To ensure double blinding, the random allocation sequence was kept } \\
\text { by a different investigator to the one who enrolled the participants (neurolo- } \\
\text { gist). Moreover, a third investigator was responsible for following up the pa- } \\
\text { tients and for assessment (rehabilitation doctor)." }\end{array}$ \\
\hline
\end{tabular}

\begin{tabular}{lll}
\hline $\begin{array}{l}\text { Incomplete outcome da- } \\
\text { ta? }\end{array}$ & Low risk & $\begin{array}{l}\text { Patients with mild to moderate Bell's palsy and obesity were excluded at inclu- } \\
\text { sion but of the participants randomised, only two were lost to follow-up. No in- } \\
\text { tention-to-treat analysis }\end{array}$ \\
\hline $\begin{array}{l}\text { Selective outcome report- } \\
\text { ing? }\end{array}$ & High risk & Adverse events were not reported \\
\hline Other sources of bias? & Low risk & Not identified \\
\hline
\end{tabular}

AS: antivirals plus corticosteroids

OS: corticosteroids alone or in combination with placebo

SD: standard deviation

\section{Characteristics of excluded studies [ordered by year of study]}

\begin{tabular}{ll}
\hline Study & Reason for exclusion \\
\hline Ramos Macias 1992 & $\begin{array}{l}\text { Inadequate allocation concealment. No information reported about methods of randomisation, di- } \\
\text { agnostic criteria used, length of follow-up, or number of participants lost to follow-up. Thirty-three } \\
\text { percent had Ramsay Hunt syndrome, abstract only available }\end{array}$ \\
\hline Ibarrondo 1999 & $\begin{array}{l}\text { Retrospective study. } 100 \text { participants collected between } 1983 \text { and } 1989 \text { received corticotherapy. } \\
100 \text { participants treated after } 1989 \text { received aciclovir }\end{array}$ \\
\hline Abdelghany 2013 & Study retracted \\
\hline
\end{tabular}




\begin{tabular}{|c|c|}
\hline Study & Reason for exclusion \\
\hline Zhou 1999 & $\begin{array}{l}\text { Prospective study. } 69 \text { participants with Bell's palsy followed up for only } 2 \text { weeks. Not double-blind, } \\
\text { and allocation concealment not described. Used own scale for palsy grading, outcome measures } \\
\text { not met. Did report adverse events. Four participants receiving aciclovir treatment had gastric } \\
\text { malaise }\end{array}$ \\
\hline Antunes 2000 & $\begin{array}{l}\text { Small-study numbers and insufficient information in original paper to assign a participant with in- } \\
\text { complete recovery to the correct control group. Author contacted by Dr D Allen, but no response } \\
\text { received }\end{array}$ \\
\hline de Aquino 2001 & $\begin{array}{l}\text { Methodology not clear from original paper. An author of a previous version of this review (D Allen) } \\
\text { attempted to obtain further information but obtained no response }\end{array}$ \\
\hline Inanli 2001 & The paper was not available \\
\hline Hato 2003 & Retrospective analysis of treatment \\
\hline Axelsson 2003 & Use of a historical control group \\
\hline Chen 2005 & Follow-up data for only 4 weeks from palsy onset \\
\hline Roy 2005 & $\begin{array}{l}\text { Inadequate information on outcome data, } 22 \% \text { lost to follow-up, abstract only published in journal } \\
\text { supplement and not traced as a full publication }\end{array}$ \\
\hline Hultcrantz 2005 & Allocation was not randomised \\
\hline Ahangar 2006 & Allocation was not randomised \\
\hline Kang 2015 & $\begin{array}{l}\text { Prospective, not randomised, not controlled study comparing antiviral agents plus prednisolone } \\
\text { with prednisolone alone in participants with Bell's palsy }\end{array}$ \\
\hline Ferreira 2016 & $\begin{array}{l}\text { A prospective single-blinded study comparing corticosteroids and neuromuscular training with fa- } \\
\text { cial neuromuscular training alone in participants with Bell's palsy }\end{array}$ \\
\hline
\end{tabular}

\section{Characteristics of studies awaiting assessment [ordered by year of study]}

IRCT201109187575N1

\begin{tabular}{ll}
\hline Methods & Randomised, parallel-assignment, open-label \\
\hline Participants & $\begin{array}{l}\text { Inclusion criteria: People with Bell's palsy, age over } 10 \text { years } \\
\text { Exclusion criteria: more than } 7 \text { days have passed since the onset of paralysis; finding another } \\
\text { cause for the paralysis } \\
\text { Target sample size } 180\end{array}$ \\
\hline Interventions & $\begin{array}{l}\text { Group 1: prednisone } 1 \mathrm{mg} / \mathrm{kg} \text { body weight daily for } 3 \text { days. The treatment was tapered over the } \\
\text { Group 2: aciclovir, } 400 \mathrm{mg} \text { every } 5 \text { hours per day for } 10 \text { days } \\
\text { Group 3: combination of aciclovir and prednisone }\end{array}$ \\
\hline
\end{tabular}

\section{Outcomes}

Primary: House-Brackmann scale every 15 days

Treatment failure (no reduction of House-Brackmann scale) at the end of month 3

\section{Notes}




\section{Characteristics of ongoing studies [ordered by year of study]}

\section{ACTRN12615000563561}

Trial name or title
Bell's palsy in children: a multicentre, double-blind, randomised, placebo-controlled trial to determine whether prednisolone improves recovery at 1 month

Multicentre, double-blind, randomised, placebo-controlled

Children ( 6 months to 18 years old) with Bell's palsy (diagnosed by treating doctor) of acute onset within 72 hours of randomisation

Planned recruitment 270 per group (540 in total) to allow for 10\% loss to follow-up at 1 month

\section{Exclusion criteria}

- Previous episode of Bell's Palsy or previously randomised in the study

- Contraindication to prednisolone

- Current systemic or inhaled steroid use, or use within 2 weeks prior to symptom onset

- Current or past oncological diagnosis

- Blood test result (if obtained during this illness) potentially indicative of leukaemia

- Pregnancy and/or lactation

- Currently receiving medications with which concomitant use of prednisolone is contraindicated

- Live vaccination within the previous 1 month or requirement for live vaccine within 6 weeks of 1 st prednisolone dose

- Signs of upper motor neuron facial nerve palsy (weakness of lower half of the face only)

- Current or recent (1 week prior to Bell's palsy symptoms) otitis media

- Evidence of vesicles on the ear or vesicles or ulcers elsewhere on the body suggestive of recent herpes simplex, herpes zoster or chickenpox

- Significant facial trauma in the week prior to appearance of symptoms

- Referred to GP clinic in Emergency Department or failed to wait

- Unable to attend a follow-up visit in one month's time

- Any other condition at risk of being influenced by study treatment or completion

- Parents unable to comply with the study, or with insufficient understanding
Prednisolone $1 \mathrm{mg} / \mathrm{kg} /$ day (dosing based on weight categories) up to a maximum of $50 \mathrm{mg} /$ day for 10 days.

Placebo (identical in look and taste, in identical glass bottles)

Both prednisolone and placebo given as a once daily dose via oral solution

\section{Primary outcomes}

- Complete recovery at 1 month post-randomisation, where recovery is defined as a House-Brackmann facial grading score of 1 . Recovery assessed in person by a specialist clinician

\section{Secondary outcomes}

- Complete recovery at 1, 3 and 6 months, using the Sunnybrook Facial Grading System (Ross 1996) and the House-Brackmann facial grading scale (House 1983; House 1985, assessed by a specialist physician 
- Parent/guardian and participant (where aged $>8$ years) perception) of facial nerve recovery at 1 , 3 and 6 months, using a lay translation of the House-Brackmann facial grading scale

- Quality of life: emotional and functional well-being of the participant assessed by the parent/guardian and participant using the Pediatric Quality of Life Inventory scale, the Child Health Utility 9D scale and sections of the Harter scale at 1, 3 and 6 months postrandomisation

- Pain (on 0 to 10 scales), assessed using child-assigned visual analogue scale (VAS), or Faces Pain Scale Revised (for participants aged 5 and older) and using parent-assigned VAS for participants at any age, at 1, 3 and 6 months postrandomisation

- Prevalence of sykinesis or autonomic dysfunction using the Sunnybrook scale augmented by a synkinesis assessment questionnaire, assessed by a specialist clinician and/or research assistant at 1,3 and 6 months postrandomisation

- Health utilisation costs assessed via Child Health Utility 9D and via capture of cost information from the parent/guardian/participant related to inpatient, outpatient, or emergency department visits and to any other health facilities, including general practitioner attendance for treatment or investigation 6 months following randomisation

Starting date First enrolment: 13 October 2015

\begin{tabular}{ll}
\hline Contact information & A/Prof Franz Babl, Emergency Research Department, Murdoch Children's Research Institute, \\
& Flemingon Road, Parkville, VIC 3052
\end{tabular}
Flemingon Road, Parkville, vIC 3052

Notes Multicentre, Australia and New Zealand

\section{NCT03781700} come assessor), phase IV RCT

\section{Participants}

Children with acute peripheral unilateral facial palsy

\section{Inclusion criteria}

- 1 to 17 years old

- Acute peripheral unilateral facial nerve palsy

- Less than 72 hours since debut of symptoms

- Signed informed consent

\section{Exclusion criteria}

- Head trauma <1 month

- Central or bilateral facial nerve palsy

- Malformations in head and neck

- Conditions not compatible with cortisone treatment

- Current or past oncological diagnosis

- Other serious medical conditions (meningitis, encephalitis, stroke)

- Acute otitis media

- Signs of herpes simplex or varicella zoster infection (vesicles in the ear region)

- Pregnancy or breastfeeding

- Use of any systemic or inhaled steroids within 2 weeks prior to onset of symptoms

- Immunisation with live vaccine 1 month prior to onset of symptoms

- Requirement of live vaccine within 2 months from start of experimental treatment (prednisolone or placebo)

- Evaluation of primary endpoint at 12 months not feasible for any reason 
NCT03781700 (Continued)

- Previously included into the FACE study

Interventions Prednisolone $5 \mathrm{mg}$ tablets, $1 \mathrm{mg} / \mathrm{kg}$ bodyweight orally per day for 10 days, maximum $50 \mathrm{mg}$ per day

Placebo: oral tablet identical in appearance

\section{Primary outcomes}

- Total recovery assessed on the House-Brackmann scale at 12 months (+/- 2 weeks) after inclusion (a scale where I is normal function and VI is total loss of function)

\section{Secondary outcomes}

- Total recovery assessed on the Sunnybrook Facial Grading System (Ross 1996) at 12 months (+/2 weeks) after inclusion (a scale where 100 is normal function and 0 is total loss of function)

- Facial Disability Index (FDI) at 12 months (+/- 2 weeks) after inclusion (a scale with 5 functional domains: 5 means no problems and 2 or 1 means problems all the time; and 5 social domains: 6 means problems all the time and 1 means no problems at all)

- Facial Clinimetric Evaluation (FaCE) Scale at 12 months (+/- 2 weeks) after inclusion (a scale with 15 functional and social domains: 1 means problems all the time and 5 means no problems at all)

- Synkinesis Assessment Questionnaire (SAQ) at 12 months (+/- 2 weeks) after inclusion. This is subjective grading of synkinesis symptoms with 9 functional domains ( 1 means no problems at all and 5 means problems all the time)

Adverse events at 12 months (+/- 2 weeks) after inclusion, assessed as number of adverse events possibly or probably related to the study drug

\begin{tabular}{ll}
\hline Starting date & 3 May 2019 \\
\hline Contact information & $\begin{array}{l}\text { Barbro Hedin Skogman: barbro.hedinskogman@ltdalarna.se, Center for Clinical Research Dalarna, } \\
\text { Sweden }\end{array}$ \\
\hline Notes & Sweden \\
\hline
\end{tabular}

\section{DATA AND ANALYSES}

Comparison 1. Antivirals plus corticosteroids versus corticosteroids plus placebo or no treatment (AS versus OS): trials at lower risk of bias

\begin{tabular}{lllll}
\hline Outcome or subgroup title & $\begin{array}{l}\text { No. of } \\
\text { studies }\end{array}$ & $\begin{array}{l}\text { No. of } \\
\text { partici- } \\
\text { pants }\end{array}$ & Statistical method & Effect size \\
\hline $\begin{array}{l}1 \text { Incomplete recovery at end of } \\
\text { study (trials at lower risk of bias) }\end{array}$ & 3 & 766 & Risk Ratio (M-H, Random, 95\% Cl) & $0.81[0.38,1.74]$ \\
\hline $\begin{array}{llll}1.1 \text { Aciclovir } \\
1.2 \text { Valaciclovir }\end{array}$ & 2 & 350 & Risk Ratio (M-H, Random, 95\% Cl) & $0.76[0.14,4.31]$ \\
\hline $\begin{array}{l}2 \text { Incomplete recovery at end of } \\
\text { study (full data set) }\end{array}$ & 13 & 1729 & Risk Ratio (M-H, Random, 95\% Cl) & $0.54[0.38,0.77]$ \\
\hline \begin{tabular}{l}
2.1 Aciclovir \\
\hline
\end{tabular} & 6 & 580 & Risk Ratio (M-H, Random, $95 \% \mathrm{Cl})$ & $0.43[0.22,0.83]$ \\
\hline
\end{tabular}




\begin{tabular}{|c|c|c|c|c|}
\hline Outcome or subgroup title & $\begin{array}{l}\text { No. of } \\
\text { studies }\end{array}$ & $\begin{array}{l}\text { No. of } \\
\text { partici- } \\
\text { pants }\end{array}$ & Statistical method & Effect size \\
\hline 2.2 Famciclovir & 3 & 321 & Risk Ratio (M-H, Random, 95\% Cl) & $0.48[0.22,1.06]$ \\
\hline 2.3 Valaciclovir & 4 & 828 & Risk Ratio (M-H, Random, 95\% Cl) & $0.79[0.57,1.08]$ \\
\hline $\begin{array}{l}3 \text { Incomplete recovery at end of } \\
\text { study in severe cases: data set limit- } \\
\text { ed to trials at lower risk of bias }\end{array}$ & 2 & 98 & Risk Ratio (M-H, Random, 95\% Cl) & $0.82[0.57,1.17]$ \\
\hline $\begin{array}{l}4 \text { Incomplete recovery at end of } \\
\text { study in severe cases: full data set }\end{array}$ & 4 & 478 & Risk Ratio (M-H, Random, 95\% Cl) & $0.64[0.41,0.99]$ \\
\hline 5 Motor synkinesis or crocodile tears & 2 & 469 & Risk Ratio (M-H, Fixed, 95\% Cl) & $0.56[0.36,0.87]$ \\
\hline $\begin{array}{l}6 \text { Adverse events (trials at lower risk } \\
\text { of bias) }\end{array}$ & 2 & 656 & Risk Ratio (M-H, Fixed, 95\% Cl) & $1.17[0.81,1.69]$ \\
\hline 7 Adverse events (full data set) & 4 & 945 & Risk Ratio (M-H, Fixed, 95\% Cl) & $1.16[0.83,1.63]$ \\
\hline
\end{tabular}

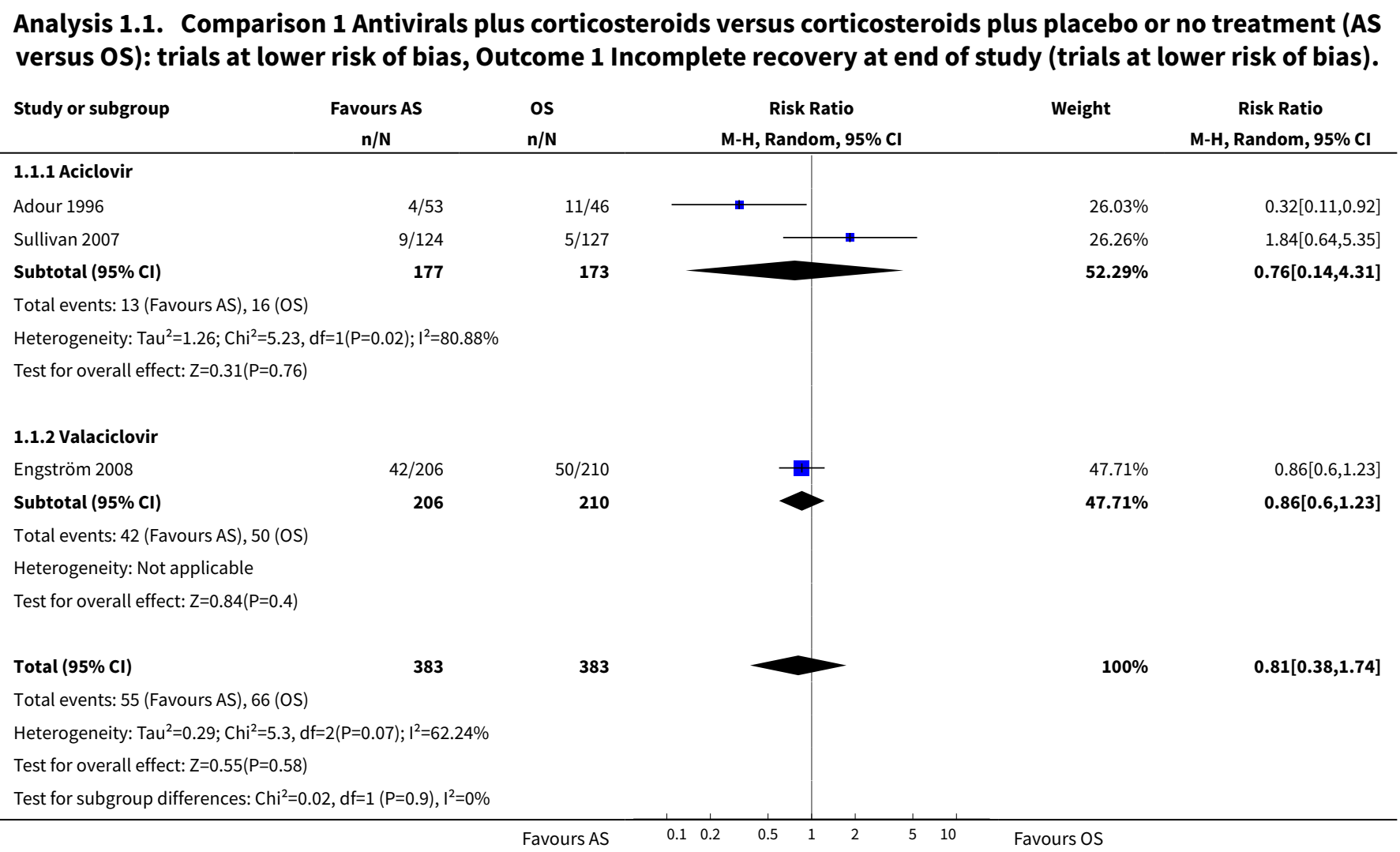


Analysis 1.2. Comparison 1 Antivirals plus corticosteroids versus corticosteroids plus placebo or no treatment (AS versus OS): trials at lower risk of bias, Outcome 2 Incomplete recovery at end of study (full data set).

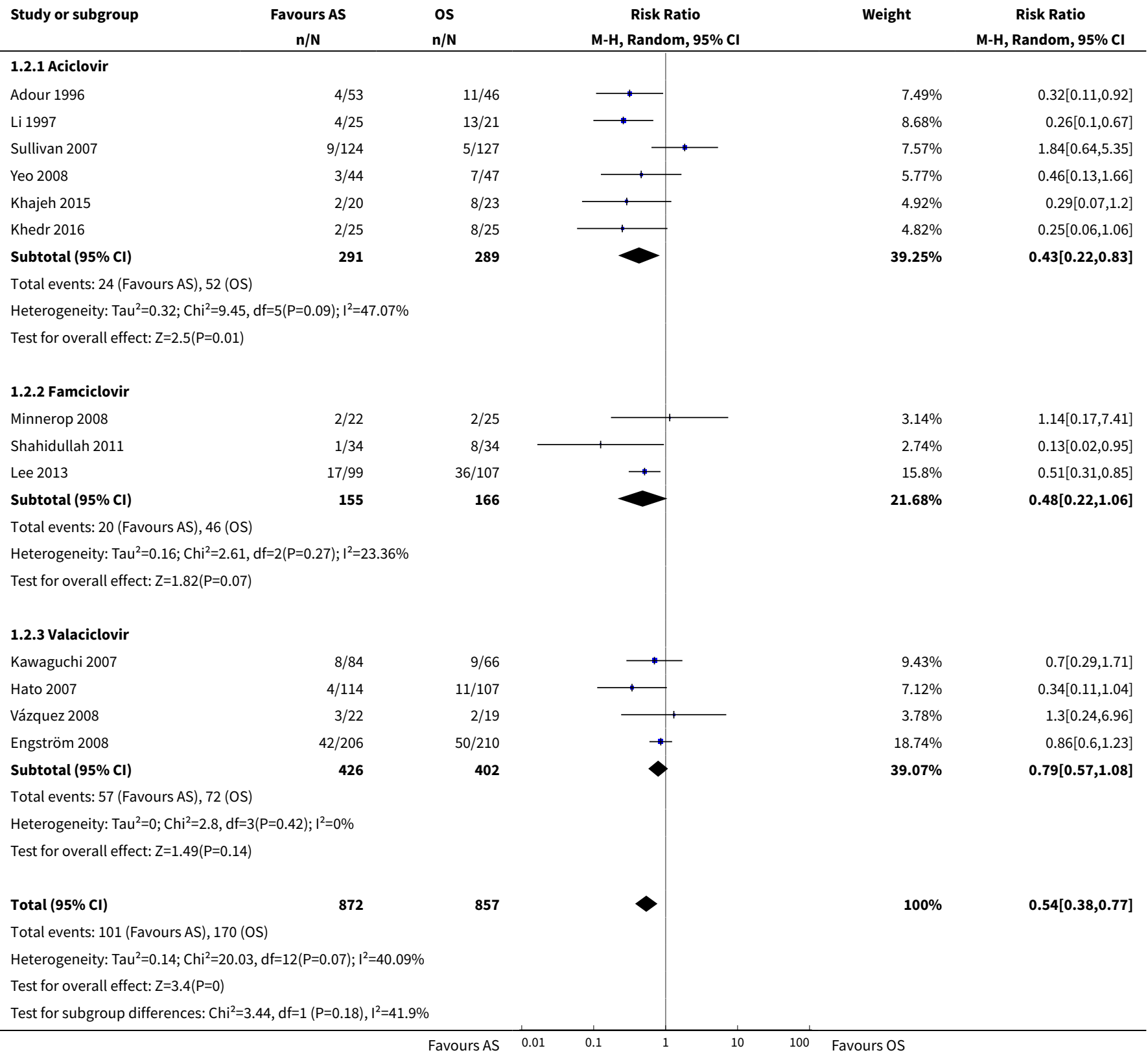

Analysis 1.3. Comparison 1 Antivirals plus corticosteroids versus corticosteroids plus placebo or no treatment (AS versus OS): trials at lower risk of bias, Outcome 3 Incomplete recovery at end of study in severe cases: data set limited to trials at lower risk of bias.

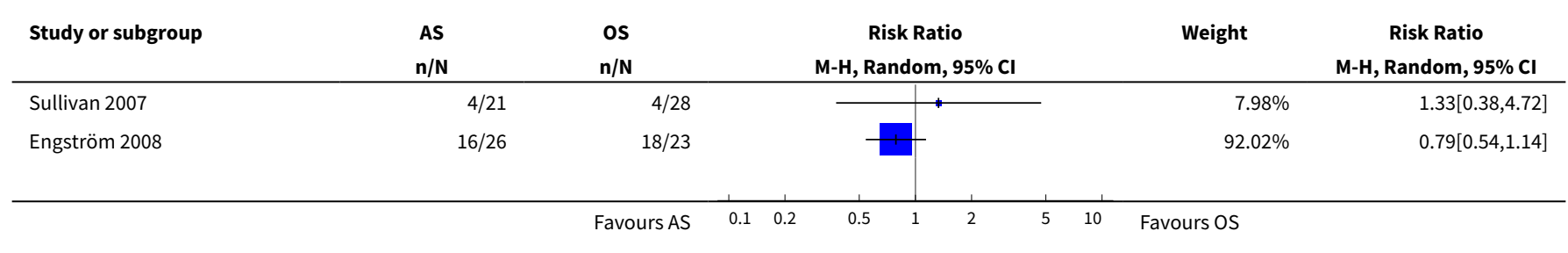




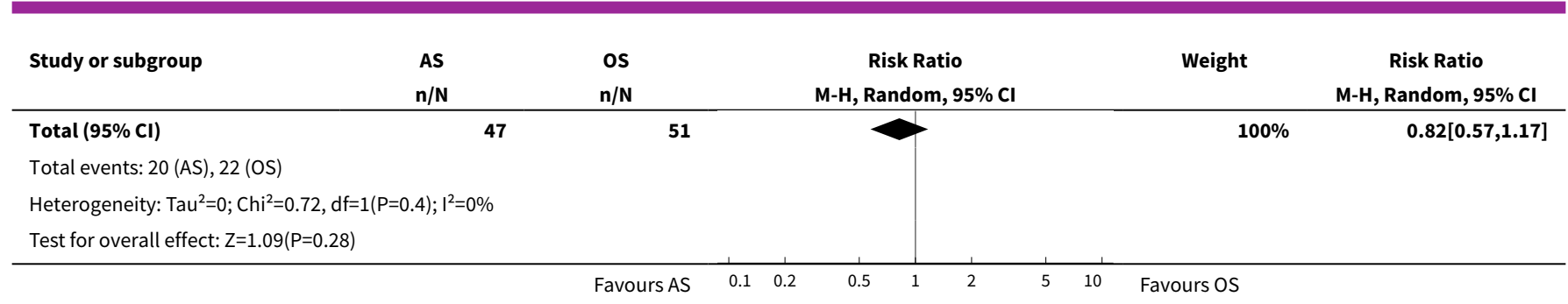

Analysis 1.4. Comparison 1 Antivirals plus corticosteroids versus corticosteroids plus placebo or no treatment (AS versus 0 ): : trials at lower risk of bias, Outcome 4 Incomplete recovery at end of study in severe cases: full data set.

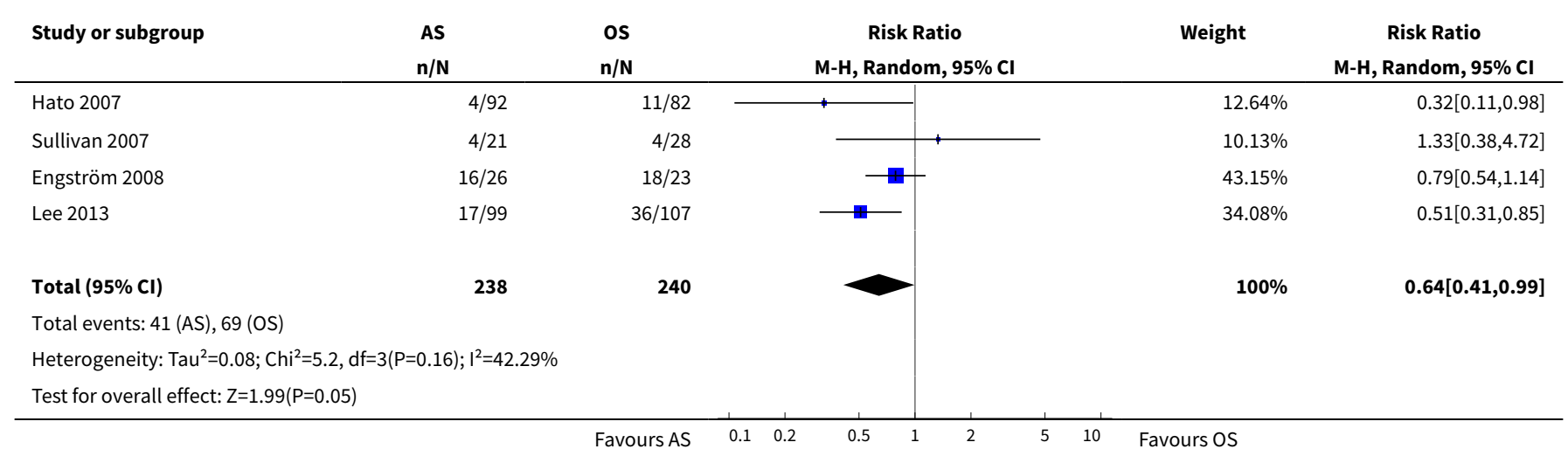

Analysis 1.5. Comparison 1 Antivirals plus corticosteroids versus corticosteroids plus placebo or no treatment (AS versus OS): trials at lower risk of bias, Outcome 5 Motor synkinesis or crocodile tears.

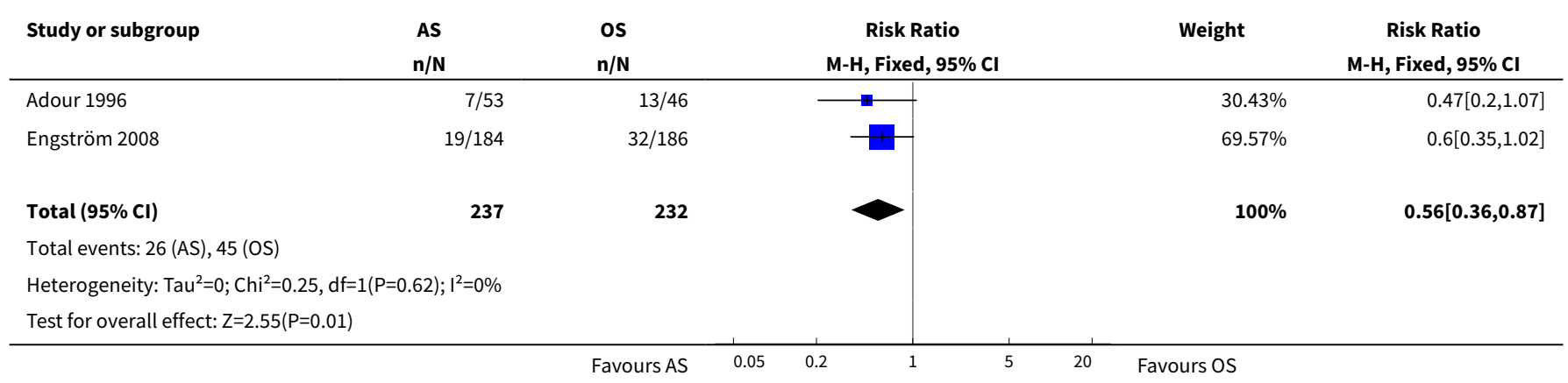

Analysis 1.6. Comparison 1 Antivirals plus corticosteroids versus corticosteroids plus placebo or no treatment (AS versus OS): trials at lower risk of bias, Outcome 6 Adverse events (trials at lower risk of bias).

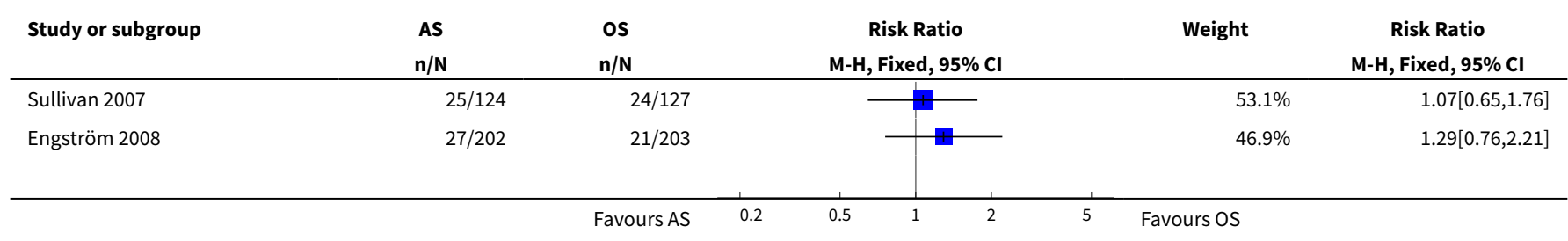




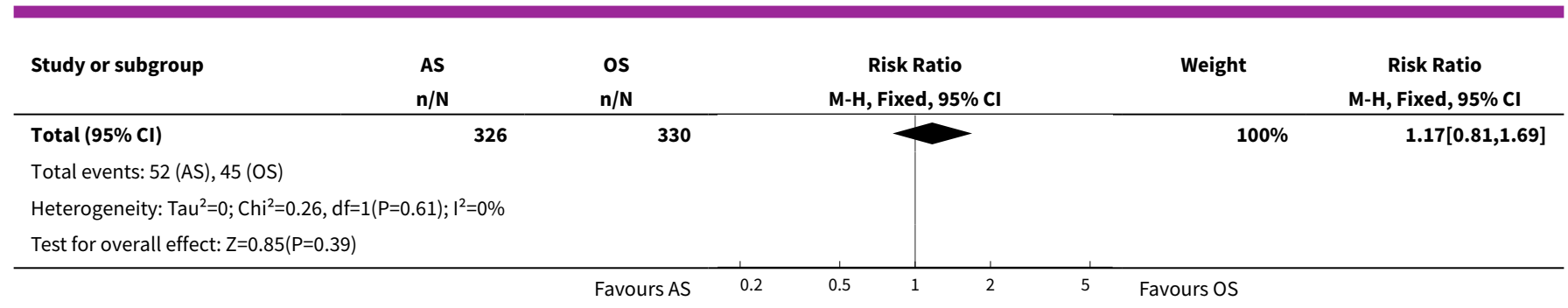

Analysis 1.7. Comparison 1 Antivirals plus corticosteroids versus corticosteroids plus placebo or no treatment (AS versus OS): trials at lower risk of bias, Outcome 7 Adverse events (full data set).

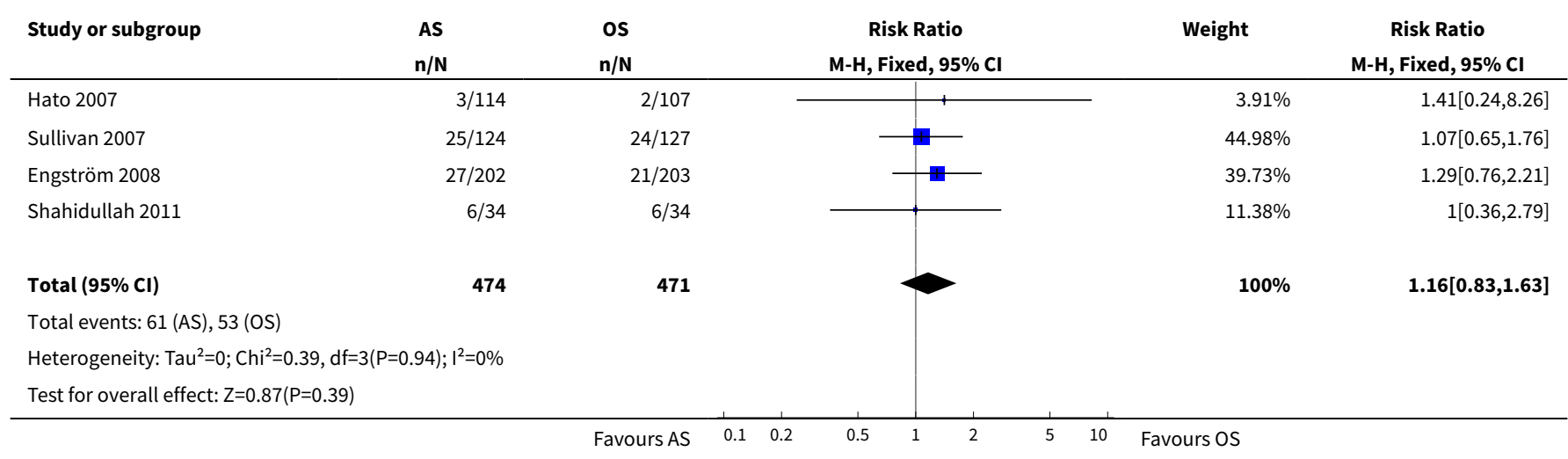

\section{Comparison 2. Antivirals versus corticosteroids (AO versus OS): trials at lower risk of bias}

\begin{tabular}{llllll}
\hline Outcome or subgroup title & $\begin{array}{l}\text { No. of } \\
\text { studies }\end{array}$ & $\begin{array}{l}\text { No. of } \\
\text { partici- } \\
\text { pants }\end{array}$ & Statistical method & Effect size \\
\hline $\begin{array}{l}1 \text { Incomplete recovery at end of study: trials } \\
\text { at lower risk of bias }\end{array}$ & 2 & 667 & Risk Ratio (M-H, Random, 95\% Cl) & $2.69[0.73,10.01]$ \\
\hline $\begin{array}{l}2 \text { Incomplete recovery at end of study: full } \\
\text { data set }\end{array}$ & 3 & 768 & Risk Ratio (M-H, Random, 95\% Cl) & $2.82[1.09,7.32]$ \\
\hline $\begin{array}{l}3 \text { Motor synkinesis and crocodile tears: trials } \\
\text { at lower risk of bias }\end{array}$ & 1 & 371 & Risk Ratio (M-H, Random, 95\% Cl) & $1.70[1.15,2.50]$ \\
\hline $\begin{array}{l}4 \text { Motor synkinesis and crocodile tears: full } \\
\text { data set }\end{array}$ & 2 & 472 & Risk Ratio (M-H, Fixed, 95\% Cl) & $1.52[1.08,2.12]$ \\
\hline \begin{tabular}{l}
5 Adverse events \\
\hline
\end{tabular} & 2 & 658 & Risk Ratio (M-H, Fixed, 95\% Cl) & $0.85[0.57,1.28]$ \\
\hline
\end{tabular}


Analysis 2.1. Comparison 2 Antivirals versus corticosteroids (AO versus OS): trials at lower risk of bias, Outcome 1 Incomplete recovery at end of study: trials at lower risk of bias.

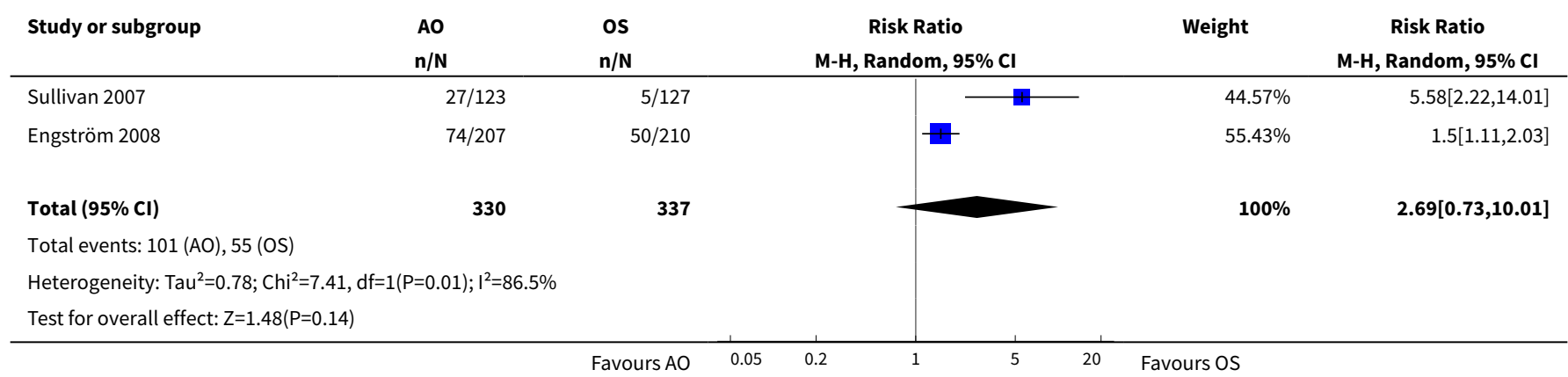

Analysis 2.2. Comparison 2 Antivirals versus corticosteroids (AO versus OS): trials at lower risk of bias, Outcome 2 Incomplete recovery at end of study: full data set.

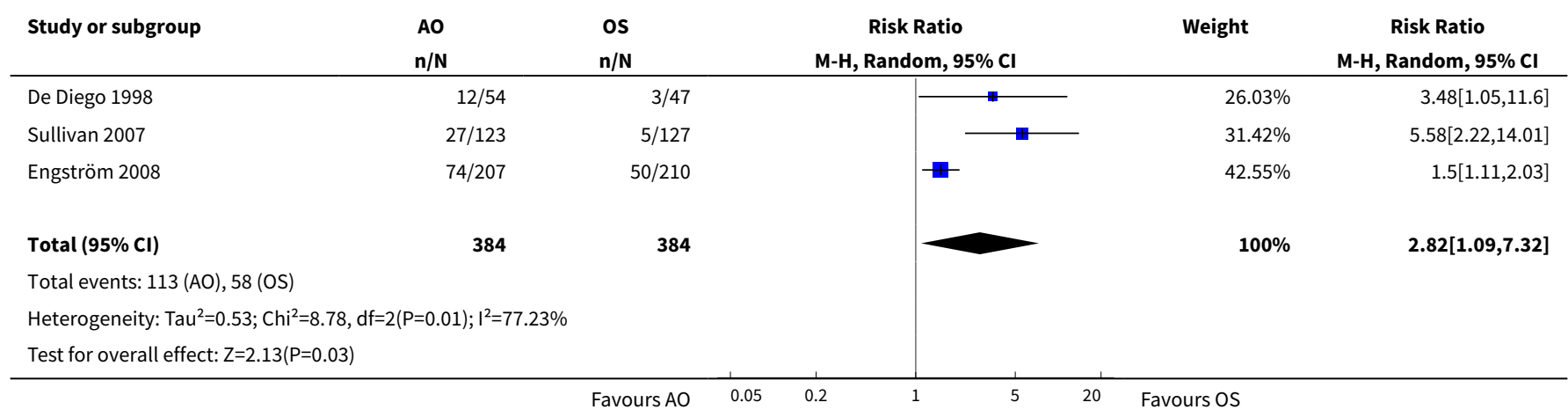

Analysis 2.3. Comparison 2 Antivirals versus corticosteroids (AO versus OS): trials at lower risk of bias, Outcome 3 Motor synkinesis and crocodile tears: trials at lower risk of bias.

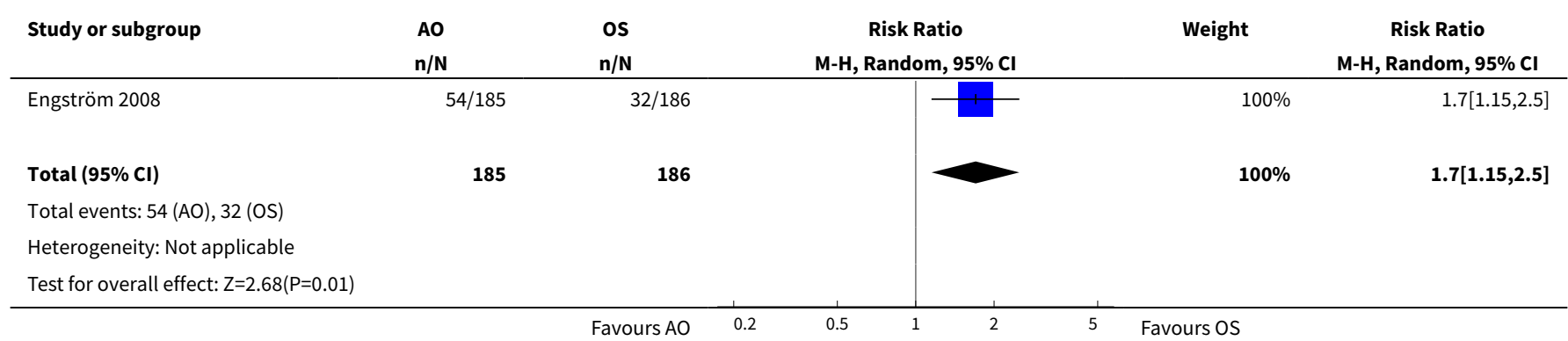


Analysis 2.4. Comparison 2 Antivirals versus corticosteroids (AO versus $O S$ ): trials at lower risk of bias, Outcome 4 Motor synkinesis and crocodile tears: full data set.

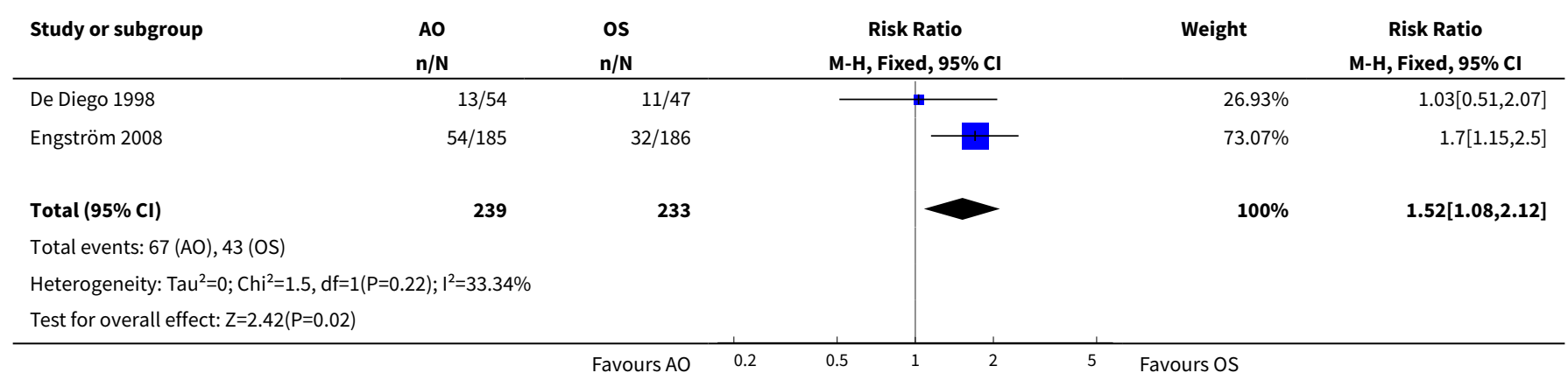

Analysis 2.5. Comparison 2 Antivirals versus corticosteroids (AO versus OS): trials at lower risk of bias, Outcome 5 Adverse events.

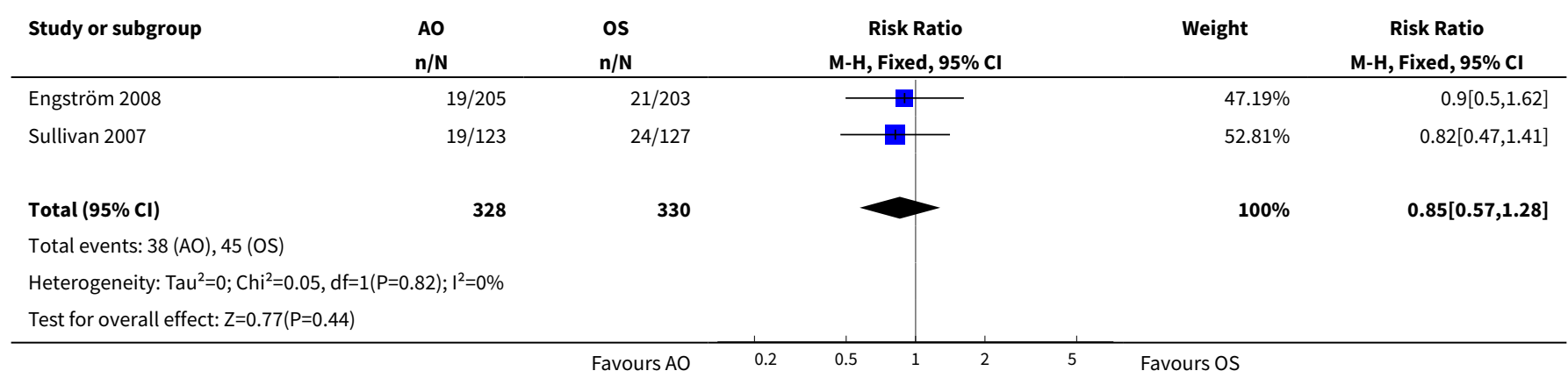

Comparison 3. Antivirals plus corticosteroids versus placebo (AS versus 00)

\begin{tabular}{llllll}
\hline Outcome or subgroup title & $\begin{array}{l}\text { No. of } \\
\text { studies }\end{array}$ & $\begin{array}{l}\text { No. of } \\
\text { partici- } \\
\text { pants }\end{array}$ & Statistical method & Effect size \\
\hline 1 Incomplete recovery at end of study & 2 & 658 & Risk Ratio (M-H, Random, 95\% Cl) & $0.56[0.42,0.76]$ \\
\hline 2 Motor synkinesis or crocodile tears & 1 & 372 & Risk Ratio (M-H, Random, 95\% Cl) & $0.37[0.23,0.59]$ \\
\hline 3 Adverse events & 2 & 649 & Risk Ratio (M-H, Fixed, 95\% Cl) & $1.14[0.79,1.65]$ \\
\hline
\end{tabular}

Analysis 3.1. Comparison 3 Antivirals plus corticosteroids versus placebo (AS versus 00), Outcome 1 Incomplete recovery at end of study.

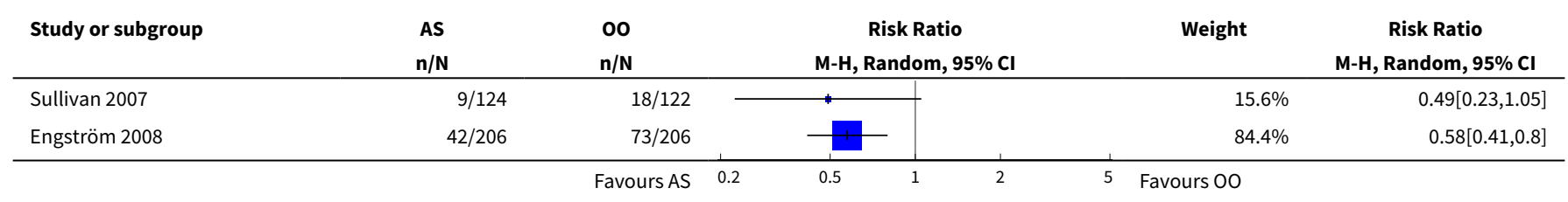




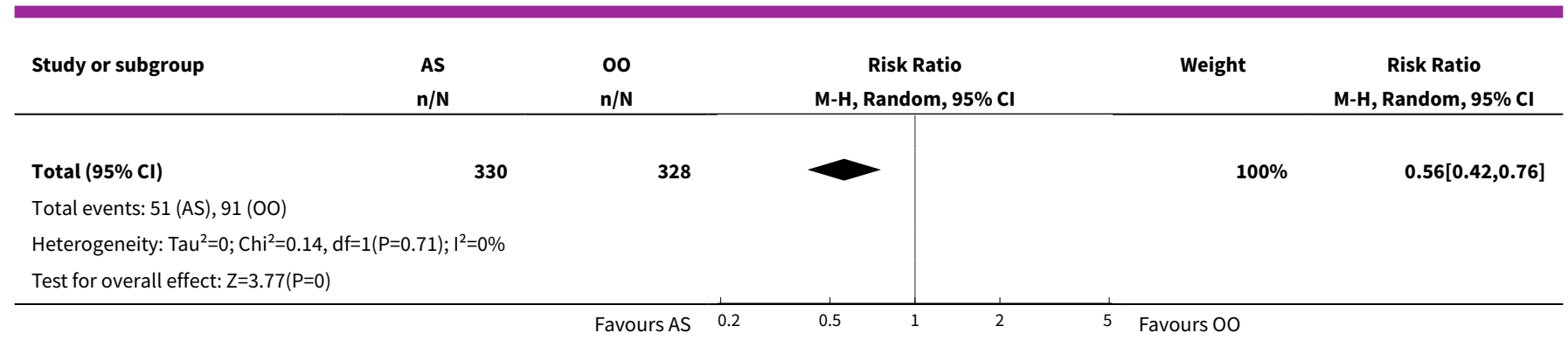

Analysis 3.2. Comparison 3 Antivirals plus corticosteroids versus placebo (AS versus 00), Outcome 2 Motor synkinesis or crocodile tears.

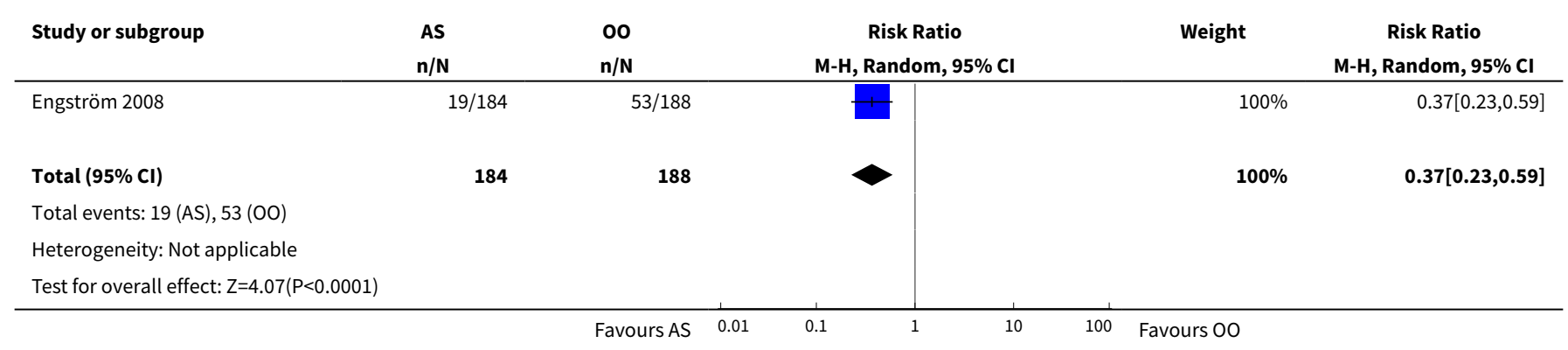

Analysis 3.3. Comparison 3 Antivirals plus corticosteroids versus placebo (AS versus 00), Outcome 3 Adverse events.

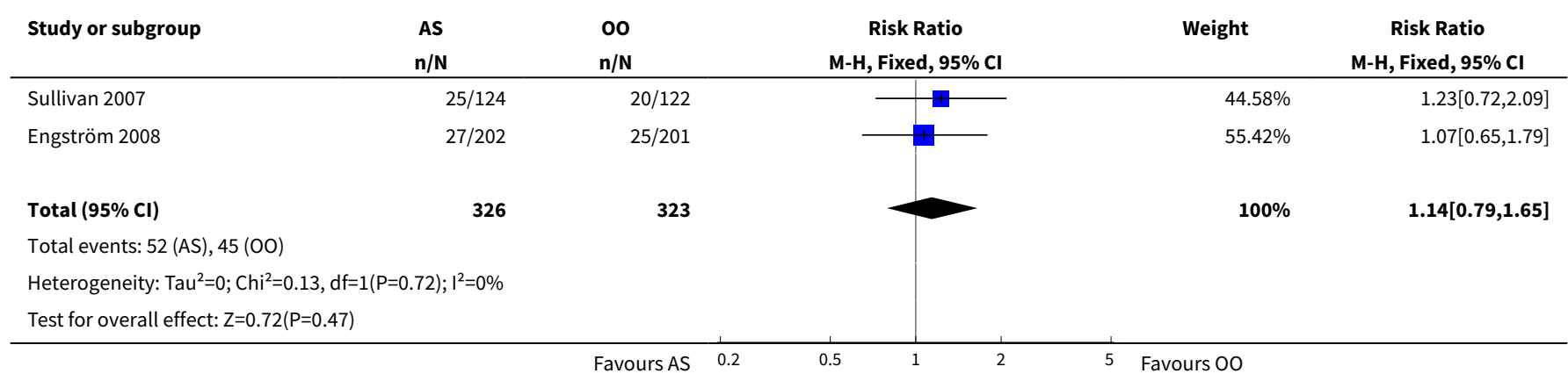

\section{Comparison 4. Antivirals versus placebo (AO versus 00)}

\begin{tabular}{llllll}
\hline Outcome or subgroup title & $\begin{array}{l}\text { No. of } \\
\text { studies }\end{array}$ & $\begin{array}{l}\text { No. of } \\
\text { partici- } \\
\text { pants }\end{array}$ & Statistical method & Effect size \\
\hline 1 Incomplete recovery at end of study & 2 & 658 & Risk Ratio (M-H, Fixed, 95\% Cl) & $1.10[0.87,1.40]$ \\
\hline 2 Motor synkinesis or crocodile tears & 1 & 373 & Risk Ratio (M-H, Random, 95\% Cl) & $1.04[0.75,1.43]$ \\
\hline 3 Adverse events & 2 & 651 & Risk Ratio (M-H, Fixed, 95\% Cl) & $0.83[0.56,1.24]$ \\
\hline
\end{tabular}


Analysis 4.1. Comparison 4 Antivirals versus placebo (AO versus 00 ), Outcome 1 Incomplete recovery at end of study.

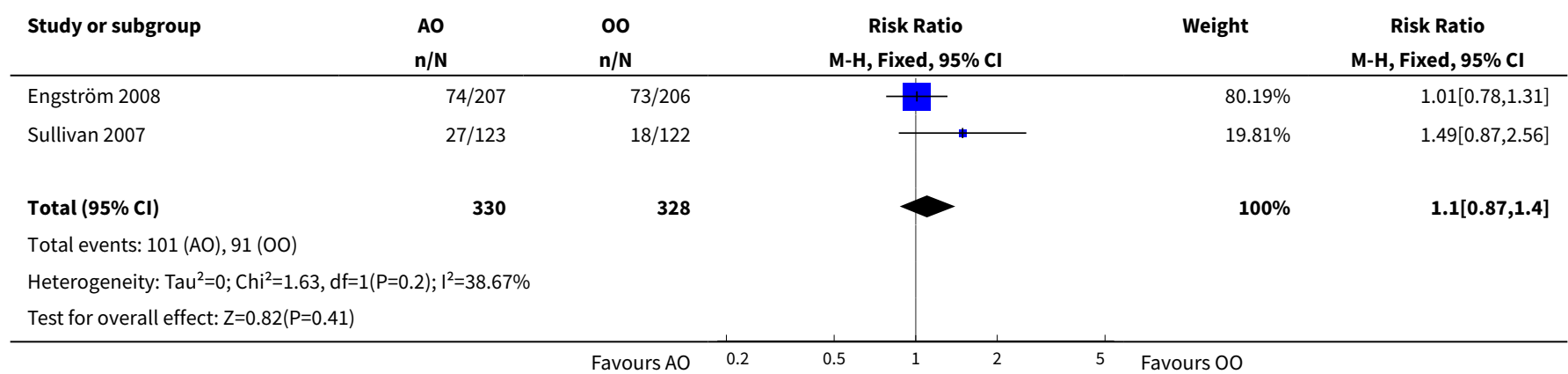

Analysis 4.2. Comparison 4 Antivirals versus placebo (AO versus 00), Outcome 2 Motor synkinesis or crocodile tears.

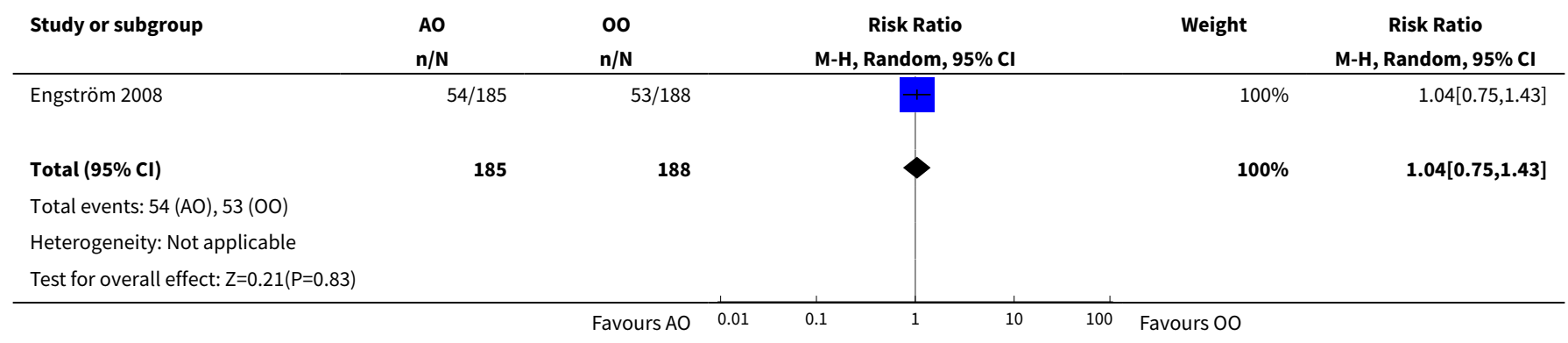

Analysis 4.3. Comparison 4 Antivirals versus placebo (AO versus 00 ), Outcome 3 Adverse events.

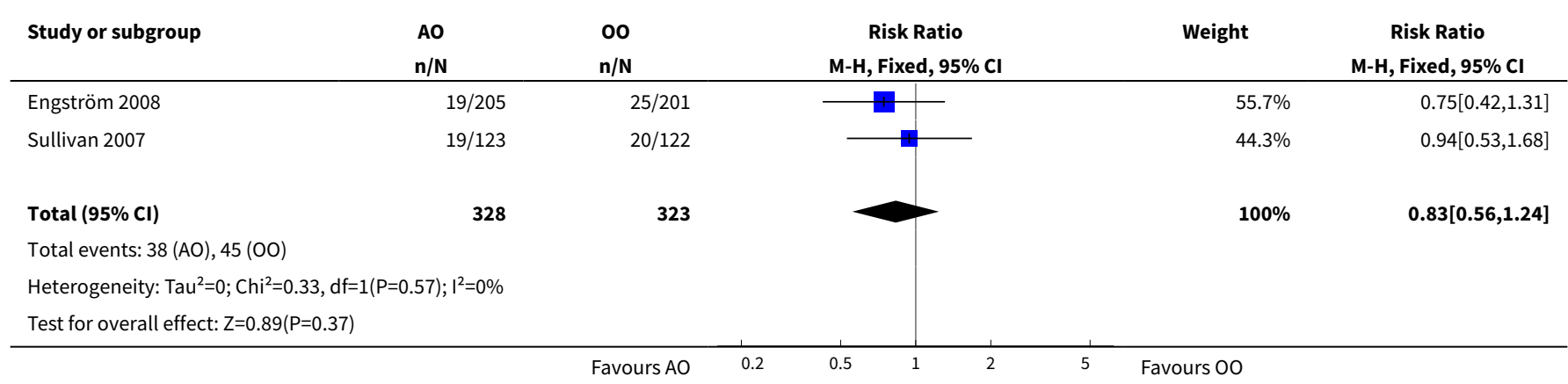

\section{ADDITIONAL TABLES}

Table 1. House-Brackmann Scale

Grade Description


Table 1. House-Brackmann Scale (Continued)

\begin{tabular}{ll}
\hline 1 & Normal \\
\hline 2 & Mild dysfunction; slight weakness noticeable only on close inspection; may have slight synkinesis \\
\hline 3 & $\begin{array}{l}\text { Moderate dysfunction; obvious but not disfiguring difference between the 2 sides; noticeable but } \\
\text { not severe synkinesis }\end{array}$ \\
\hline 4 & Moderately severe dysfunction; obvious weakness or disfiguring asymmetry, or both \\
\hline 6 & Only barely perceptible motion \\
\hline
\end{tabular}

House 1983; House 1985

Table 2. Sunnybrook Scale

\section{Facial grading system}

Resting symmetry

Compared to normal side

Eye

\begin{tabular}{c} 
Normal $=0$ \\
Narrow $=1$ \\
\hline
\end{tabular}

\begin{tabular}{ll}
\hline Wide $=1$ & Lyelid surgery $=1$ \\
\hline Cheek & \\
\hline & Normal $=0$ \\
\hline
\end{tabular}

\begin{tabular}{ll}
\hline & Absent $=2$ \\
\hline Less pronounced $=1$ \\
\hline Mouth & \\
\hline Normal $=0$ \\
\hline Corner drooped $=1$ \\
\hline Corner pulled up/out $=1$
\end{tabular}

\begin{tabular}{lcc}
\hline TOTAL & TOTAL & TOTAL \\
\hline
\end{tabular}

\section{Symmetry of voluntary movement Synkinesis}

Degree of muscle excursion compared to normal side

Degree of involuntary muscle contraction associated with each expression

\section{Standard expressions}

Forehead wrinkle

Gentle eye closure

Open mouth smile

Snarl

Lip pucker

Score each out of 5 , where 5 is normal and

1 is gross asymmetry/no movement

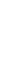

\section{Standard expressions}

Forehead wrinkle

Gentle eye closure

Open mouth smile

Snarl

Lip pucker

Score each facial movement listed under standard expressions on a scale 0 to 3 , where 0 is no asymmetry and 3 is severe asymmetry 
Table 2. Sunnybrook Scale (Continued)

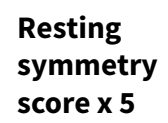

\section{Total $x 4$}

Voluntary movement score - resting symmetry score - synkinesis score = composite Score

Weighted regional evaluation using five separate expressions. Composite score from 0 (total paralysis) to 100 (normal function) (Ross 1996).

Table 3. Yanagihara Scale

\begin{tabular}{llllll}
\hline Mode & \multicolumn{2}{l}{ Degree of paralysis } & & \\
\hline & $\mathbf{4}$ & $\mathbf{3}$ & $\mathbf{2}$ & $\mathbf{1}$ & $\mathbf{0}$ \\
& normal & slight & moderate & severe & total \\
\hline
\end{tabular}

At rest

Wrinkle forehead

\section{Blink}

Normal closure of eye

Forced closure of eye

Closure of eye on involved side

Wrinkle nose

Whistle

Grin

Depress lower lip/ blow out cheek

10 separate categories of function, each scored 0 (total paralysis) to 4 (normal), then summed, giving a total score from 0 (total paralysis) to 40 (normal function) (Yanagihara 1977).

\section{APPENDICES}

\section{Appendix 1. Cochrane Neuromuscular Specialised Register via the Cochrane Register of Studies (CRS-Web)}

\#1 MeSH DESCRIPTOR Facial Nerve Diseases AND INSEGMENT

\#2 MeSH DESCRIPTOR Bell Palsy AND INSEGMENT

\#3 MeSH DESCRIPTOR Facial Paralysis AND INSEGMENT

\#4 MeSH DESCRIPTOR Hemifacial Spasm AND INSEGMENT

\#5 (((bell ${ }^{\star}$ or facial ${ }^{\star}$ or hemifacial ${ }^{\star}$ or cranial $\left.^{\star}\right)$ NEAR3 (pals* or paralys ${ }^{\star}$ or paresi* or spasm $\left.\left.^{\star}\right)\right)$ ) AND INSEGMENT

\#6 \#1 or \#2 or \#3 or \#4 or \#5 AND INSEGMENT

\#7 MeSH DESCRIPTOR Acyclovir Explode 1 AND INSEGMENT

\#8 MeSH DESCRIPTOR 2-Aminopurine AND INSEGMENT

\#9 MeSH DESCRIPTOR Antiviral Agents Explode 1 AND INSEGMENT

\#10 (aciclovir or valaciclovir or famciclovir or antiviral ${ }^{\star}$ ) AND INSEGMENT

\#11 (acyclovir or valacyclovir or famcyclovir) AND INSEGMENT

$\# 12$ \#7 or \#8 or \#9 or \#10 or \#11 AND INSEGMENT 
\#13 \#6 and \#12 AND INSEGMENT

\#14 (\#13) AND (INREGISTER)

\section{Appendix 2. Cochrane Central Register of Controlled Trials (CENTRAL) via the Cochrane Register of Studies (CRS-} Web)

\#1 MeSH DESCRIPTOR Facial Nerve Diseases AND CENTRAL:TARGET

\#2 MeSH DESCRIPTOR Bell Palsy AND CENTRAL:TARGET

\#3 MeSH DESCRIPTOR Facial Paralysis AND CENTRAL:TARGET

\#4 MeSH DESCRIPTOR Hemifacial Spasm AND CENTRAL:TARGET

\#5 (((bell ${ }^{\star}$ or facial ${ }^{\star}$ or hemifacial ${ }^{\star}$ or cranial $\left.^{\star}\right)$ NEAR3 $\left(\right.$ pals $^{\star}$ or paralys ${ }^{\star}$ or paresi ${ }^{\star}$ or $\left.\left._{\text {spasm }}{ }^{\star}\right)\right)$ ) AND CENTRAL:TARGET

\#6 \#1 or \#2 or \#3 or \#4 or \#5 AND CENTRAL:TARGET

\#7 MeSH DESCRIPTOR Acyclovir Explode 1 AND CENTRAL:TARGET

\#8 MeSH DESCRIPTOR 2-Aminopurine AND CENTRAL:TARGET

\#9 MeSH DESCRIPTOR Antiviral Agents Explode 1 AND CENTRAL:TARGET

\#10 (aciclovir or valaciclovir or famciclovir or antiviral ${ }^{\star}$ ) AND CENTRAL:TARGET

\#11 (acyclovir or valacyclovir or famcyclovir) AND CENTRAL:TARGET

$\# 12$ \#7 or \#8 or \#9 or \#10 or \#11 AND CENTRAL:TARGET

\#13 \#6 and \#12 AND CENTRAL:TARGET

\section{Appendix 3. MEDLINE (OvidSP) search strategy}

Database: Ovid MEDLINE(R) and Epub Ahead of Print, In-Process \& Other Non-Indexed Citations and Daily <1946 to July 30, 2019> Search Strategy:

1 randomized controlled trial.pt. (486353)

2 controlled clinical trial.pt. (93185)

3 randomized.ab. (450604)

4 placebo.ab. (199708)

5 drug therapy.fs. (2127161)

6 randomly.ab. (315646)

7 trial.ab. (472150)

8 groups.ab. (1939321)

9 or/1-8 (4494102)

10 exp animals/ not humans.sh. (4603844)

119 not 10 (3889737)

12 exp Facial Nerve Diseases/ (16491)

13 bell palsy/ (1164)

14 facial paralysis/ or hemifacial spasm/ (12868)

15 ((Bell\$ or facial\$ or hemifacial\$ or cranial\$) adj3 (pals\$ or paralys\$ or paresi\$ or spasm\$)).mp. (23603)

1612 or 13 or 14 or 15 (36322)

17 Acyclovir/ (8662)

18 exp Acyclovir/ (13943)

19 2-Aminopurine/ (1348)

20 exp Antiviral Agents/ (343232)

21 (aciclovir or valaciclovir or famciclovir or antiviral\$).tw. (82176)

22 (acyclovir or valacyclovir or famcyclovir).tw. (8204)

23 or/17-22 (382476)

2411 and 16 and 23 (501)

25 remove duplicates from 24 (498)

\section{Appendix 4. Embase (OvidSP) search strategy}

Database: Embase Classic+Embase <1947 to 2019 July 29>

Search Strategy:

1 crossover-procedure.sh. (60421)

2 double-blind procedure.sh. (165969)

3 single-blind procedure.sh. (36041)

4 randomized controlled trial.sh. (564306)

5 (random\$ or crossover\$ or cross over\$ or placebo $\$$ or (doubl\$ adj blind\$) or allocat\$).tw,ot. (1690153)

6 trial.ti. (284789)

7 or/1-6 (1875917) 
8 (animal/ or nonhuman/ or animal experiment/) and human/ (1923553)

9 animal/ or nonanimal/ or animal experiment/ (4308434)

109 not 8 (3597276)

117 not 10 (1722629)

12 limit 11 to (conference abstracts or embase) (1452930)

13 bell palsy/ (3925)

14 facial nerve paralysis/ or hemifacial spasm/ (26877)

15 ((Bell\$ or facial\$ or hemifacial\$ or cranial\$) adj3 (pals\$ or paralys\$ or paresi\$ or spasm\$)).mp. (41282)

16 or/13-15 (41282)

17 exp antivirus agent/ (944141)

18 aciclovir/ (37650)

19 famciclovir/ (3817)

20 (aciclovir or valaciclovir or famciclovir or antiviral\$).tw. (113174)

21 (acyclovir or valacyclovir or famcyclovir).tw. (11679)

22 or/17-21 (977133)

2312 and 16 and $22(142)$

24 remove duplicates from 23 (135)

\section{Appendix 5. LILACS (IAHx) search strategy}

("Bell palsy" or "paralisis de Bell" or "paralisia de Bell" or "facial or paralysis" or "paralisis facial" or "paralisia facial" or "hemifacial spasm" or "espasmo hemifacial") and (MH:D03.438.759.758.399.454.250\$ or acyclovir or 2-Aminopurine or 2-Aminopurina or MH:D27.505.954.122.388\$ or aciclovir or acyclovir or valaciclovir or valacyclovir or famciclovir or famcyclovir or antivira\$) and ((PT:"Randomized Controlled Trial" or "Randomized Controlled trial" or "Ensayo Clínico Controlado Aleatorio" or "Ensaio Clínico Controlado Aleatório" or PT:"Controlled Clinical Trial" or "Ensayo Clínico Controlado" or "Ensaio Clínico Controlado" or "Random allocation" or "Distribución Aleatoria" or "Distribuição Aleatória" or randon\$ or Randomized or randomly or "double blind" or "duplo-cego" or "duplo-cego" or "single blind" or "simples-cego" or "simples cego" or placebo\$ or trial or groups) AND NOT (B01.050\$ AND NOT (humans or humanos or humanos)))

\section{Appendix 6. ClinicalTrials.gov}

("Bell palsy" or "facial palsy" or "facial paralysis")

\section{Appendix 7. World Health Organization International Clinical TrialsRegistry Platform}

("Bell palsy" or "facial palsy" or "facial paralysis")

WHAT'S NEW

Date Event Description

8 January $2019 \quad$ New search has been performed

The authorship had changed. Dhruvashree Somasundara, Michael Sullivan and Fiona Gammie withdrew from this update.

We included four additional studies in the analyses (Minnerop 2008; Shahidullah 2011; Khajeh 2015; Khedr 2016). These suggested that antivirals conferred additional benefit in the treatment of Bell's palsy compared to the use of corticosteroids alone. The new data were from small studies at high risk of bias.

$\begin{array}{ll}19 \text { March } 2018 & \text { New citation required and conclusions } \\ \text { have changed }\end{array}$

We performed sensitivity analyses that excluded studies at high or unclear risk of bias in several domains, to analyse whether this changed the results.

For our primary analysis we reported the meta-analysis excluding studies at high risk of bias. The risk ratio (RR) for incomplete recovery was $0.81,95 \%$ confidence interval $(\mathrm{Cl}) 0.38$ to $1.74 ; 3$ trials, $\mathrm{N}=766$, low-certainty evidence, in comparison to the previous version of the review, which reported a RR of $0.61,95 \% \mathrm{Cl}$ 0.39 to $0.97 ; 10$ trials, $\mathrm{N}=1315$; very low-certainty evidence.

We found no clear effect of antivirals combined with corticosteroids compared to corticosteroids alone in severe cases in this 


\begin{tabular}{lll}
\hline Date Event Description & Den
\end{tabular}

update, based on our analysis of studies at lower risk of bias (RR $0.82,95 \% \mathrm{Cl} 0.51$ to $1.31 ; 2$ trials, $\mathrm{N}=98)$. The previous review reported results from a larger data set and a RR of $0.64,95 \% \mathrm{Cl} 0.41$ to $0.99 ; \mathrm{N}=478$.

For adverse events, when comparing antivirals plus corticosteroids to corticosteroids alone, we further downgraded the body of evidence from the previous judgement of low, to very low.

\section{H ISTORY}

Protocol first published: Issue 3, 1999

Review first published: Issue 2, 2001

\begin{tabular}{lll}
\hline Date & Event & Description \\
\hline 14 September 2015 & Amended & $\begin{array}{l}\text { With the removal of Abdelghany 2013, this review concludes that } \\
\text { there is a benefit from the combination of antivirals with corti- } \\
\text { costeroids compared to corticosteroids alone for the treatment } \\
\text { of Bell's palsy of various degrees of severity. The evidence con- } \\
\text { tinues to support a benefit of combination therapy compared } \\
\text { with corticosteroids alone in severe Bell's palsy. The evidence on } \\
\text { which these findings are based is of low quality. }\end{array}$ \\
\hline
\end{tabular}

14 September 2015 Amended Authors have removed a previously included study from the in-
cluded studies owing to withdrawal of the paper for plagiarism (Abdelghany 2013).

\begin{tabular}{|c|c|c|}
\hline 22 May 2015 & $\begin{array}{l}\text { New citation required and conclusions } \\
\text { have changed }\end{array}$ & $\begin{array}{l}\text { The authors have reviewed and reworded the conclusions, which } \\
\text { bear re-reading for clarification. }\end{array}$ \\
\hline 12 May 2015 & Amended & $\begin{array}{l}\text { As an updated search was recently incorporated, there has been } \\
\text { no new search for this amended version. }\end{array}$ \\
\hline 28 February 2014 & $\begin{array}{l}\text { New citation required but conclusions } \\
\text { have not changed }\end{array}$ & $\begin{array}{l}\text { Review updated with no change to conclusions. New authors: } \\
\text { Ildiko Gagyor, Vishnu B Madhok, Dhruvashree Somasundara, } \\
\text { Michael Sullivan, and Fiona Gammie. Previous authors Pauline } \\
\text { Lockhart, Marie Pitkethly, and Natalia Comerford withdrew. }\end{array}$ \\
\hline 22 January 2014 & New search has been performed & $\begin{array}{l}\text { New trials added, text rewritten, new calculations, references up- } \\
\text { dated }\end{array}$ \\
\hline 12 May 2010 & Amended & Correction to reference \\
\hline 10 November 2009 & Amended & Correction of minor error in Discussion \\
\hline 25 February 2009 & $\begin{array}{l}\text { New citation required and conclusions } \\
\text { have changed }\end{array}$ & $\begin{array}{l}\text { This is a substantive update to the previous edition of the review } \\
\text { with a new review team. Five new studies added to the analysis } \\
\text { with changes made to Results and Discussion sections as neces- } \\
\text { sary. }\end{array}$ \\
\hline 5 February 2009 & New search has been performed & Substantive update to $p$ \\
\hline
\end{tabular}




\begin{tabular}{|c|c|c|}
\hline Date & Event & Description \\
\hline & & $\begin{array}{l}\text { Abstract and background information rewritten. Modification } \\
\text { of outcomes: all data from trials, whatever the trial length as } \\
\text { opposed to 6-month outcomes. Five new studies added to the } \\
\text { analysis with necessary changes made to Results and Discussion } \\
\text { sections. One study removed from the previous review as no da- } \\
\text { ta contributed and none forthcoming to previous authors when } \\
\text { approached. }\end{array}$ \\
\hline
\end{tabular}

1 November $2007 \quad$ Amended Two trials, one with 551 participants comparing prednisolone
with aciclovir with both and with neither, another with 221 participants comparing prednisolone and valaciclovir with prednisolone and placebo have just been published and will be included in an update of this review.

\begin{tabular}{lll}
\hline 1 March 2004 & $\begin{array}{l}\text { New citation required and conclusions } \\
\text { have changed }\end{array}$ & Substantive amendment \\
\hline 1 January 2004 New search has been performed & $\begin{array}{l}\text { The review was updated in January 2004. Searches were up- } \\
\text { dated as follows: Neuromuscular Disease Group Trials Register } \\
\text { (searched April 2003), MEDLINE (searched January 1966 to April } \\
\text { 2003), Embase (searched January 1980 to April 2003), and LILACS } \\
\text { (searched January 1982 to April 2003) }\end{array}$ \\
& &
\end{tabular}

\section{CONTRIBUTIONS OF AUTHORS}

All review authors contributed to the review and data extraction process. Professor I Gagyor wrote the first draft of the report with additional clinical input from Professor F Sullivan, Dr V Madhok, Dr F Daly. Professor I Gagyor incorporated the work into the existing review and was responsible for the 'Risk of bias' and the GRADE assessment, data analysis, and use of Review Manager 5 and GRADEpro GDT software (RevMan 2014; GRADEpro GDT 2015).

\section{DECLARATIONS OF INTEREST}

Ildiko Gagyor: None known

Vishnu B Madhok: I have received payment for reviewing a review prepared by BMJ Evidence and have also received a consultancy fee as a committee member for the Medical Defense Society and a Psoriatic Arthritis Research study.

Fergus Daly: The fact that I am a named author on one of the included articles (Sullivan 2007), did not influence in any way my thinking, presentation or contribution to this review.

Frank Sullivan: Received an Exploration Fund grant from North York General Hospital of $\$ 7800$ for a review of the accuracy and completeness of coding of Bell's Palsy in Canadian family physician electronic medical records. The grant was used to pay for a summer student. I am the author of one of the included studies (Sullivan 2007). I have no other known conflicts of interest.

\section{SOURCES OF SUPPORT}

\section{Internal sources}

- University of Dundee, UK.

\section{External sources}

- No sources of support supplied

\section{DIFFERENCES BETWEEN PROTOCOLANDREVIEW}

There were several differences between the published review protocol and the previous update of the review in 2015 (Gagyor 2015c). These mainly reflected changes over time to treatment options and Cochrane methodology. 
- The search for studies included treatment with valaciclovir and famciclovir, either alone or in combination with any other therapy, to reflect the treatment options now available for Bell's palsy.

- We undertook 'Risk of bias' assessment according to Chapter 8 of the Cochrane Handbook for Systematic Reviews of Interventions (Higgins 2011).

- We documented the selection criteria relating to high risk of bias and study duration. The minimum study duration was three months.

- For this update, seven review authors read a selection of papers, reviewed them for 'Risk of bias', and extracted data. The review authors distributed the work so that at least two review authors reviewed each paper. IG performed the final 'Risk of bias' assessment, which FS and VM independently reviewed.

- We focused the search on people who were immunocompetent, which we did not stipulate in the original protocol. We did this as treatment protocols for immunocompromised individuals and treatment response may differ significantly from other individuals and could not be fully explored in this analysis.

- The authors of Lockhart 2009 widened the outcome criteria to include outcomes at the end of the study, as opposed to one year or six months after treatment, in order to allow for the inclusion of a maximal number of published studies. This previous update included studies with durations of three to 12 months, which allowed for maximum data inclusion. As it was understood that this method might introduce significant heterogeneity to the results, the review authors included a sensitivity analysis looking at outcomes in participants in studies reporting at 12 weeks or less and six months or less in order to assess the influence this had on the robustness of published results. The authors of the current review accepted these changes. For the subgroup analysis of incomplete recovery, we extracted data on the severity of Bell's palsy at month six or imputed using the last measure carried forward. As for the previous update, we omitted the outcome 'complete facial paralysis at the end of the study'.

- We have added in this update the outcome 'incomplete recovery in severe cases', measured at month six or imputed using the last measure carried forward. We defined severe cases as a severe-to-complete facial paralysis, graded as equal to or greater than $\mathrm{V}$ in the House-Brackmann grading system (House 1985), equal to or less than 20 in the Sunnybrook score (Ross 1996), and equal to or less than 20 in the Yanagihara score (Yanagihara 2003).

- We modified the outcome measures since the previous review to take into account the heterogeneity of this group of studies.

- We altered incomplete recovery to include the range of definitions used by the included studies in order to allow for maximum data capture: as opposed to the previous definition of moderate dysfunction, the term now includes participants with a lack of full function. By this definition, more participants will be classified as having 'incomplete recovery'.

- The Lockhart 2009 update replaced 'adverse events attributable to antiviral treatment' with 'adverse events'; in studies where both agents are administered, it is difficult to assess which agent is causing the adverse event. Similarly, even when only an antiviral is being prescribed, it is difficult to know whether a specific event should be attributed to the medication or to another intercurrent cause. The level of detailed analysis of adverse events in studies did not permit such a judgement to be made. This review reported adverse events for each analysis separately.

- The review authors added a 'Summary of findings' table and additional sections to the methods to comply with current Cochrane standards.

For this update, three review authors read a selection of papers, reviewed them for 'Risk of bias', and extracted data. The review authors distributed the work so that at least two review authors reviewed each paper. IG performed the final 'Risk of bias' assessment and assessed the certainty of evidence using GRADEpro GDT 2015, which FS and VM independently reviewed.

We decided to include the data of the study of Lee 2013 in the main analysis, although Lee included participants with severe Bell's palsy only. Since the proportion of participants with severe Bell's palsy in the remaining 13 studies was different, the heterogeneity between the studies was high.

We conducted a subgroup analysis to assess heterogeneity between the studies. We analysed the effect of different antivirals (aciclovir, valaciclovir and famciclovir) on the effect estimates for incomplete recovery (Analysis 2.1). An additional analysis shows the results of the subgroup of patients with severe Bell's palsy (Analysis 2.2).

We performed sensitivity analyses for each outcome where possible, separately to investigate whether the exclusion of trials at a high or unclear risk of bias in at least five categories influenced the results.

\section{N DEX TERMS}

\section{Medical Subject Headings (MeSH)}

Anti-Inflammatory Agents [*therapeutic use]; Antiviral Agents [*therapeutic use]; Bell Palsy [ ${ }^{\star}$ drug therapy] [virology]; Drug Therapy, Combination; Randomized Controlled Trials as Topic; Treatment Outcome

\section{MeSH check words}

Humans 